University of Louisville

ThinkIR: The University of Louisville's Institutional Repository

Electronic Theses and Dissertations

$5-2013$

\title{
Environmental regulation of cardiovascular disease risk and regenerative capacity.
}

Natasha Krystal DeJarnett

University of Louisville

Follow this and additional works at: https://ir.library.louisville.edu/etd

\section{Recommended Citation}

DeJarnett, Natasha Krystal, "Environmental regulation of cardiovascular disease risk and regenerative capacity." (2013). Electronic Theses and Dissertations. Paper 328.

https://doi.org/10.18297/etd/328

This Doctoral Dissertation is brought to you for free and open access by ThinkIR: The University of Louisville's Institutional Repository. It has been accepted for inclusion in Electronic Theses and Dissertations by an authorized administrator of ThinkIR: The University of Louisville's Institutional Repository. This title appears here courtesy of the author, who has retained all other copyrights. For more information, please contact thinkir@louisville.edu. 
ENVIRONMENTAL REGULATION OF CARDIOVASCULAR DISEASE RISK AND REGENERATIVE CAPACITY

\title{
By
}

Natasha Krystal DeJarnett

B.S., Western Kentucky University, 2004

M.P.H., University of Louisville, 2009

\author{
A Dissertation \\ Submitted to the Faculty of the \\ School of Public Health and Information Sciences \\ In Partial Fulfillment of the Requirements \\ for the Degree of
}

\author{
Doctor of Philosophy \\ Department of Environmental and Occupational Health Sciences \\ University of Louisville \\ Louisville, KY
}

May 2013 


\section{Copyright 2013 by Natasha Krystal DeJarnett}

All rights reserved 

ENVIRONMENTAL REGULATION OF CARDIOVASCULAR DISEASE RISK AND REGENERATIVE CAPACITY

\author{
By
}

Natasha Krystal DeJarnett

B.S., Western Kentucky University, 2004

M.P.H., University of Louisville, 2009

A Dissertation Approved on

April 11, 2013

by the following Dissertation Committee

Dissertation Director, Aruni Bhatnagar

David Tollerud

Kathy Baumgartner

Robert Jacobs

John Myers 


\section{DEDICATION}

This dissertation is dedicated to my parents

Mrs. Wyteria Reed DeJarnett

and

Mr. Zachariah DeJarnett, Jr.

who have been amazing examples of hard work and dedication. 


\section{ACKNOWLEDGEMENTS}

I thank Dr. Aruni Bhatnagar for his patient guidance and for the opportunity to perform research in such an incredible center with high-impact research. I thank Dr. David Tollerud for always providing sound direction and invaluable support in helping me achieve my dreams. I thank Dr. Robert Jacobs for being the reason I discovered my love for environmental health. I thank Dr. John Myers for his time and patience in helping me to understand our dataset. I thank Dr. Kathy Baumgartner for challenging me to examine factors from multiple perspectives; who I hope to resemble as a mentor in the future. I express great thanks to my parents, Zack and Wyteria DeJarnett. There are not enough words to thank my parents for their prayers, support, and encouragement, but know that I am eternally grateful. They encouraged me when I could no longer encourage myself; their faith held strong when mine dwindled. I thank the department of Environmental and Occupational Health Sciences for providing me with a Graduate Assistantship from 2009-2011 and the School of Interdisciplinary and Graduate Studies for the Ethnic Minority Fellowship from 2011-2013, without which my continued education would not have been possible. I also thank my friend Jasmihn Woodard and my cousin Inetta DeJarnett Bostock for their support. Also, I give many thanks to my friend Dr. Yanci Mannery for countless edits to abstracts and manuscripts, along with inspiration. Finally, I would like to thank my grandparents and the Johnson, Hamilton, Reed, and Faulk families. 


\section{ABSTRACT \\ ENVIRONMENTAL REGULATION OF CARDIOVASCULAR DISEASE RISK AND REGENERATIVE CAPACITY}

Natasha Krystal DeJarnett

April 11, 2013

Cardiovascular disease (CVD) is the leading cause of morbidity and mortality in the U.S., and its prevalence is predicted to increase through 2030. Acute and chronic exposure to fine particulate matter $\left(\mathrm{PM}_{2.5}\right)$ and traffic pollution is positively associated with cardiovascular morbidity and mortality. It has been recently shown that exposure to elevated levels of combustion pollutants including tobacco smoke and $\mathrm{PM}_{2.5}$ is associated with decreased circulating levels of vascular progenitor cells (VPCs), angiogenic cells that participate in vascular repair and regeneration. Several investigators have reported that decreased VPC levels is associated with an increase in CVD risk and endothelial dysfunction (a decrease in vasodilatation), which is a key feature in atherosclerosis. Nevertheless, the mechanisms by which combustion pollutants affect VPC levels remains unclear, and the contribution of pollutant-induced VPC depletion to elevated CVD risk has not been assessed. This dissertation investigates how exposure to environmental pollution is associated with VPC levels in a population with increased CVD risk.

The first chapter assesses 15 phenotypically distinct VPC populations with different angiogenic potential to describe the association between VPC levels and CVD risk factors, the Framingham Risk Score (FRS), and markers of thrombosis (fibrinogen 
and platelet mononuclear cell aggregates) and inflammation (high sensitivity C-reactive protein (hsCRP)). The second chapter describes the association between acrolein exposure (a combustion pollutant) and VPC levels, a novel assessment in human subjects. To understand the vascular effects of exposure to traffic pollution, the association between roadway proximity and VPC levels was evaluated in the third chapter. Together, these investigations suggest that VPCs may be a mechanistic link between CVD risk and environmental exposures. Results from these investigations may drive future mechanistic explorations, as well as targeted diagnostic examinations and prevention interventions. 


\section{TABLE OF CONTENTS}

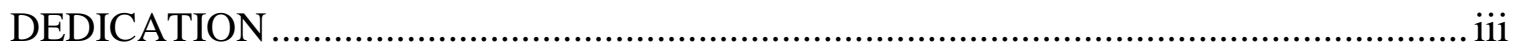

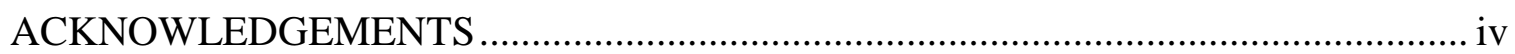

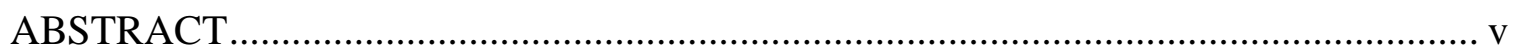

TABLE OF CONTENTS .................................................................................. vii

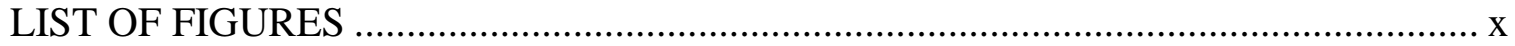

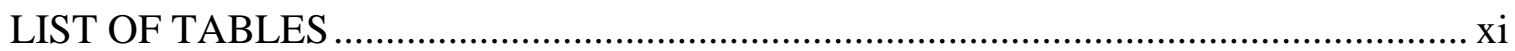

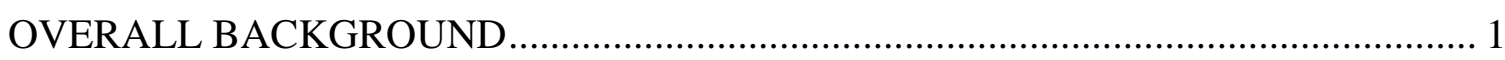

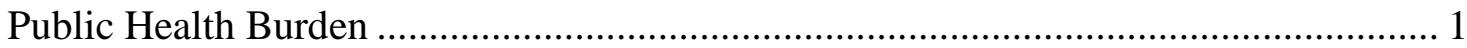

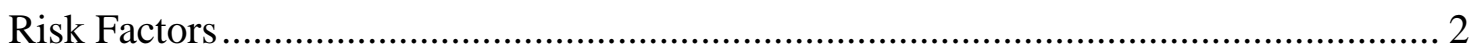

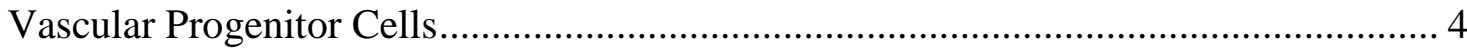

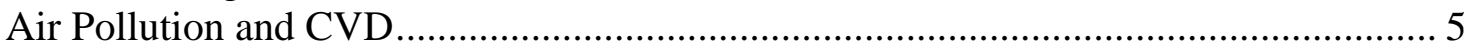

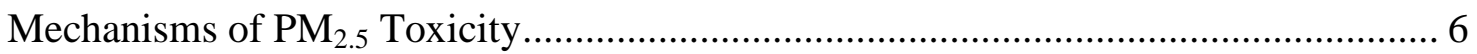

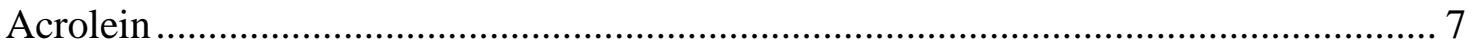

Summary

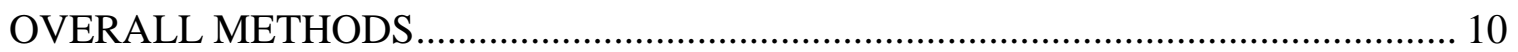

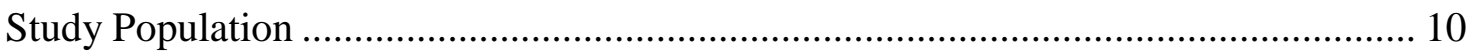

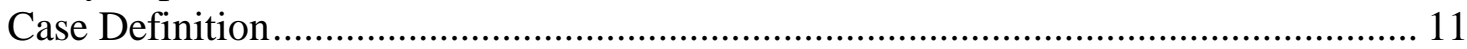

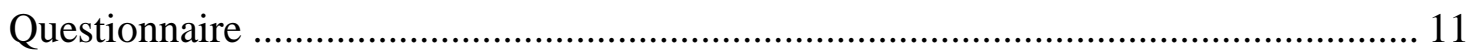

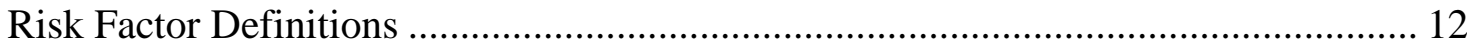

Biological Sample Collection and Processing ....................................................... 12

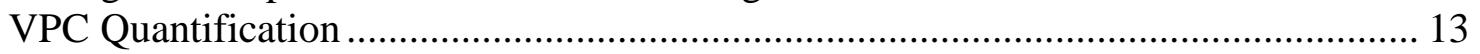

Platelet Mononuclear Cell Aggregate Identification .................................................... 14

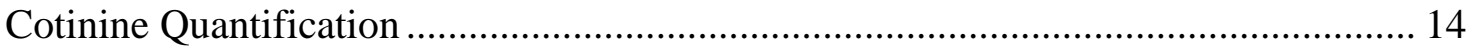

High Sensitivity C-Reactive Protein Quantification .................................................... 15

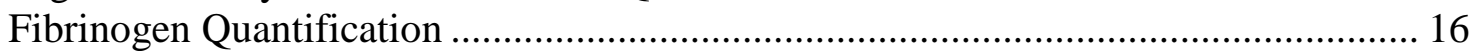

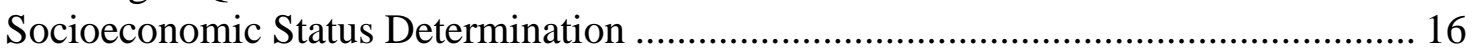

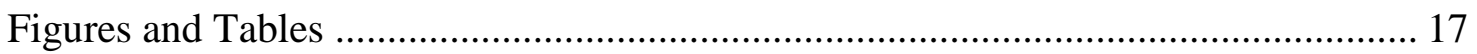

CHAPTER I: Circulating Vascular Progenitor Cells are Associated with Cardiovascular

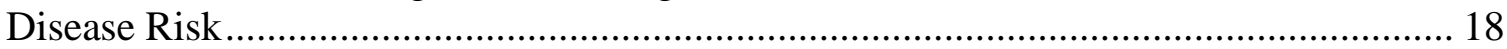

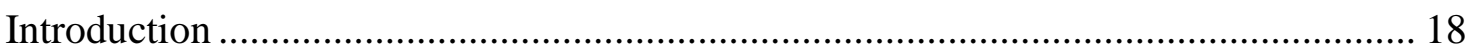

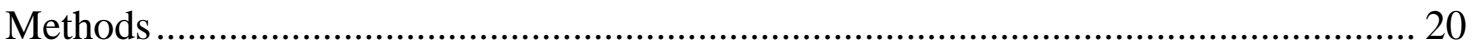

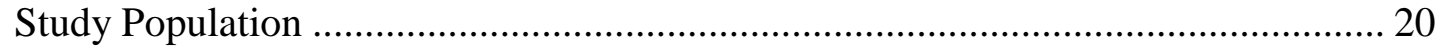

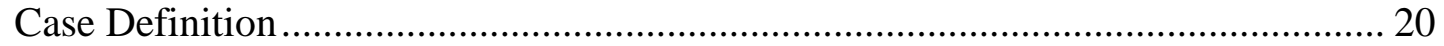

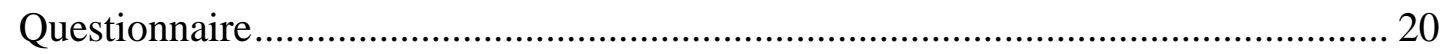


Biological Sample Collection and Processing ..................................................... 20

VPC Quantification .................................................................................. 20

Platelet Mononuclear Cell Aggregate Identification ......................................... 21

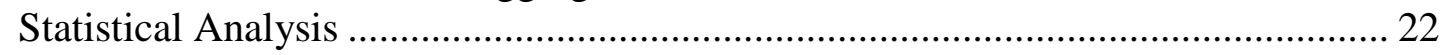

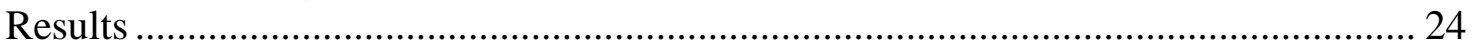

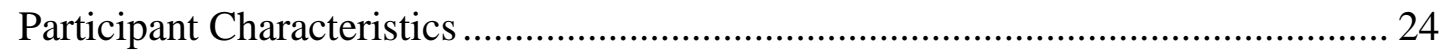

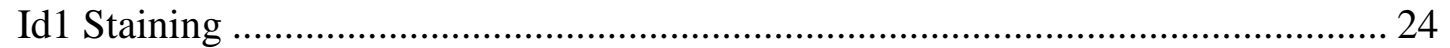

CVD Risk and its association with VPCs, Thrombosis, and Inflammation .............. 25

Demographic Comparisons among VPC-3 Tertiles .............................................. 25

Demographic Comparisons among VPC-5 Tertiles .............................................. 26

Adjusted Association between FRS and Circulating VPC Levels ........................... 26

Adjusted Associations between Thrombosis and VPC Levels................................ 26

Adjusted Association between Inflammation and VPC Levels ............................... 27

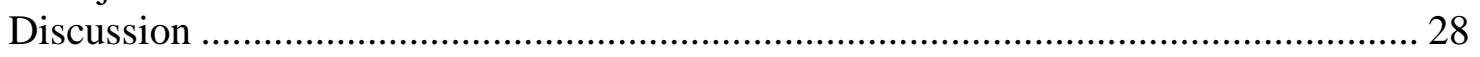

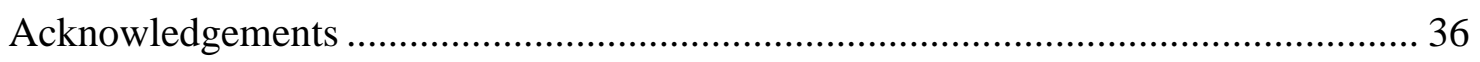

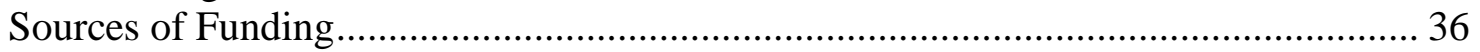

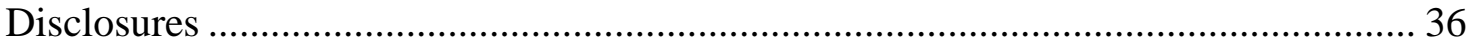

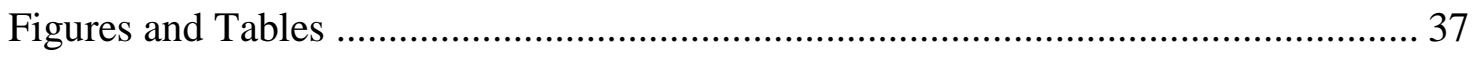

CHAPTER II: Contribution of Acrolein to Cardiovascular Disease Risk and Vascular

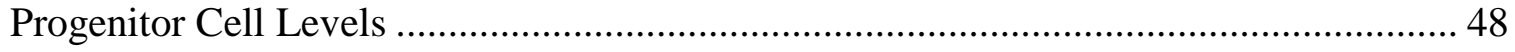

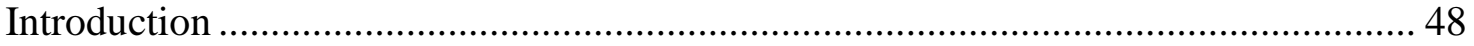

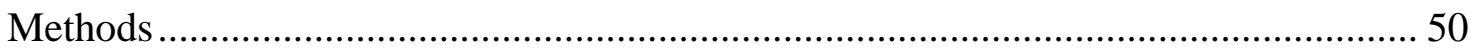

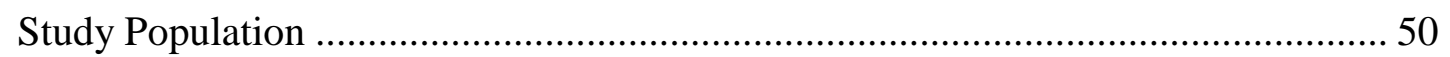

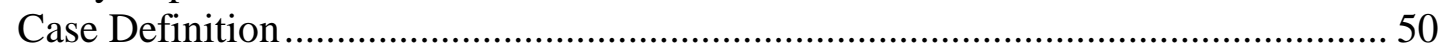

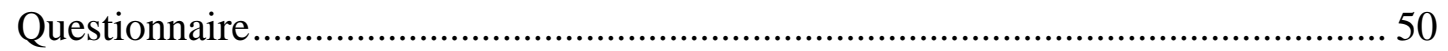

Biological Sample Collection and Processing ...................................................... 50

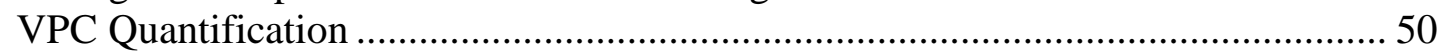

Platelet Mononuclear Cell Aggregate Identification ........................................ 50

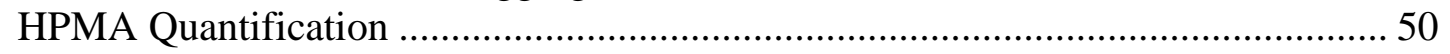

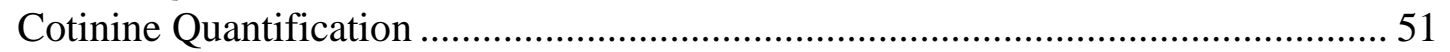

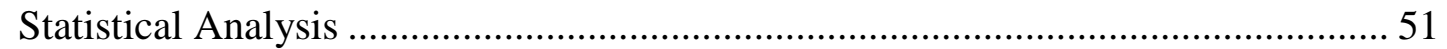

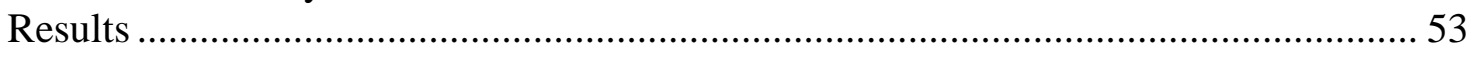

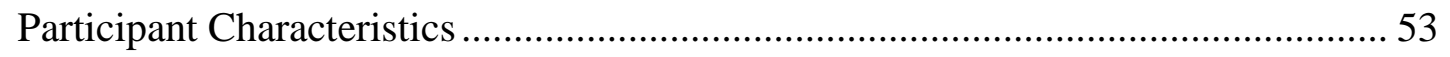

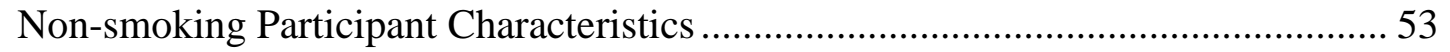

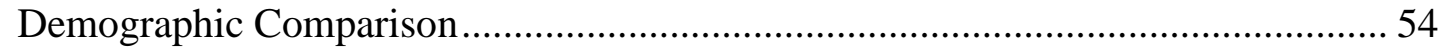

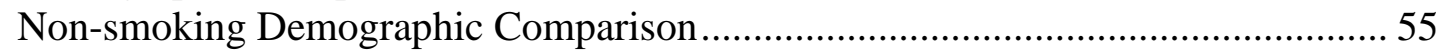

Association between VPCs and CVD Risk with HPMA Tertile............................. 55

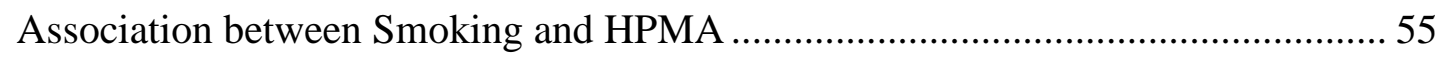

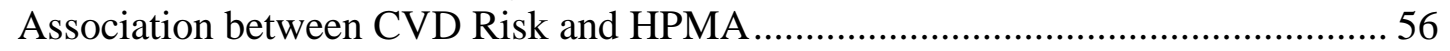

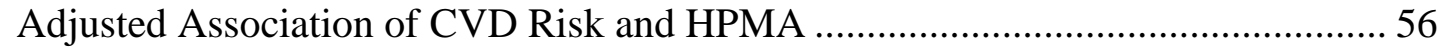

Adjusted Association of CVD Risk and HPMA in Non-smokers........................... 57

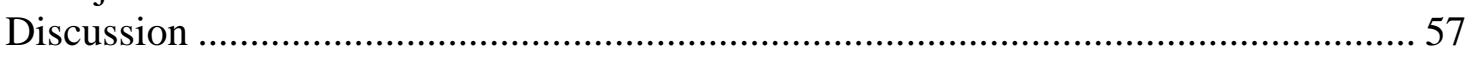

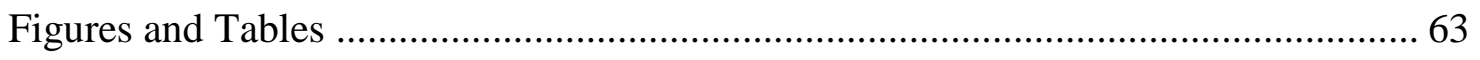


CHAPTER III: The Association of Residential Proximity to Roadway with Circulating Vascular Progenitor Cell Levels

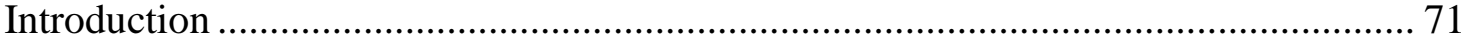

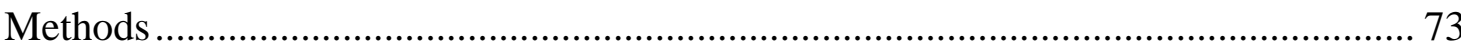

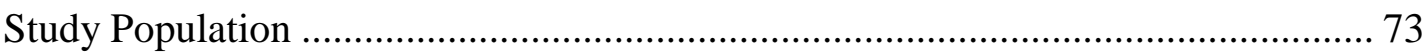

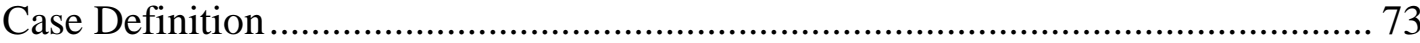

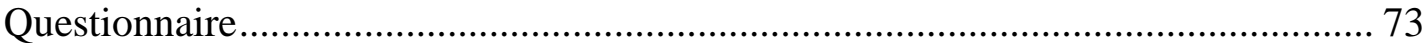

Biological Sample Collection and Processing.................................................... 73

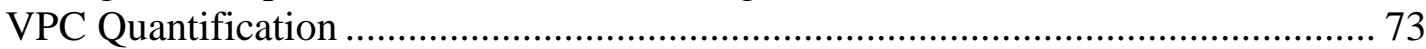

Platelet Mononuclear Cell Aggregate Identification .............................................. 74

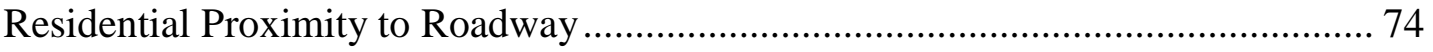

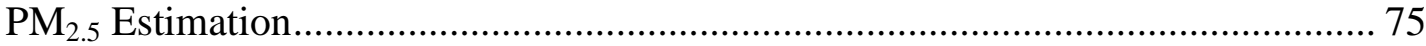

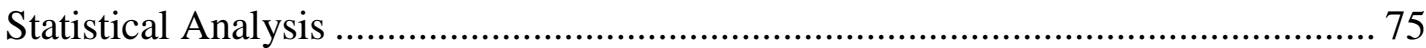

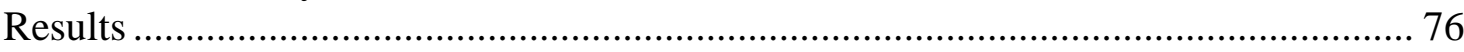

Participant Characteristics ............................................................................ 76

Participant Characteristics of the Population with a Residential Proximity of 6

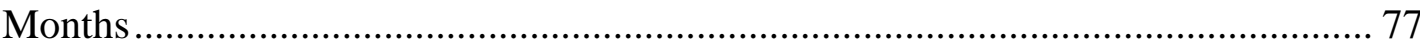

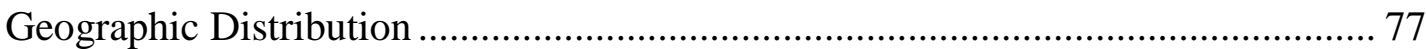

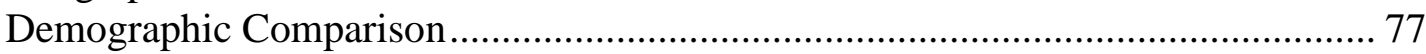

Demographic Comparison of the Population with a Residential Proximity of 6

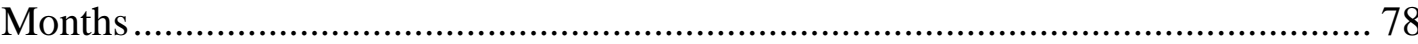

Association between VPCs and CVD Risk with Distance to Roadway................... 78

Association between VPCs and CVD Risk with Distance to Roadway in the

Population with a Residential Proximity of 6 Months .......................................... 79

Adjusted Association of VPCs and Distance to Roadway for the Total Population. 79

Adjusted Association of VPCs and Distance to Roadway in the Population with a

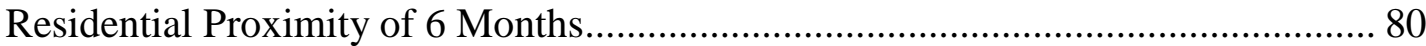

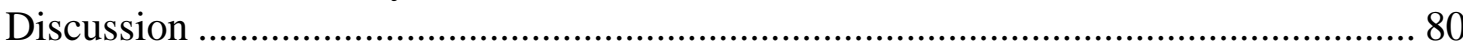

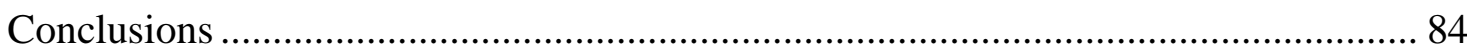

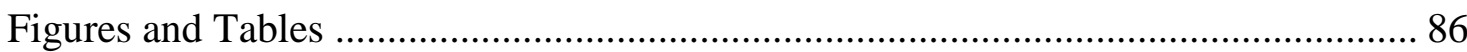

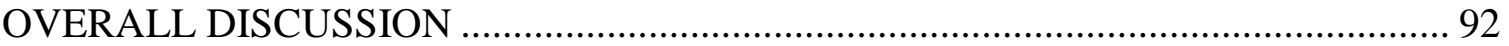

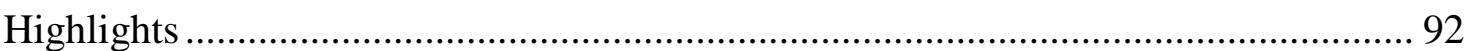

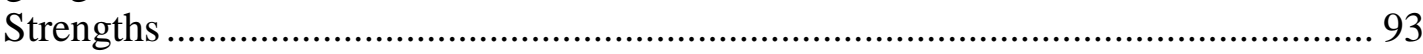

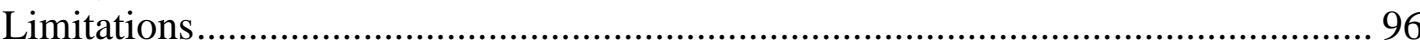

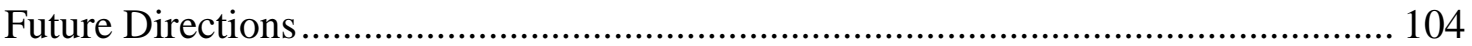

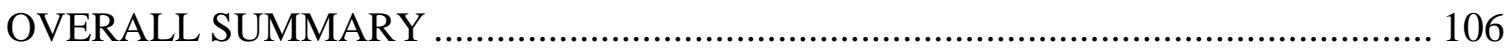

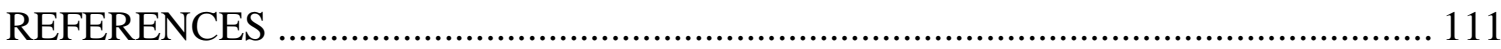

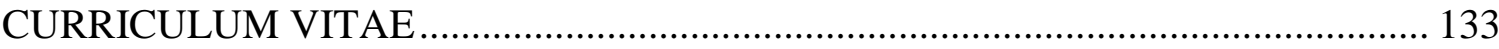




\section{LIST OF FIGURES}

Figure 1. Flow cytometry gating scheme for VPC populations.................................. 17

Figure 2. Abundance of Id-1 in populations of human blood progenitor cells................ 38

Figure 3. Adjusted association between VPCs and fibrinogen.................................. 45

Figure 4. Adjusted association between VPCs and platelet mononuclear cell aggregates.

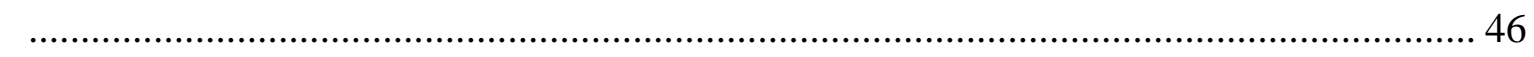

Figure 5. Adjusted association between VPCs and hsCRP..................................... 47

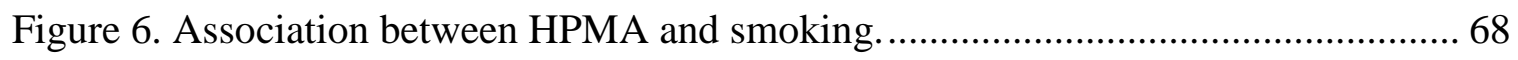

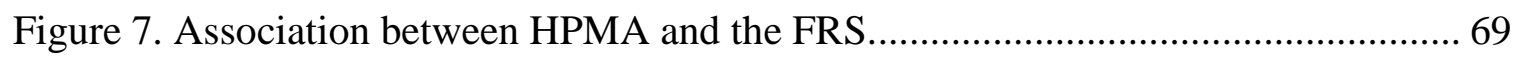

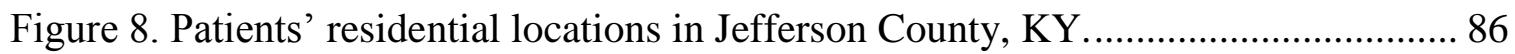




\section{LIST OF TABLES}

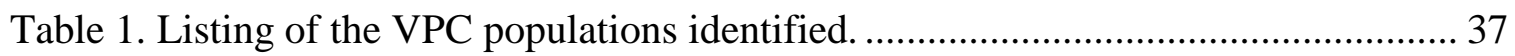

Table 2. Comparison between the low- and high- FRS risk populations. ...................... 39

Table 3. Comparison between the low- and high- CVD risk factor populations.............. 40

Table 4. Demographic comparison stratified by VPC-3 tertile. .................................. 41

Table 5. Demographic comparison stratified by VPC-5 tertile. ................................... 43

Table 6. Association between VPCs and FRS Category. .......................................... 44

Table 7. Demographic comparison stratified by HPMA tertile................................... 63

Table 8. Demographic comparison stratified by HPMA tertile in non-smokers.............. 65

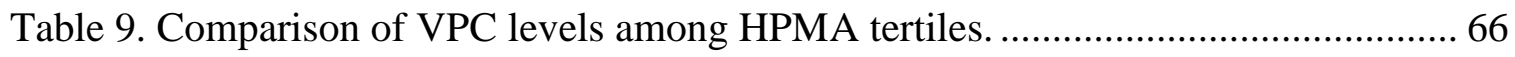

Table 10. Comparison of VPC levels among HPMA tertiles in non-smokers. ................ 67

Table 11. Adjusted association between HPMA and CVD Risk................................. 70

Table 12. Adjusted association between HPMA and CVD Risk in non-smokers........... 70

Table 13. Demographics and CVD risk history stratified by roadway proximity........... 87

Table 14. Demographics and CVD risk history stratified by roadway proximity in people

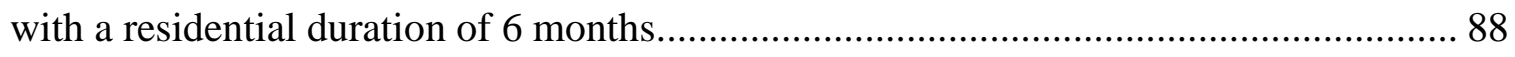

Table 15. Comparison of VPC levels, thrombosis, inflammation, and CVD risk between

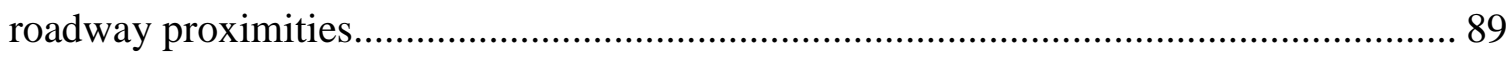

Table 16. Comparison of VPC levels, thrombosis, inflammation, and CVD risk between roadway proximities in people with a residential duration of at least 6 months.............. 90

Table 17. Association between roadway proximity, VPC levels, and CVD risk. ........... 91 
Table 18. Association between roadway proximity and VPC levels in people with a residential duration of at least 6 months. ... 


\section{OVERALL BACKGROUND}

\section{Public Health Burden}

Cardiovascular disease (CVD) is a class of non-infectious diseases of the circulatory system, affecting the heart or blood vessels ${ }^{1}$. Some CVD conditions include myocardial infarction, stroke, and heart failure. CVD is the top cause of death both globally and in the U.S. ${ }^{1,2}$. The U.S. CVD prevalence in adults $\geq 20$ years of age was $35.3 \%$ in $2010^{1}$. From 2007-2009, Kentucky was ranked seventh highest in the nation for CVD mortality, with a rate of 281.2 per 100,000 , exceeding the U.S. mortality rate of 243.9 per 100,000 population ${ }^{1}$. In $2009,32.3 \%$ of deaths were attributed to CVD, representing nearly 1 in every 3 deaths. Between 1999 and 2009, an average of 2,150 people in the U.S. died daily from CVD (1 death per every 40 seconds) ${ }^{1}$. Coronary artery disease (CAD; disease affecting the vessels that supply the heart) is the top cause of CVD mortality, responsible for $45 \%$ of CVD deaths ${ }^{3}$. Though CVD mortality rates have declined in recent decades, the burden of CVD remains high. In addition to the heavy public health burden of CVD, it also carries a substantial economic burden. The total estimated cost of CVD in the U.S. for 2009 was $\$ 312.6$ billion in direct and indirect costs (much greater, by comparison, than the $\$ 228$ billion for cancer costs in 2008$)^{1}$. The national health and economic burden of CVD drives interest in CVD prevention.

Although CVD burden is high, most CVD conditions are preventable through lifestyle choices including diet, physical activity, and cigarette smoking. Results from the Nurses' Health Study cohort indicated that $82 \%$ of coronary events were attributed to 
modifiable CVD risk factors, including proper diet and body weight, regular physical activity, abstaining from smoking, and moderate alcohol consumption; but only $3 \%$ of study subjects were considered low risk among all of those factors ${ }^{4}$. Additionally, it is estimated that $63 \%$ of heart attacks and $31 \%$ of strokes could be prevented by eliminating modifiable risk factors ${ }^{5}$. This emphasizes the need to investigate modifiable risk factors for CVD development to identify opportunities for prevention.

\section{Risk Factors}

Non-modifiable risk factors for CVD are ethnicity, gender, age, and heredity. African Americans have higher CVD mortality rates than Caucasians, and men have higher death rates from CVD than women. In 2009 the age-adjusted CVD mortality rates were 387.0 per 100,000 population for African American males, 281.4 per 100,000 population for Caucasian males, 267.9 per 100,000 population for African American females, and 190.4 per 100,000 population for Caucasian females ${ }^{1}$. As age increases, CVD incidence and mortality risk increase. As much as $83 \%$ of CAD mortality occurs at or above the age of 65 years ${ }^{6}$. It has been estimated that persons with a first-degree relative (parent, sibling, or child) that had a heart attack before age 55 in men and 65 in women have about a 2-fold increased risk of cardiovascular events ${ }^{7}$.

Traditional independent, modifiable risk factors for CVD include age, gender, hypertension (high blood pressure), hypercholesterolemia (high blood cholesterol), diabetes mellitus, and cigarette smoking ${ }^{8}$. Hypertension increases CVD risk because narrowed blood vessels cause the heart to work harder to pump blood to the body ${ }^{9}$. Nine out of 10 people 40 years or older with hypertension are expected to develop CVD in their lifetime ${ }^{8,10}$. People with hypercholesterolemia, total blood cholesterol levels of 
$240 \mathrm{mg}$ or greater, have a 2 -fold increased risk of heart attack, and that risk grows to 4fold with cholesterol levels of $300 \mathrm{mg}$ or greater ${ }^{11}$. It is estimated that a $10 \%$ populationwide reduction in blood cholesterol would result in a 30\% decrease in CAD incidence ${ }^{12}$. Diabetes mellitus is associated with a 2 - to 3 - times higher risk for developing $\mathrm{CAD}^{13}$. Cigarette smokers have been reported to be $2-4$ times more likely to develop CAD than nonsmokers ${ }^{14}$. Additionally, among people who had ever smoked cigarettes, 58\% reported having 3 or more circulatory diseases ${ }^{15}$.

Additional risk factors include physical inactivity and obesity. Physical inactivity is estimated to contribute toward $12.2 \%$ of the global burden of myocardial infarctions ${ }^{16}$. Additionally, physical inactivity has been shown to double the risk of developing CAD ${ }^{17}$. Physical inactivity also contributes to overweight and obese conditions. People who are overweight or obese are believed to be more at risk for CVD because weight increases cause the heart to work harder delivering oxygen-rich blood to the body ${ }^{11}$. Overweight men (body mass index $((\mathrm{BMI}) \geq 25)$ with CVD have been found to be more at risk for CVD mortality than normal weight $(\mathrm{BMI} \leq 25)$ men with $\mathrm{CVD}^{18}$. Overweight status in men and women has been associated with increased age-adjusted relative risks for CVD of 1.21 and 1.20 , respectively ${ }^{19}$. Additionally, being overweight is associated with population attributable risks of $23 \%$ (men) and $15 \%$ (women) for $\mathrm{CAD}^{19}$. Nine to $13 \%$ of total CVD mortality has been attributed to obesity $(\mathrm{BMI} \geq 30)^{20}$.

The Framingham Risk Score (FRS) is a risk algorithm created from a longitudinal study in Framingham, MA, calculated using the traditional CVD risk factors including age, gender, hypertension, cholesterol, smoking, and diabetes. The FRS is commonly used in clinical practice to predict patients' risk of future adverse CAD - myocardial 
infarction or cardiac mortality ${ }^{21}$. The FRS only predicts CAD events, not other conditions including stroke and heart failure. Criticism of the FRS suggests that the score is less accurate for predicting risk in women and populations with intermediate FRS levels (FRS 10-20) ${ }^{22}$. The FRS only assesses people who do not have CAD, primary preventive individuals. To account for the secondary prevention population, the risk score can be dichotomized into low FRS (FRS $>20$ ) or high FRS (FRS $\geq 20$ or confirmed CAD) categories.

\section{Vascular Progenitor Cells}

Emerging evidence suggests that vascular progenitor cell (VPC) populations are a sensitive indicator of cardiovascular health. VPCs are circulating progenitor cells with angiogenic properties ${ }^{23,24}$. They have been referenced in the literature under many names, including circulating angiogenic progenitors, peripheral blood mononuclear cells, and circulating progenitors from the bone marrow. Much of the research to support their role in the vasculature focuses on a subpopulation of VPCs, endothelial progenitor cells (EPCs). EPCs are mobilized from the bone marrow into peripheral blood circulation through endogenous factors (including cytokines, hormones, and growth factors) and exogenous factors (including statin use, exercise, injury, ischemia, and tumors) ${ }^{25}$. Following mobilization, EPCs are found lining the endothelium. The endothelium mediates coagulation, vasodilatation, thrombosis and thromboresistance, smooth muscle cell proliferation, and muscle wall inflammation. EPCs are necessary for upkeep and repair of the endothelium ${ }^{26}$ by participating in revascularization including angiogenesis (new vessel formation from pre-existing vessels) and vasculogenesis (de novo vessel formation ${ }^{25}$. Decreased EPC levels are associated with endothelial dysfunction, which is 
a hallmark of atherosclerosis development and a key mechanism in myocardial infarction ${ }^{27}$. Cigarette smoking, hypertension, hypercholesterolemia, diabetes, obesity, CAD, and congestive heart failure are all associated with endothelial dysfunction ${ }^{28}$. In humans, exposure to combustion pollutants is associated with vasoconstriction ${ }^{29}$. In mice, combustion pollutant exposure is associated with decreased endothelial-mediated vasodilatation ${ }^{29}$. Thus, EPC levels are reduced in populations with CVD. EPC levels are also reduced in healthy people populations exposed to combustion pollutants ${ }^{30}$.

\section{Air Pollution and CVD}

There is growing evidence that air pollution exposure should be considered a modifiable risk factor for CVD. In 2004, the American Heart Association issued its first scientific statement regarding CVD risk and particulate matter exposure ${ }^{31}$, and in 2010, they issued another scientific statement with a much larger body of work highlighting that exposure to fine particulate matter is a modifiable risk factor for $\mathrm{CVD}^{32}$. Air pollution has been found to trigger CVD events and increase CVD severity. Associations between fine particulate matter, aerosolized particles with an aerodynamic diameter of $2.5 \mu \mathrm{m}$ or less $\left(\mathrm{PM}_{2.5}\right)$, and CVD have been defined both spatially and temporally. A 10 $\mu \mathrm{g} / \mathrm{m}^{3}$ increase in $\mathrm{PM}_{2.5}$ concentration has been associated with a $4.5 \%$ increased risk of ischemic heart disease events in short term exposure ${ }^{33}$. An interquartile range increase in $\mathrm{PM}_{2.5}$ over long term exposure has been associated with a $16 \%$ increased odds of acute myocardial infarction (95\% confidence interval (CI): $1.04-1.29){ }^{34}$. Exposure to trafficgenerated air pollution has been associated with an odds ratio of 2.92 (95\% CI: $2.22-$ 3.83) for a nonfatal myocardial infarction ${ }^{35}$ and 2.54 (95\% CI: 1.96-3.29) for myocardial infarction mortality ${ }^{36}$. People living closer to a major roadway or highway, a common 
measure used to indicate traffic exposure, have been reported to be at higher risk for CAD mortality (relative risk $1.29,95 \%$ CI: $1.18-1.41)^{37}$. Living closer to a road has also been associated with increased cardiovascular mortality following a myocardial infarction, suggesting that people who have experienced a cardiovascular event may be more susceptible ${ }^{38}$. Compared with people living $200 \mathrm{~m}$ or more from a major roadway, odds ratios for coronary artery calcification were 1.63 (95\% CI: 1.14-2.33) for individuals living 50m or less from a major roadway and 1.34 (95\% CI: 1.00-1.79) for individuals living between $50 \mathrm{~m}$ and $100 \mathrm{~m}$ from a major roadway ${ }^{39}$. This suggests an association between roadway traffic exposure and vascular outcomes.

\section{Mechanisms of $\mathbf{P M}_{2.5}$ Toxicity}

It is well-understood that $\mathrm{PM}_{2.5}$ can be inhaled and adversely affects the respiratory system, but research indicates that it also affects the vascular and cardiovascular systems. There are three biological pathways by which $\mathrm{PM}_{2.5}$ exposure may contribute to heart disease. First, the presence of $\mathrm{PM}_{2.5}$ in the lung bronchioles elicits pulmonary oxidative stress and inflammation. This results in increased cellular inflammatory responses including: increased cytokine levels; increased activation of white blood cells and platelets; increased inflammatory markers (C-reactive protein (CRP)); and increased thrombosis factors (fibrinogen). Ultimately this systemic oxidative stress and inflammation leads to endothelial cell dysfunction (functional impairment of the cells that line blood vessels), vasoconstriction (constriction of the blood vessels), and progression of atherosclerosis. In the second pathway, the presence of $\mathrm{PM}_{2.5}$ in the bronchioles causes activation of the lung autonomic nervous system (ANS) reflex arcs. This causes an imbalance in the ANS where the sympathetic nervous system (SNS; fight- 
or-flight response) response is increased, and the parasympathetic nervous system (PSNS; resting state) response is inhibited. Outcomes include increases in vasoconstriction, blood pressure, platelet aggregation, heart rate, endothelial dysfunction (an imbalance between vasoconstriction and vasodilation), and systemic oxidative stress and inflammation. In the final pathway, $\mathrm{PM}_{2.5}$ in the bronchioles may lead to translocation of $\mathrm{PM}_{2.5}$ or its constituents (ultrafine particulates, soluble metals, or organic compounds) into circulating blood. This may cause vasoconstriction, endothelial dysfunction, increased blood pressure, and systemic oxidative stress and inflammation. Each of these three pathways suggest that the cardiovascular effects of particulate matter exposure may be mediated by vascular effects of environmental exposures $31,32,40,41,42$.

\section{Acrolein}

Acrolein (2-propenal) is a combustion air pollutant associated with tobacco smoke, vehicular exhaust, open fires, and industrial emissions. Acrolein is a highly reactive electrophilic compound found in air, soil, and water, but it rapidly evaporates from soil and water, with a half-life in the environment of approximately 1 day ${ }^{43}$. People are also exposed to acrolein through foods, including beer, cheese, bread, and fried food ${ }^{44}$, and acrolein is formed endogenously through biochemical processes of lipid peroxidation. Targets for acrolein toxicity include the hematological, ocular, respiratory, and cardiovascular systems ${ }^{43}$. Acrolein metabolism in the body results in the formation of 15 detectable products. About $20-30 \%$ of acrolein is excreted through feces (none of the individual metabolites are excreted through the feces in significant quantities), while $60-70 \%$ of acrolein is excreted through urine ${ }^{45}$. Hydroxypropylmercapturic acid (HPMA) is the acrolein metabolite found in highest quantity in the urine and is only 
produced by acrolein metabolism ${ }^{46}$. Acrolein undergoes conjugation with glutathione, cleavage of the $\gamma$-glutamic acid and glycine residues, $\mathrm{n}$-acetylation of the cysteine to form S-(3-oxyproply)-N-acetylcysteine (OPMA), and reduction of OPMA to form HPMA ${ }^{47}$.

Acrolein poses a high risk for cardiovascular toxicity. Acrolein exposure is associated with increased CVD risk, including hypertension, atherogenesis, decreased plaque stability, suppression of cardiac flow, thrombosis, and cardiac contractility ${ }^{48}$. Acrolein exposure in mice is associated with dyslipidemia, decreased VPC levels, and endothelial dysfunction ${ }^{49-51}$. Additionally, protein-acrolein adducts have been found in atherosclerotic lesions in the vessels of mice exposed to acrolein ${ }^{51}$. In human endothelial cells, acrolein can form protein adducts and oxidize thioredoxins, which promotes atherogenesis ${ }^{48}$, but its effects on human VPCs are unknown.

In addition to being a source of acrolein exposure, cigarette smoking increases risk of hypertension and atherosclerosis. Moreover, chronic smoke exposure is associated with decreased EPC levels ${ }^{52}$. It is predicted that $50-70 \mathrm{ppm}$ of acrolein is generated in tobacco smoke, compared to 6-8ppm generated by automobile exhaust from gasoline and diesel engines ${ }^{51,53}$. Smoke exposure can be empirically measured by determining metabolite levels. Nicotine, a metabolite of tobacco smoke, has a shorter in vivo half-life than cotinine, a nicotine metabolite, with an in vivo half-life of 2-3 hours for nicotine in blood, compared to $15-19$ hours for cotinine ${ }^{54}$. Cotinine can be measured in urine, saliva, and serum for acute exposures, and can be measured in hair to assess chronic exposure. Cotinine is detectable in the system for up to 7 days. 


\section{Summary}

The current study addresses an important problem: CVD is the primary cause of morbidity and mortality and is associated with high economic burden. This research investigates how environmental exposures may contribute to CVD risk. The results of this investigation will expand scientific knowledge by exploring the association of VPCs with CVD and acrolein's primary metabolite. Theoretically, this association could become an example and guide for future understanding of CVD risk consequences in combustion pollutant exposure. Understanding the association between acrolein exposure and CVD susceptibility will be important for future CVD prevention intervention policies and mitigation of environmental risks, which may ultimately reduce the environmental burden associated with CVD.

The current study investigates the association between environmental pollution exposure and VPC levels. Chapter 1 presents an investigation of the relationship between circulating VPC counts and CVD risk. Chapter 2 examines the relationship between circulating VPC counts and HPMA, an acrolein metabolite. Chapter 3 explores the relationship between circulating VPC counts and residential proximity to roadways. Results of this investigation build support for the association between VPCs and CVD risk and environmental exposures. The scientific knowledge attained by defining these associations has the potential to drive future mechanistic pathway explorations, impact pollution prevention interventions, and guide therapeutic interventions in the field of environmental cardiology. 


\section{OVERALL METHODS}

The following is a listing of methods common to each chapter. Methods that are specific to each chapter are included in the methods section of the respective chapter. Please note that the populations are slightly different in each chapter depending on the outcome variable measures and missing data.

\section{Study Population}

To test the research hypothesis, 240 adults undergoing primary or secondary preventive treatment for CVD at the University of Louisville Hospital and/or Clinic System were recruited between October 2009 and March 2011. All study consent forms and research protocols were approved through the Institutional Review Board at the University of Louisville (IRB 09.0174).

Inclusion criteria: : Eligible individuals were (1) 18 years of age or older at the time of enrollment; and (2) patients of the University of Louisville Hospital and/or Clinic System requiring primary or secondary prevention for cardiovascular disease (see the Case Definition section below).

Exclusion criteria: (1) Persons unwilling or unable to provide informed consent; (2) subjects with significant and/or severe co-morbidities including the following conditions: significant chronic lung, liver, kidney, hematological, or neoplastic disease; chronic neurological or psychiatric illness; chronic infectious disease such as HIV or hepatitis; severe coagulopathies; drug/substance abuse; and chronic cachexia; (3) 
pregnant women; and (4) prisoners and other vulnerable populations were excluded from the current study.

Patients who met the enrollment criteria answered a brief questionnaire to obtain demographic information, address, CVD history, tobacco smoke exposure, alcohol intake, physical activity, and baseline clinical characteristics.

\section{Case Definition}

Primary prevention. In the current study, primary prevention cases were defined as individuals with heart disease risk factors, including hypertension, hypercholesterolemia, obesity, and diabetes that require management, but who had no evident coronary artery disease (CAD). Therefore, primary prevention patients had cardiac risk factors, but no CAD.

Secondary prevention. Secondary prevention cases were defined as individuals with heart disease risk factors that required management/treatment and had evident heart disease. That is, secondary prevention patients had a clinical manifestation of CAD and were undergoing modification of risk factors. As such, in the current study, the absence or presence of CAD determined whether a patient was defined as primary or secondary.

\section{Questionnaire}

All participants in the study were administered an interview questionnaire to determine their medical and familial history of CVD. The questionnaire, which was created by a cardiologist, was descriptive and asked questions regarding their demographic information; residential address; smoking status and history; secondhand smoke exposure; alcohol consumption; physical activity status; medication usage; and CVD history including heart attack, heart failure, angina; hypertension, 
hypercholesterolemia, diabetes, stroke, revascularization, arrhythmia, peripheral artery disease, aortic aneurism, and bleeding disorders. Medical records were reviewed to verify addresses, medication history, and to provide the blood pressure reading at the time of visit.

\section{Risk Factor Definitions}

Patients were asked if they had been told by a doctor that they had CVD risk factors or conditions. Hypertension was defined as systolic blood pressure $\geq 140 \mathrm{mmHg}$ or diastolic blood pressure $\geq 90 \mathrm{mmHg}$. Diabetes mellitus includes glycosylated hemoglobin test (hbA1C) results $\geq 6.5 \%$, fasting plasma glucose levels $\geq 126 \mathrm{mg} / \mathrm{dL}$, and/or oral glucose tolerance test blood glucose levels $\geq 200 \mathrm{mg} / \mathrm{dL}$. Hyperlipidemia was defined as having total cholesterol of $240 \mathrm{mg} / \mathrm{dL}$ or above, high-density lipoprotein (HDL) levels less than $40 \mathrm{mg} / \mathrm{dL}$ for men or less than $50 \mathrm{mg} / \mathrm{dL}$ for women, low-density lipoprotein of $160 \mathrm{mg} / \mathrm{dL}$ or greater, and/or triglyceride levels of $200 \mathrm{mg} / \mathrm{dL}$ or more. ${ }^{1}$

\section{Biological Sample Collection and Processing}

Biological samples (urine, blood) were obtained from each participant. Urine collected at the time of the visit was used to measure the levels of urine acrolein and nicotine metabolites. Blood sampling was performed by a licensed phlebotomist or nurse by venipuncture. Approximately $8 \mathrm{~mL}$ of blood was collected in a Vacutainer® CPT Mononuclear Cell Preparation Tube (Becton Dickinson) for VPC analysis, $2.6 \mathrm{~mL}$ in a Vacutainer ${ }^{\circledR} \mathrm{ACD}$ tube for platelet mononuclear cell aggregate analysis, $6 \mathrm{~mL}$ in a Vacutainer® Serum Tube for high-sensitivity C-reactive protein analysis, and $6 \mathrm{~mL}$ in a Vacutainer® K2 EDTA (plasma) Tube for fibrinogen analysis. 


\section{VPC Quantification}

Human VPCs were identified by fluorescence-activated cell sorting (FACS) flow cytometry following the methods first described by Duda et al. ${ }^{55}$ and modified by O'Toole et al. ${ }^{30}$. Within 24 hours of the blood draw, blood was separated in the CPT mononuclear separator tube by centrifugation at $2750 \mathrm{rpm}$ for 30 minutes. Mononuclear cells were separated from serum by centrifugation at $1500 \mathrm{rpm}$ for $10 \mathrm{~min}$. The pelleted cells were then washed twice with $2 \%$ FBS in PBS and then incubated with $2 \% \mathrm{FBS} / \mathrm{PBS}$ and FcR Blocking Reagent (Miltenyi Biotec) for 10 minutes. on ice in the dark. The cells were incubated in the dark for 30 minutes. on ice with a panel of fluorescentlyconjugated antibodies including: PE-labeled anti-CD34 (Becton Dickinson), APClabeled anti-AC133 (Miltenyi Biotec), PE-Cy5.5-labeled anti-CD14 (Abcam), APCAlexaFluor 750-labeled anti-CD45 (Invitrogen), PE-Cy7-labeled anti-CD16 (Becton Dickinson), FITC-labeled anti-CD31 (Becton Dickinson), anti-CD41a (Becton Dickinson) and anti-CD235a (Becton Dickinson), Pacific Blue (Pacific Blue monoclonal antibody labeling kit; Invitrogen), and a marker for dead cells (LIVE/DEAD fixable dead cell stain; Invitrogen). The cells were then pelleted and washed once in $2 \% \mathrm{FBS} / \mathrm{PBS}$. Finally, the cells were resuspended in $1 \%$ FACS formaldehyde ${ }^{30}$.

Following cell resuspension, 500,000 events were collected using the LSR II flow cytometer (Becton Dickinson). Positive/negative boundaries for all gating was accomplished using unstained controls. The lymphocyte population was selected in the initial gating scheme by measuring the population that was negative for CD235a, CD41a, and the dead cell marker (all stained with pacific blue). From that population, the CD14 and CD16 negative population were selected. Cells positive for both $\mathrm{CD}^{+} 4^{+}$(stem cells) 
and $\mathrm{CD} 31^{+}$(endothelial cells) were selected for the final population. Additionally, VPCs

were subdivided into monocytic/non-monocytic $\left(\mathrm{CD} 45^{+/ \mathrm{dim}}\right)$ and early/mature progenitors $\left(\mathrm{AC} 133^{+/-}\right)$. FlowJo software was used to analyze the collected events. VPC counts were normalized to the sample volume used in analysis ${ }^{30}$. The gating scheme is shown in Figure 1.

\section{Platelet Mononuclear Cell Aggregate Identification}

Peripheral blood was collected in an ACD tube. One mL of blood was fixed with $1.3 \mathrm{~mL}$ of $4 \%$ paraformaldehyde and diluted with $3 \mathrm{~mL}$ of deionized water for a minimum of 30 minutes. on ice. Red blood cells were lysed with the addition of $24 \mathrm{~mL}$ of water. The sample was centrifuged for 10 minutes. at $400 \mathrm{~g}$, and the pelleted cells were resuspended with $1 \mathrm{~mL}$ of Tyrode's buffer. The Tyrode's-resuspended cells were divided into 2 equal aliquots. Both aliquots were incubated on ice with FcR Blocking Reagent (Miltenyi Biotec) for 5 minutes. The first aliquot of the platelet-mononuclear cells was then incubated with the following antibodies for 30 minutes. on ice: FITC-labeled anti CD41a (Becton Dickinson) and PerCP-Cy5.5-labeled anti-CD45 (Becton Dickinson). The second aliquot was labeled with isotype control antibodies and incubated on ice for 30 minutes. Following incubation, both aliquots were washed and resuspended in Tyrode's Buffer. Using FACS flow cytometry, platelet mononuclear cell aggregates were counted as events that were labeled FITC $\left(\mathrm{CD} 41^{+}\right)$and PerCP-CY5.5 $\left(\mathrm{CD} 45^{+}\right)$and were calculated as a percentage of total events ${ }^{30}$.

\section{Cotinine Quantification}

Cotinine was measured in urine using gas chromatography / mass spectrometry (GC/MS) following the methods described by Man et al. Urine in quantities of $1 \mathrm{~mL}$ for 
self-reported current non-smokers or $0.25 \mathrm{~mL}$ for self-reported current smokers (diluted with $0.75 \mathrm{~mL}$ of deionized water) was pipetted into Teflon vials. Either 0.2 nmoles (nonsmokers) or 0.5 nmoles (smokers) of the internal standard of D-3 cotinine in $0.175 \mathrm{~mL}$ of methanol was added. This was followed by the addition of $0.05 \mathrm{~mL}$ of $0.1 \mathrm{M} \mathrm{NaOH}$ and $0.325 \mathrm{~mL}$ of chloroform. This mixture was vortexed for $1 \mathrm{~min}$. and then centrifuged at $13000 \mathrm{rpm}$ for 4 minutes. After discarding the aqueous layer, $100 \mathrm{mg}$ of sodium sulphate was added to remove any excess water, briefly mixed, and the solution was allowed to sit at room temperature for 1 minute. The clear organic extract was transferred to a gas chromatography vial and $0.001 \mathrm{~mL}$ was injected to the gas chromatographer. Ions used to monitor cotinine were 176 (cotinine) and 179 (D-3 cotinine) ${ }^{56}$.

\section{High Sensitivity C-Reactive Protein Quantification}

The quantitative measurement of high sensitivity $\mathrm{C}$-reactive protein (hsCRP) in serum is performed using the VITROS Chemistry Products hsCRP Reagent in conjunction with the VITROS Chemistry Products Calibrator Kit 17 and VITROS Chemistry Products FS Calibrator 1 on VITROS 5,1 FS Chemistry Systems. Samples, calibrators, and controls are mixed with Reagent 1 containing a buffer. Addition of antiCRP antibodies coupled to latex microparticles (Reagent 2) produces an immunochemical reaction yielding CRP antigen/antibody complexes. The turbidity is measured spectrophotometrically at $660 \mathrm{~nm}$. Once a calibration has been performed for each reagent lot, the CRP concentration in each unknown sample can be determined using the stored calibration curve and the measured absorbance obtained in the assay of the sample. Values from hsCRP were divided into three groups for low $(<1.0 \mathrm{mg} / \mathrm{L})$, intermediate (1.0-2.9 mg/L), and high ( $\geq 3 \mathrm{mg} / \mathrm{L})$ levels ${ }^{57}$. 


\section{Fibrinogen Quantification}

The STA Fibrinogen kit is intended for the quantitative determination of

fibrinogen in plasma by the Clauss clotting method ${ }^{58}$. In the presence of excess thrombin, the clotting time of diluted plasma is inversely proportional to the level of plasma fibrinogen. The clot is detected by the STA-Compact, a fully automated coagulation instrument that uses an electromagnetic mechanical clot detection system. The oscillation of a steel ball within the cuvette containing thrombin and diluted plasma is monitored by the STA-Compact. When the oscillation of the steel ball is stopped by clot formation, the sensor registers the time in seconds. The time is read from a stored curve on the STA-Compact. The time read is translated into a fibrinogen concentration based on the manufacturer's standard curve from the STA-Compact.

\section{Socioeconomic Status Determination}

To determine socioeconomic status (SES), addresses were geocoded in Geographic Information System (GIS) ArcMap 9.3 (ESRI, Redlands, CA). Data for geocoding addresses was provided by the Louisville/Jefferson County Information Consortium (LOJIC) composite locator in ArcGIS. SES was estimated using the proxy variable, "median household income," and was provided at the block group level from the 2000 U.S. Census. 
Figures and Tables

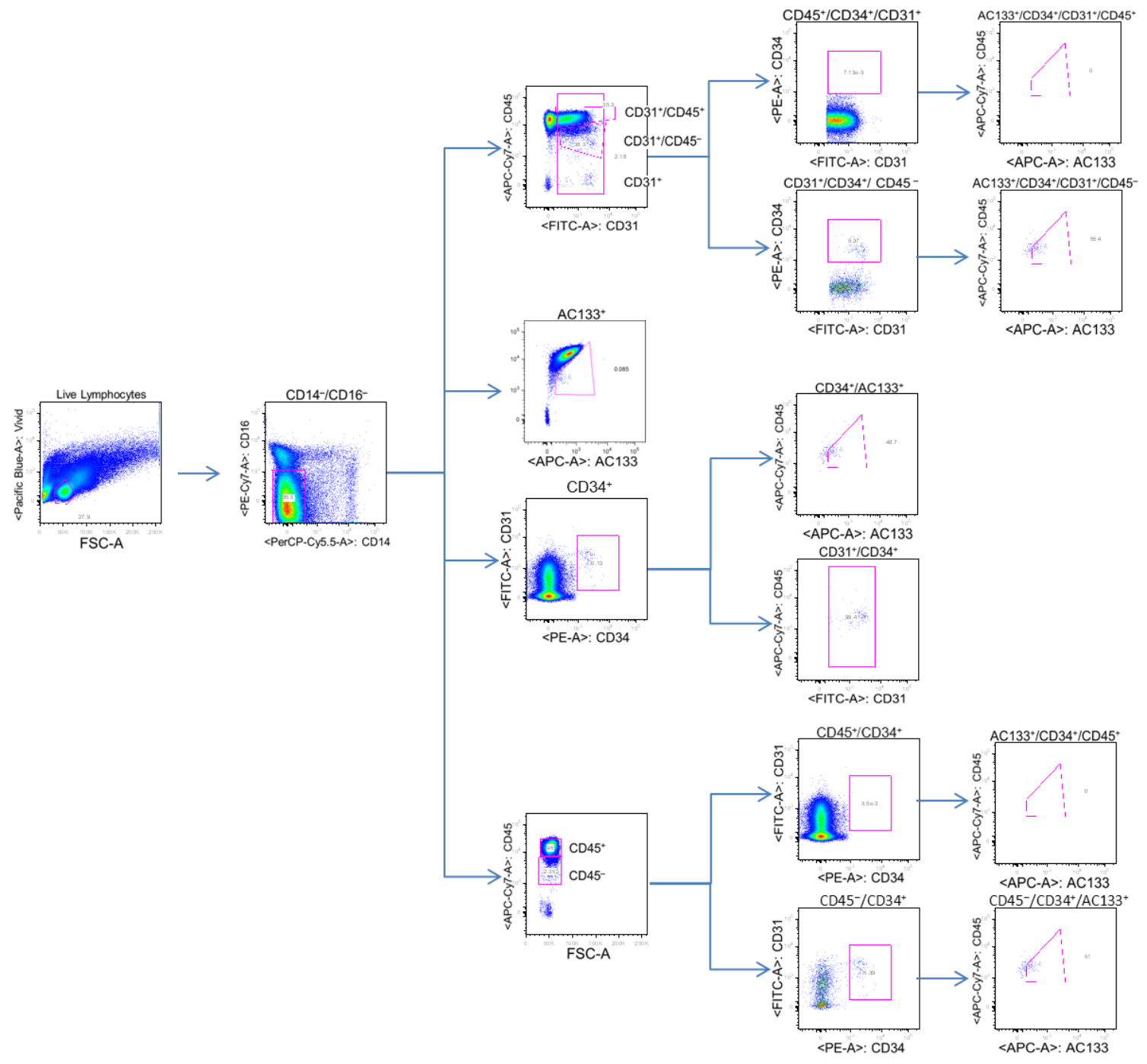

Figure 1. Flow cytometry gating scheme for VPC populations. 


\section{CHAPTER I:}

\section{Circulating Vascular Progenitor Cells are Associated with Cardiovascular Disease}

\section{Risk}

\section{Introduction}

Cardiovascular disease (CVD) is the leading cause of morbidity and mortality worldwide ${ }^{1}$. Understanding CVD risk is critical to characterizing and enhancing future preventive approaches. Vascular progenitor cells (VPCs) are believed to be necessary for upkeep and repair of blood vessels ${ }^{26}$ by participating in revascularization, including angiogenesis ${ }^{23}$ and vasculogenesis ${ }^{59-61}$. Reduced migratory capacity and quantity of VPCs are associated with endothelial dysfunction ${ }^{62}$, which is a hallmark of atherosclerosis development ${ }^{63}$. VPC levels have been shown to be inversely associated with intima-media thickness, also linked with atherosclerosis ${ }^{64}$. Cigarette smoking, hypertension, hypercholesterolemia, diabetes, obesity, coronary artery disease (CAD), and congestive heart failure are all associated with endothelial dysfunction ${ }^{28}$. VPC counts are positively associated with brachial reactivity ${ }^{65,66}$. Circulating VPC levels have been suggested to reflect CVD risk, with inverse associations between VPC levels and traditional CVD risk factors including smoking ${ }^{52}$, diabetes mellitus ${ }^{67}$, total cholesterol ${ }^{65 \text {, }}$ ${ }^{68}$, and low-density lipoprotein (LDL) cholesterol ${ }^{63,68}$. They have also been inversely associated with the Framingham Risk Score (FRS) ${ }^{65}$ 69, 70 . VPCs are often depleted in populations with CVD ${ }^{63,65,69}$, increased CVD severity ${ }^{66,71-73}$, and CVD mortality ${ }^{74}$. The aforementioned results have not been entirely consistent in that a number of other 
studies have observed positive associations with VPC levels and the FRS ${ }^{64}$, smoking ${ }^{66}$, and found no VPC differences in hypertension, hyperlipidemia, and diabetes ${ }^{74}$.

Discrepancies in these findings are likely because VPCs are a heterogeneous population containing cells with different angiogenic potential, and it has not yet been determined which specific cell types are associated with CVD risk and specific CVD risk factors. We investigated the relationship between VPCs and CVD risk factors using antigenicallydefined VPC sub-populations with demonstrated angiogenic potential (through inhibitor of DNA binding 1 (Id1) positive staining). Our study determined which among the 15 VPC populations, were associated with varying degrees of CVD risk in an at-risk population.

A 7-color flow cytometry procedure was used to describe the VPC profile from peripheral blood cells among a population with varied degrees of CVD risk. The use of antigenic markers CD $31^{+}$(endothelial), CD $34^{+}$(stem), CD45 $5^{+/ \mathrm{dim}}$ (hematopoietic/ nonhematopoietic), and $\mathrm{AC} 133^{+/-}$(early/ late stem) is novel because previous studies have used different antigenic markers to define VPCs, some of which were not specific to VPCs including, 1,1'-dioctadecyl-3,3,3',3'-tetramethyl-indocarbocyanine perchlorate labeled acetylated low-density lipoprotein (DiI-Ac-LDL) and lectin. Previous human studies have also assessed cells after growth in culture, a measure indicating cellular growth capacity and function - rather than the number of cells in circulation. This has resulted in mixed findings in terms of the association between VPCs and CVD risk factors.

In summary, several studies have suggested that circulating VPC levels are decreased in populations with CVD; however, these studies used cellular definitions that 
were not specific to VPCs. We evaluated the relationship between CVD risk and VPC levels using antigentically defined VPCs with demonstrated angiogenic potential. We hypothesize that VPC levels are inversely associated with CVD risk. Fifteen VPC populations measured from peripheral blood using VPC-specific antigenic markers were quantified using flow cytometry.

\section{Methods}

\section{Study Population}

See Overall Methods (Study Population).

\section{Case Definition}

See Overall Methods (Case Definition).

\section{Questionnaire}

See Overall Methods (Questionnaire).

\section{Biological Sample Collection and Processing}

See Overall Methods (Biological Sample Collection and Processing).

\section{VPC Quantification}

VPC populations in blood were characterized using a 7-color flow cytometry procedure using established markers: $\mathrm{CD} 31^{+}, \mathrm{CD} 34^{+}, \mathrm{CD} 45^{+/ \mathrm{dim}}$, and $\mathrm{AC} 133^{+}$. This method was first described by Duda et al. to define circulating endothelial cell (CEC) and circulating progenitor cell (CPC) populations in human peripheral blood ${ }^{55}$. Additionally, O'Toole et al. used modifications of this model to determine human VPC populations using the aforementioned 4 antigenic markers ${ }^{30}$. We expanded the number of cell populations from 6 to 15 (see Table 1). See Overall Methods (VPC Quantification). 
Selected VPC populations were also assessed for the transcription factor inhibitor of DNA binding 1 (Id1), an antigenic marker for endothelial progenitor cells. Murine studies suggest that this marker indicates endothelial progenitor cell activity; when Id1 ${ }^{+}$ cells are suppressed from the bone marrow in trans-genic mice, angiogenesis is impaired in tumors, and circulating endothelial progenitor cell levels in circulation are depleted ${ }^{75-}$ 77. The current study used modifications of the Wheat et al. protocol for Id1 determination ${ }^{51}$. White blood cells isolated from human blood of healthy volunteers (University of Louisville IRB 11.0432) were sorted for selected subsets by fluorescenceactivated cell sorting (FACS), permeabilized (0.1\% Triton X-100/ phosphate buffered saline (PBS), room temperature, 3 minutes), blocked (1 \% bovine serum albumin (BSA)/PBS, room temperature, 15 minutes) and incubated over night with the primary antibody against Id1 (proteintech, Chicago, Il; 1:250) at $4^{\circ} \mathrm{C}$. After incubation with the fluorescence labeled secondary antibody (1:500, 1 hour, room temperature; anti-rabbit488, Invitrogen, Carlsbad, CA), cells were mounted with DAPI containing mounting media (Invitrogen, Carlsbad, CA) and images were taken by fluorescence microscopy (EVOSfl, AMG, Hill Creek, WA).

\section{Platelet Mononuclear Cell Aggregate Identification}

Platelet mononuclear cell aggregates were identified using flow cytometry following the procedures described in O'Toole et al. Using flow cytometry, platelet mononuclear cell aggregates were counted as events that were FITC $\left(\mathrm{CD} 41^{+}\right)$and PerCPCY5.5 $\left(\mathrm{CD} 45^{+}\right)$and were calculated as a percentage of total events ${ }^{30}$. See Overall Methods (Platelet Mononuclear Cell Aggregate Identification). 


\section{Statistical Analysis}

\section{Influence of CVD Risk on VPCs, Thrombosis and Inflammation}

Independent samples t-tests (Wilcoxon methods when appropriate) were used to test for differences (association) in mean VPC values, thrombosis markers (fibrinogen and platelet mononuclear cell aggregates), and inflammation markers (hsCRP), between those in the low Framingham Risk Score (FRS) category (FRS $\leq 20)$ and high FRS category (FRS $\geq 20$ or established CVD). Additionally, t-test techniques were used to compare these variables among people with a low number of risk factors $(<2 \mathrm{CVD}$ risk factors among age $\geq 40$ years, male gender, hypertension, diabetes, hyperlipidemia, diabetes, and current smoking) and a higher number of risk factors ( $\geq 2$ CVD risk factors). This more crude comparison was utilized to determine if individuals with a small number of risk factors in the study population were different from the remaining population or if the use of this crude variable provided additional information or understanding in addition to the FRS t-test comparisons. The VPC levels assessed were $\log$ transformed for normality, consistent with previous literature ${ }^{74}$. VPC values presented are the VPC counts normalized to sample volume for consistency.

Additionally, population demographics and CVD risk factors were compared among tertiles of low, medium, and high log-transformed VPC levels for a VPC population positively associated with the FRS category and a population inversely associated with the FRS category. Tertiles were defined by dividing the population's VPC levels into cut points for 3 evenly distributed groups. Demographics and CVD risk factors were compared using $X$-squared analysis for categorical variables and analysis of variance (ANOVA) for continuous variables. 
Simple linear regression modeling techniques were used to test for associations between VPC and the FRS category (unadjusted). Generalized Linear Modeling (GLM) techniques examined whether FRS category was independently associated with VPC levels, adjusting for, ethnicity, whether they consumed alcohol, body mass index (BMI) and, socioeconomic status (SES; median household income at the block group level). GLM techniques are appropriate for variables that are not normally distributed. The VPCs followed a gamma distribution rather than a normal distribution; therefore, the GLMs with each VPC entered as the dependent variable utilized the gamma probability distribution and the log link function. Traditional model fit statistics (log-likelihood) were used to develop the most parsimonious model. In addition we tested whether higher order modeling (e.g., exponential, cubic) improved model fit using traditional model-fit statistics (AIC, log-likelihood, etc.).

\section{Influence of Thrombosis and Inflammation on VPCs}

Similar to above, simple linear regression modeling techniques were used to test for associations between (1) VPC and thrombosis markers (fibrinogen and platelet mononuclear cell aggregates) and (2) VPC and inflammation markers (hsCRP) unadjusted. That is, we tested whether VPC values were associated with thrombosis markers and/or inflammation markers, unadjusted. Also similar to above, GLM techniques for the VPC models utilized the gamma probability distribution and the log link function to examine whether thrombosis (fibrinogen and platelet mononuclear cell aggregates), and inflammation markers (hsCRP) were independently associated with VPC levels, adjusting for hypertension, hyperlipidemia, diabetes, smoking, age, ethnicity, alcohol, gender, BMI, and SES. Traditional model fit statistics (log-likelihood) were used 
to develop the most parsimonious model. In addition we tested whether higher order modeling (e.g., exponential, cubic) improved model fit using traditional model-fit statistics (AIC, log-likelihood, etc.).

Note: The current study only reports/presents the models that had a significant relationship with a VPC and the main effect of interest. Also, there was significant overlap between many of the 15 VPC populations measured; therefore associations for each VPC population were measured separately in individual GLMs.

\section{Results}

\section{Participant Characteristics}

The Healthy Heart Study population was $51 \pm 10$ years of age; $53.6 \%(n=53.6)$ male; 56.3\% ( $\mathrm{n}=103)$ Caucasian; $40.3 \%(\mathrm{n}=73)$ current smokers; 82.2\% $(\mathrm{n}=148)$ hypertensive; $64.8 \%(n=116)$ had hypercholesterolemia; $59.6 \%(n=106)$ obese; and were taking medications including 55.3\% $(n=99)$ angiotensin-converting-enzyme (ACE) inhibitors, $63.7 \%(n=114)$ beta-blockers, and 52.5\% $(n=94)$ statins. Population demographics are shown in Tables 3 and 4. Small differences between the demographics are due to missing data attributed to log transforming VPC-levels: 0 values cannot be log transformed and are, therefore, missing.

\section{Id1 Staining}

Id1 staining was used to determine if the isolated VPC populations were endothelial progenitor cells. VPC-1 $\left(\mathrm{CD} 31^{+} / 34^{+} / 45^{\mathrm{dim}}\right)$, VPC-2 $\left(\mathrm{CD} 31^{+} / 34^{+} / 45^{+}\right)$, VPC-5 $\left(\mathrm{CD} 31^{+} / \mathrm{AC} 133^{+}\right), \mathrm{VPC}-6\left(\mathrm{CD} 31^{+} / 34^{+}\right), \mathrm{VPC}-7\left(\mathrm{CD} 31^{+} / 34^{+} / 45^{\mathrm{dim}} / \mathrm{AC} 133^{-}\right), \mathrm{VPC}-8$ $\left.\left(\mathrm{CD} 31^{+} / 34^{+} / 45^{+} / \mathrm{AC} 33^{-}\right), \mathrm{VPC}-11(\mathrm{AC}) 3^{+}\right)$, and $\mathrm{VPC}-13\left(\mathrm{CD} 34^{+} / \mathrm{AC} 133^{+}\right)$were positive for Id1 (Figure 2). VPC-4 (CD $\left.31^{+} / 34^{+} / 45^{+} / \mathrm{AC} 133^{+}\right)$and VPC-14 
$\left(\mathrm{CD} 34^{+} / 45^{+} / \mathrm{AC} 133^{+}\right)$had positive and negative Id1 cells (Figure 2$)$. Id1 staining on the remaining cell populations is pending.

\section{CVD Risk and its association with VPCs, Thrombosis, and Inflammation}

Comparisons between VPC levels, thrombosis, and inflammation were made among the risk score levels. A number of the VPC populations and fibrinogen were significantly different between the low and high FRS populations, Table 2. Specifically, the high FRS population had significantly higher levels of VPC-1 (CD3 $1^{+} / 34^{+} / 45^{\mathrm{dim}}$; $\mathrm{p}=0.023), \mathrm{VPC}-3\left(\mathrm{CD} 31^{+} / 34^{+} / 45^{\mathrm{dim}} / \mathrm{AC} 133^{+} ; \mathrm{p}=0.008\right), \mathrm{VPC}-13\left(\mathrm{CD} 34^{+} / \mathrm{AC} 133^{+}\right.$; $\mathrm{p}=0.020), \mathrm{VPC}-15\left(\mathrm{CD} 34^{+} / 45^{\mathrm{dim}} / \mathrm{AC} 133^{+} ; \mathrm{p}=0.006\right)$, and fibrinogen $(\mathrm{p}=0.006)$.

Additionally, comparisons between VPC levels, thrombosis, and inflammation were also made among the number of risk factors, Table 3 . The high risk population had $\geq 2$ CVD risk factors and the low risk population had $<2$ CVD risk factors. None of the VPCs, hsCRP, or fibrinogen were different between the risk factor strata, but platelet mononuclear cell aggregates were higher in the high-risk population $(\mathrm{p}=0.040)$.

\section{Demographic Comparisons among VPC-3 Tertiles}

Differences between the characteristics of the populations within low, medium, and high VPC-3 $\left(\mathrm{CD} 31^{+} / 34^{+} / 45^{\mathrm{dim}} / \mathrm{AC} 133^{+}\right)$tertiles are shown in Table 4 . VPC-3 was selected because it is the most specific sub-population positively associated with FRS. Participants in the high FRS category (FRS $\geq 20$ or experienced a cardiovascular event) were significantly more likely to have high VPC-3 levels ( $\mathrm{p}=0.004)$. Lymphocyte count was positively associated with VPC-3 levels $(\mathrm{p}<0.001)$. Fibrinogen was positively associated with VPC-3 levels $(\mathrm{p}=0.003)$. 


\section{Demographic Comparisons among VPC-5 Tertiles}

Differences between the characteristics of the populations within low, medium, and high VPC-5 (CD31 $\left.{ }^{+} / \mathrm{AC}_{133^{+}}\right)$tertiles are shown in Table 5. VPC-5 was selected because it is positively (not significant) associated with FRS in the t-test comparison; levels in the high-FRS were more than double in the low-FRS population. Only lymphocyte count was positively associated with VPC-5 levels $(\mathrm{p}<0.001)$.

\section{Adjusted Association between FRS and Circulating VPC Levels}

Significant associations between FRS category and VPC levels adjusted for ethnicity, alcohol, body mass index (BMI), and socioeconomic status (SES; median household income at the block group level) are shown in Table 6. FRS category was inversely associated with VPC-5 $\left(\mathrm{CD} 31^{+} / \mathrm{AC} 133^{+} ; \beta=-0.679, \mathrm{p}=0.003\right)$. FRS category was positively associated with VPC-3 $\left(\mathrm{CD} 31^{+} / 34^{+} / 45^{\mathrm{dim}} / \mathrm{AC} 133^{+} ; \beta=0.840, \mathrm{p}<0.001\right)$, VPC-13 $\left(\mathrm{CD}_{3} 4^{+} / \mathrm{AC} 133^{+} ; \beta=0.706, \mathrm{p}=0.001\right)$, and VPC-15 $\left(\mathrm{CD} 34^{+} / 45^{\mathrm{dim}} / \mathrm{AC} 133^{+}\right.$; $\beta=0.864, \mathrm{p}<0.001)$. None of the remaining covariates explored above improved model fit and are not included in the final model.

\section{Adjusted Associations between Thrombosis and VPC Levels}

The association between VPCs and thrombosis was assessed using fibrinogen as a marker of thrombosis (Figure 3A). The regression model adjusted for hypertension, hyperlipidemia, diabetes, smoking, age, ethnicity, alcohol, gender, BMI, and SES (Figure 3A). VPC-1 $\left(\mathrm{CD} 31^{+} / 34^{+} / 45^{\mathrm{dim}} ; \beta=0.002, p=0.007\right), \mathrm{VPC}-3(\beta=0.002, p=0.004), \mathrm{VPC}-13$ $(\beta=0.002, p=0.004)$, and VPC-15 $(\beta=0.003, p=0.003)$ were positively associated with fibrinogen. In addition, as seen in Figure 3B, C, D, and E, positive associations are demonstrated in scatterplots of fibrinogen and the predicted means of the VPCs from the 
adjusted regression models for VPC-1 $\left(\mathrm{R}^{2}=0.399, \mathrm{p}<0.001\right), \mathrm{VPC}-3\left(\mathrm{R}^{2}=0.335\right.$, $\mathrm{p}<0.001)$, VPC-13 $\left(\mathrm{R}^{2}=0.386, \mathrm{p}<0.001\right)$, and VPC-15 $\left(\mathrm{R}^{2}=0.414, \mathrm{p}<0.001\right)$.

The association between VPCs and thrombosis was also assessed using platelet mononuclear cell aggregates as a marker of thrombosis. As seen in Figure 4A, there was a positive association between VPC- $6\left(\mathrm{CD} 31^{+} / 34^{+} ; \beta=0.040, \mathrm{p}=0.036\right), \mathrm{VPC}-9\left(\mathrm{CD} 34^{+}\right.$;

$\beta=0.044, \mathrm{p}=0.026)$, and VPC $-14\left(\mathrm{CD} 34^{+} / 45^{+} / \mathrm{AC} 133^{+} ; \beta=0.118, \mathrm{p}<0.001\right)$ and platelet mononuclear cell aggregates $\left(\mathrm{CD} 41^{+} / 45^{+}\right)$adjusted for hypertension, hyperlipidemia, diabetes, smoking, age, ethnicity, alcohol, gender, BMI, and SES. In addition, as seen in Figure 4B, C, and D, positive associations are demonstrated in scatterplots of platelet mononuclear cell aggregates and the predicted means of the VPCs from the adjusted regression models for VPC-6 $\left(\mathrm{R}^{2}=0.287, \mathrm{p}<0.001\right)$, VPC-9 $\left(\mathrm{R}^{2}=0.315, \mathrm{p}<0.001\right)$, and VPC-14 $\left(\mathrm{R}^{2}=0.431, \mathrm{p}<0.001\right)$.

\section{Adjusted Association between Inflammation and VPC Levels}

The association between VPCs and inflammation was assessed using hsCRP levels as a marker of inflammation (Figure 5). The adjusted regression excluded the population with hsCRP levels above $10 \mathrm{mg} / \mathrm{L}(\mathrm{n}=19)$ due to increased likelihood of an infection or inflammatory diseases unrelated to cardiovascular disease ${ }^{78,79}$. The models were adjusted for hypertension, hyperlipidemia, diabetes, smoking, ethnicity, alcohol, gender, BMI, and SES. VPC-5 (CD31 $\left.{ }^{+} / \mathrm{AC} 133^{+}\right)$and VPC-11 $\left(\mathrm{AC} 133^{+}\right)$levels were significantly inversely associated with hsCRP levels $(\beta=-0.076, p=0.042)$ and $(\beta=-$ $0.078, \mathrm{p}=0.037)$. In addition, as seen in Figure 5B inverse associations are demonstrated in a scatterplot of hsCRP and the predicted means of the VPCs from the adjusted regression models for VPC-5 $\left(\mathrm{R}^{2}=0.032, \mathrm{p}=0.033\right)$. The scatterplot of hsCRP and the 
predicted means of the VPCs from the adjusted regression models for VPC-11 $\left(\mathrm{R}^{2}=\right.$ $0.008, \mathrm{p}=0.278)$ was not significant.

\section{Discussion}

We conducted a cross-sectional assessment of the association between VPC levels and CVD risk in the Healthy Heart Study. A majority of the VPC populations assessed were $\mathrm{Id} 1^{+}$, indicating they have endothelial progenitor cell lineage. The high FRS population had significantly higher levels of VPC-1 $\left(\mathrm{CD} 31^{+} / 34^{+} / 45^{\mathrm{dim}}\right)$, VPC-3 $\left(\mathrm{CD} 31^{+} / 34^{+} / 45^{\mathrm{dim}} / \mathrm{AC} 133^{+}\right), \mathrm{VPC}-13\left(\mathrm{CD} 34^{+} / \mathrm{AC} 133^{+}\right), \mathrm{VPC}-15\left(\mathrm{CD} 34^{+} / 45^{\mathrm{dim}} / \mathrm{AC} 133^{+}\right)$, and fibrinogen. In the adjusted analysis of VPCs vs. CVD risk, we found that VPC-5 $\left(\mathrm{CD} 31^{+} / \mathrm{AC} 33^{+}\right)$was significantly inversely associated with the FRS category, while VPC-3, VPC-13, and VPC-15 were positively associated with the FRS category. VPC-1, VPC-3, VPC-13, and VPC-15 were positively associated with fibrinogen, and VPC-6, VPC-9, and VPC-14 were positively associated with platelet mononuclear cell aggregates. VPC-5, and VPC-11 (AC133 $\left.{ }^{+}\right)$were inversely associated with hsCRP, which is associated with inflammation.

VPC levels are hypothesized to decrease as CVD risk increases and atherosclerosis progresses ${ }^{80}$. Multiple studies have reported an inverse association between the number of risk factors and VPC levels ${ }^{63,81}$. Vasa et al. found this association in $\mathrm{CD}_{3} 4^{+} / \mathrm{KDR}^{+}$cells (kinase insert domain receptor (KDR); marks for endothelial cells) ${ }^{63}$, and Schmidt-Lucke et al. found this association the VPC population $\mathrm{KDR}^{+} / \mathrm{CD} 34^{+} / \mathrm{CD} 45^{\mathrm{dim} 81}$. We did not find a significant association between VPCs and the number of risk factors. It may be that our population was a rather unhealthy population, in terms of cardiovascular health, and there are not enough people with few 
risk factors to accurately depict the association between VPCs and the number of CVD risk factors. Future studies should include a comparison population with less than 2 Framingham risk factors.

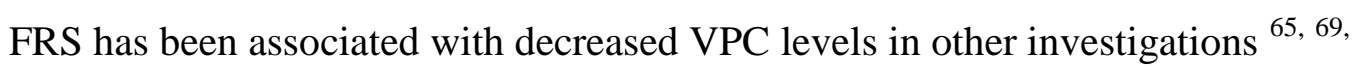
${ }^{70}$. In the current study, VPC-5 significantly decreased as FRS category increased. This suggests that the depletion of $\mathrm{CD} 31^{+} / \mathrm{AC} 133^{+}$may be driving the inverse association with FRS and VPC levels. Additionally, these cells were significantly associated with hsCRP, suggesting that the association between VPC-5 and FRS may be associated with inflammation. Furthermore, VPC-11 $\left(\mathrm{AC} 133^{+}\right)$was inversely associated with FRS category in the univariate analysis (not in the adjusted model; $\beta=-0.406, p=0.076$ ); but this population was also inversely associated with hsCRP, suggesting reason to investigate the potential role of inflammation in depletion of VPCs in the high FRS category. More research is required to understand how risk factors potentially influence the VPC levels, thereby contributing to risk: more specifically CVD risk factors, e.g. hypertension, in the reduction of circulating levels of $\mathrm{CD} 31^{+} / \mathrm{AC} 133^{+}$VPCs. A future direction for our research involves understanding how each risk factor influences VPC levels and incorporating a weight for each into our model. Other future directions should involve the prognostic diagnostic utility of VPCs, particularly VPC-5, in the clinical setting.

The current study also determined that 3 cell populations were positively associated with the FRS category, VPC-3, VPC-13, and VPC-15. VPC-3 is a subcategory of VPC-13 and VPC-15, suggesting that VPC-3 may be driving the associations seen through the $\mathrm{CD} 31^{+}$(endothelial) and $\mathrm{CD} 45^{\mathrm{dim}}$ (non-hematopoietic) phenotypes. 
Faidini et al. described that as atherosclerosis progresses to an event in low risk populations, VPCs are mobilized into circulation ${ }^{80}$. This suggests that people who have had a CVD event may have higher levels of some VPCs. Because the secondary preventive population is included in the high FRS category, a cardiovascular event in these individuals may have mobilized VPC-3, VPC-13, and VPC-15 into circulation. Güven et al. reported a positive association between VPCs and coronary artery disease severity ${ }^{72}$. Shintani et al. demonstrated that VPCs increase following an acute myocardial infarction (AMI), with a peak 7 days post-AMI ${ }^{82}$. Leone et al. and Massa et al. observed that VPC counts increase following an acute AMI by comparison to healthy controls ${ }^{83,84}$. Similarly, Sobrino et al. and Yip et al. demonstrated increased VPC levels following a stroke ${ }^{85,86}$. Xiao et al. also indicated a positive association between FRS and VPC levels ${ }^{64}$. Their investigation, however, evaluated a population with FRS $\leq 10$, a low risk population. Our population included high-risk individuals and secondary preventive patients. Additionally, Xiao et al. investigated this association in DiI-Ac-LDL ${ }^{+} /$lectin $^{+}$ cells grown in culture, which are markers that are not highly specific to VPCs.

Furthermore, the culture assay reflects VPC growth and proliferative capacity, rather than circulating VPC levels. A second possible explanation for the positive association between VPCs and FRS is that as risk increases, the more likely the subjects are receiving primary preventive treatment for CVD risk factors. Therefore, they are more likely to be taking medications, including statins, which may increase VPC levels ${ }^{64,81,87,88}$ and VPC mobilization ${ }^{89-91}$. VPC-3, VPC-13, and VPC-15, however, were not associated with statin use in the current study population. VPC-3, VPC-13, and VPC-15 were positively associated with aspirin use, indicating that aspirin may play a role in the association. 
When the regression model was adjusted for aspirin, the association between FRS and VPC-3, VPC-13, and VPC-15 remained positive and significant. Additionally, these cells were positively associated with fibrinogen. This suggests that thrombosis may be driving the positive association between FRS and VPC-3, VPC-13, and VPC-15. Moreover, fibrinogen was significantly higher in people in the high FRS category $(\beta=51.24$, $\mathrm{p}<0.001$; adjusted for ethnicity, alcohol, BMI, and SES). Aspirin was positively correlated with hypertension and hyperlipidemia in the current study, suggesting that future research should assess hypertension and hyperlipidemia in association with VPC3, VPC-13, and VPC-15 levels, although there was no association revealed from the current at-risk study population. Future directions should investigate risk factors and medications that are positively associated with VPCs and the potential for positive cardiovascular outcomes.

There were 2 remaining VPC populations that were inversely associated with FRS category in the univariate analysis, VPC-7 $\left(\mathrm{CD} 31^{+} / 34^{+} / 45^{\mathrm{dim}} / \mathrm{AC} 133^{-} ; \beta=-0.419\right.$, $\mathrm{p}=0.036)$ and VPC-11 $\left(\mathrm{AC} 133^{+} ; \beta=-0.609, \mathrm{p}<0.001\right)$. VPC-7 lost significance when BMI was entered into the model, the positive association with BMI seems to suppress the relationship between FRS category and the VPC-7. VPC-11 lost significance when ethnicity was entered into the model; African Americans had significantly higher levels of VPC-11. VPC-2 $\left(\mathrm{CD} 31^{+} / 34^{+} / 45^{+}\right)$and VPC-8 $\left(\mathrm{CD} 31^{+} / 34^{+} / 45^{+} / \mathrm{AC} 133^{-}\right)$were positively associated with FRS in the univariate model, but when ethnicity was entered into the model, both lost significance. African Americans had significantly lower levels of VPC-2 and VPC-8. We do not report the non-significant models as discussed. While BMI, ethnicity, and SES seem to be independently associated with some of the remaining 
VPCs and may account for the differences observed, FRS category may not account for the differences after adjustment for these variables. Future planned manuscripts will further explore these relationships.

We found that VPC-1, VPC-3, VPC-13, and VPC-15 levels were positively associated with fibrinogen, suggesting a pro-thrombotic state. This association may be driven by the $\mathrm{CD} 1^{+}$(endothelial) and $\mathrm{CD} 45^{\mathrm{dim}}$ (non-hematopoietic) phenotypes. Additionally, the current study found that VPC-6, VPC-9, and VPC-14 were positively associated with platelet mononuclear cell aggregate levels, also suggesting a thrombotic state. The association may be driven by the $\mathrm{CD} 45^{+}$(hematopoietic) and $\mathrm{AC} 133^{+}$(early stem) cell phenotypes. The thrombin receptor protease activated receptors-1 (PAR-1) is expressed on VPCs, and thrombin may activate the fibrinolytic pathway that balances thrombosis by breaking down thrombi ${ }^{92,93}$. Additionally, VPCs were shown to be recruited to resolving venous thrombi ${ }^{94}$. This suggests that VPC levels could increase in the presence of a thrombus. In the current study, some VPC levels were positively associated with fibrinogen and platelet mononuclear cell aggregates, verifying this hypothesis. Further research is needed to understand the relationship of VPCs with thrombosis in advanced stages of CVD.

We determined that circulating levels of VPC-5 and VPC-11were inversely associated with hsCRP in subjects with a range of CVD risk factors. Because systemic inflammation is linked to CVD and vascular injury, this association is biologically plausible. Previous investigations of this association have provided mixed results. Studies that investigated the effects of hsCRP -treated VPCs in culture also demonstrated VPC decreases defined as DiI-Ac-LDL ${ }^{+} /$lectin $^{+}$cells ${ }^{95}$ and vascular endothelial growth factor 
receptor- $2^{+}\left(\right.$VEGFR-2 $2^{+}$, also known as $\left.\mathrm{KDR}^{+}\right)$cells ${ }^{96}$. George et al. determined that DiI$\mathrm{Ac}^{-\mathrm{LDL}^{+} / \text {lectin }}{ }^{+}$- colony forming units (CFU) were positively associated with hsCRP levels ${ }^{86}$. As previously mentioned, DiI-Ac-LDL and lectin are not highly specific to VPCs, and CFUs are more indicative of the proliferative capacity of the isolated VPCs. Additionally, inverse associations between hsCRP and VPCs have been found in individuals with diabetes mellitus (a major risk factor for CVD) for $\mathrm{CD} 34^{+}$cells ${ }^{97,98}$ and $\mathrm{CD} 34^{+} / 133^{+}$cells ${ }^{97}$. In the current study, we did not find an association between CD34 ${ }^{+}$ (VPC-9) or CD34 $/ \mathrm{AC}^{+} 33^{+}$(VPC-13). Schmidt-Lucke et al. showed that circulating VPCs, defined as $\mathrm{CD} 34^{+} / \mathrm{KDR}^{+}$cells, quantified using flow cytometry were not significantly associated with hsCRP ${ }^{99}$. Our study also found no significant association between $\mathrm{CD} 31^{+} / 34^{+}$(VPC-6) cells and hsCRP (both $\mathrm{KDR}^{+}$and $\mathrm{CD} 31^{+}$cells indicate endothelial lineage and the VPC-6 population was Id1 positive, also indicating endothelial progenitor cell lineage). Results from the current study suggest that VPC-5 and VPC-11, likely driven by the more specific sub-population VPC-5 (CD31 $\left.{ }^{+} / \mathrm{AC} 133^{+}\right)$, decreased with increased markers of inflammation in adults at increased heart disease risk. Future research should investigate the role of VPC-5 and inflammation.

Among the multiple strengths of the current investigation, we had a large population with varying degrees and types of CVD risk. Because we were able to measure 15 different populations of VPCs, we were able to investigate which antigenic markers are associated with CVD risk factors. Through the thorough questionnaire and medical records review, we were able to conduct an extensive evaluation of CVD risk factors. Additionally, we reduced risk of misclassification and potential confounding in self-reported smoking status by measuring cotinine levels, the primary urine metabolite 
of nicotine. Cotinine levels accounted for both smoking and environmental tobacco smoke exposure.

Some of the limitations to the investigation involve the type of study we have selected. Cross-sectional studies are limited in their ability to demonstrate causality, but are useful to identify associations that can be used to generate hypotheses for future cohort studies. Other potential limitations include the time of sample collection. Some of the research on VPCs indicates that they demonstrate diurnal variations and should be collected at the same point each day ${ }^{64}$. Additionally, studies on urine metabolites suggest that the urine sample should be collected at the first catch or first void. Recruitment limitations include the inability to recruit a population that is representative of the population that visits the clinics. None of the recruiting personnel fluently spoke languages other than English; therefore, some potential participants that did not have a translator present were not able to provide consent for the study or participate in the interview questionnaire. In addition, based on the recruitment being entirely from cardiology clinics, we lack a true population-based sample, we had an at-risk population. This poses a limitation in being able to generalize the results to the entire population. Also, our study does not account for all population variabilities that may affect VPC levels; for example, some studies exclude pre-menopausal women because of the VPC fluctuations that result due to menstruation ${ }^{100,101}$. Our study did not include a variable for cyclic variability due to the menstruation phase of female study participants nor did we exclude women from study, although the regression models did adjust for gender.

Future studies should include a healthy comparison population or healthy ageand sex-matched controls. Regressing VPCs against the sum of CVD risk factors will be 
more robust when including more people that have $\leq 1 \mathrm{CVD}$ risk factor. Future planned investigations will explore relationships between VPCs and ethnicities. Our population is richly diverse with just over $40 \%$ of the population being African American, and understanding risks and VPC levels in this population will be of added scientific benefit. Additionally, the VPC levels should be assessed in their association with CAD severity determined by angiography. The association between VPC levels and cardiac output, determined through echocardiography, should also be assessed to understand the association between VPC levels and cardiac outcomes.

In summary, these observations suggest that levels of some VPCs are associated with increased CVD risk, a pro-thrombotic state, and inflammation. Previous research has indicated mixed results in terms of CVD risk and VPC levels. It appears that this is because VPCs are a heterogeneous population containing cells with varied angiogenic potential. Additionally, some previous research employed markers that are not specific to VPCs and assays not specific to circulating VPC levels. The inverse association between VPCs and FRS category appears to be driven by the $\mathrm{CD} 31^{+} / \mathrm{AC} 133^{+}$phenotype. The positive associations between VPCs and FRS category as well as VPCs and fibrinogen appear to be driven by the $\mathrm{CD} 31+/ 34+/ 45^{\mathrm{dim}} / \mathrm{AC} 133^{+}$phenotype. The positive association between VPCs and platelet mononuclear cell aggregates appears to be driven by the $\mathrm{CD} 4^{+} / 45^{+} / \mathrm{AC} 133^{+}$phenotype. The inverse association between VPCs and hsCRP appears to be driven by the $\mathrm{CD} 31^{+} / \mathrm{AC} 133^{+}$phenotype. Future direction should assess VPC changes in a cohort study following people forward in terms of the interaction between VPC levels, risk factors, and disease. Determining the phenotype associated with risk could guide future use of VPC phenotypes for diagnostic and therapeutic purposes. 


\section{Acknowledgements}

The authors thank the phlebotomists at the UofL Ambulatory Care and University Medical Associates for biological sample collection. The authors also thank Duane

Bolanowski, Dave Young, Melissa Peak, the Statistical Consulting Service, and the

Diabetes and Obesity Center for technical expertise. Lastly, we thank the Jortani

Laboratory for fibrinogen and hsCRP analysis.

\section{Sources of Funding}

This work was supported in part by grants provided by the Anthem WellPoint Foundation

(GMB090410), National Institute of Environmental Health Sciences (ES11860,

ES019217), National Institute of General Medical Sciences (GM103492), and the Center

for Environmental Genomics and Integrative Biology (P30ES014443).

\section{Disclosures}

N.K. DeJarnett: None. D.J. Conklin: None. J.A. Myers: None. I. Hamzeh: None. S. Wagner: None. T.E. O'Toole: None. A. Chugh: None. M. Zahn: None. D.J. Tollerud: None. A.P. DeFilippis: None. D. Higdon: None. C. Becher: None. B. Wyatt: None. T. Ciszewski: None. D. Riggs: None. J. McCracken: None. P. Haberzettl: None. W. Abplanalp: None. S.D. Prabhu: Consultant/Advisory Board; Modest; Liposcience. Consultant/Advisory Board; Significant; Sulfagenix. A. Bhatnagar: None. 


\section{Figures and Tables}

\begin{tabular}{|c|c|c|c|c|c|}
\hline \multicolumn{2}{|c|}{ Cell Group } & Antigenic Marker & Cell Differentiation State & $\%$ in Total & Id-1 \\
\hline \multirow{3}{*}{$\frac{5}{9}$} & VPC-9 & $\mathrm{CD} 34^{+}$ & Stem & $0.3 \pm 0.6 \%$ & $\mathrm{n} / \mathrm{d}$ \\
\hline & VPC-13 & $\mathrm{CD} 34^{+} / \mathrm{AC} 133^{+}$ & Stem/Early Progenitor & $0.1 \pm 0.1 \%$ & + \\
\hline & VPC-15 & $\mathrm{CD} 34^{+} / \mathrm{AC} 133^{+} / \mathrm{CD} 45^{\mathrm{dim}}$ & Stem/Early Progenitor/Non-hematopoietic & $0.1 \pm 0.1 \%$ & $\mathrm{n} / \mathrm{d}$ \\
\hline \multirow{4}{*}{ 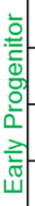 } & VPC-11 & $\mathrm{AC} 133^{+}$ & Early Progenitor & $0.4 \pm 1.5 \%$ & + \\
\hline & VPC-5 & $\mathrm{AC} 133^{+} / \mathrm{CD} 31^{+}$ & Early Progenitor/Endothelial & $0.3 \pm 0.7 \%$ & + \\
\hline & VPC-4 & $\mathrm{AC} 133^{+} / \mathrm{CD} 34^{+} / \mathrm{CD} 31^{+} / \mathrm{CD} 45^{+}$ & Early Progenitor/Stem/Endothelial/Hematopoietic & $0.01 \pm 0.04 \%$ & $+1-$ \\
\hline & VPC-14 & $\mathrm{AC} 133^{+} / \mathrm{CD} 34^{+} / \mathrm{CD} 45^{+}$ & Early Progenitor/Stem/Hematopoietic & $0.005 \pm 0.022 \%$ & $+1-$ \\
\hline \multirow{5}{*}{ 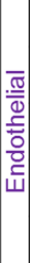 } & VPC-10 & CD31+ & Endothelial & $32 \pm 12 \%$ & $n / d$ \\
\hline & VPC-6 & CD31+/CD34+ & Endothelial/Stem & $0.4 \pm 1.3 \%$ & + \\
\hline & VPC-1 & CD31+/CD34+/CD45 ${ }^{\mathrm{dim}}$ & Endothelial/Stem/Non-hematopoietic & $0.2 \pm 1.1 \%$ & + \\
\hline & VPC-7 & $\mathrm{CD} 31^{+} / \mathrm{CD} 34^{+} / \mathrm{AC} 133-/ \mathrm{CD} 45^{\mathrm{dim}}$ & Endothelial/Stem/Late Progenitor/Non-hematopoietic & $0.2 \pm 1.1 \%$ & + \\
\hline & VPC-3 & CD31+/CD34+/AC133+/CD45 dim & Endothelial/Stem/Early Progenitor/Non-hematopoietic & $0.1 \pm 0.1 \%$ & $\mathrm{n} / \mathrm{d}$ \\
\hline \multirow{3}{*}{ 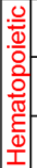 } & VPC-12 & CD45+ & Hematopoietic & $55 \pm 20 \%$ & $n / d$ \\
\hline & VPC-2 & $\mathrm{CD} 45^{+} / \mathrm{CD} 34^{+} / \mathrm{CD} 31^{+}$ & Hematopoietic/Stem/Endothelial & $0.1 \pm 0.2 \%$ & + \\
\hline & VPC-8 & $\mathrm{CD} 45^{+} / \mathrm{CD} 34^{+} / \mathrm{CD} 31^{+} / \mathrm{AC} 133^{-}$ & Hematopoietic/Stem/Endothelial/Late Progenitor & $0.1 \pm 0.2 \%$ & + \\
\hline
\end{tabular}

Table 1. Listing of the VPC populations identified.

$n / d$ : not determined. 


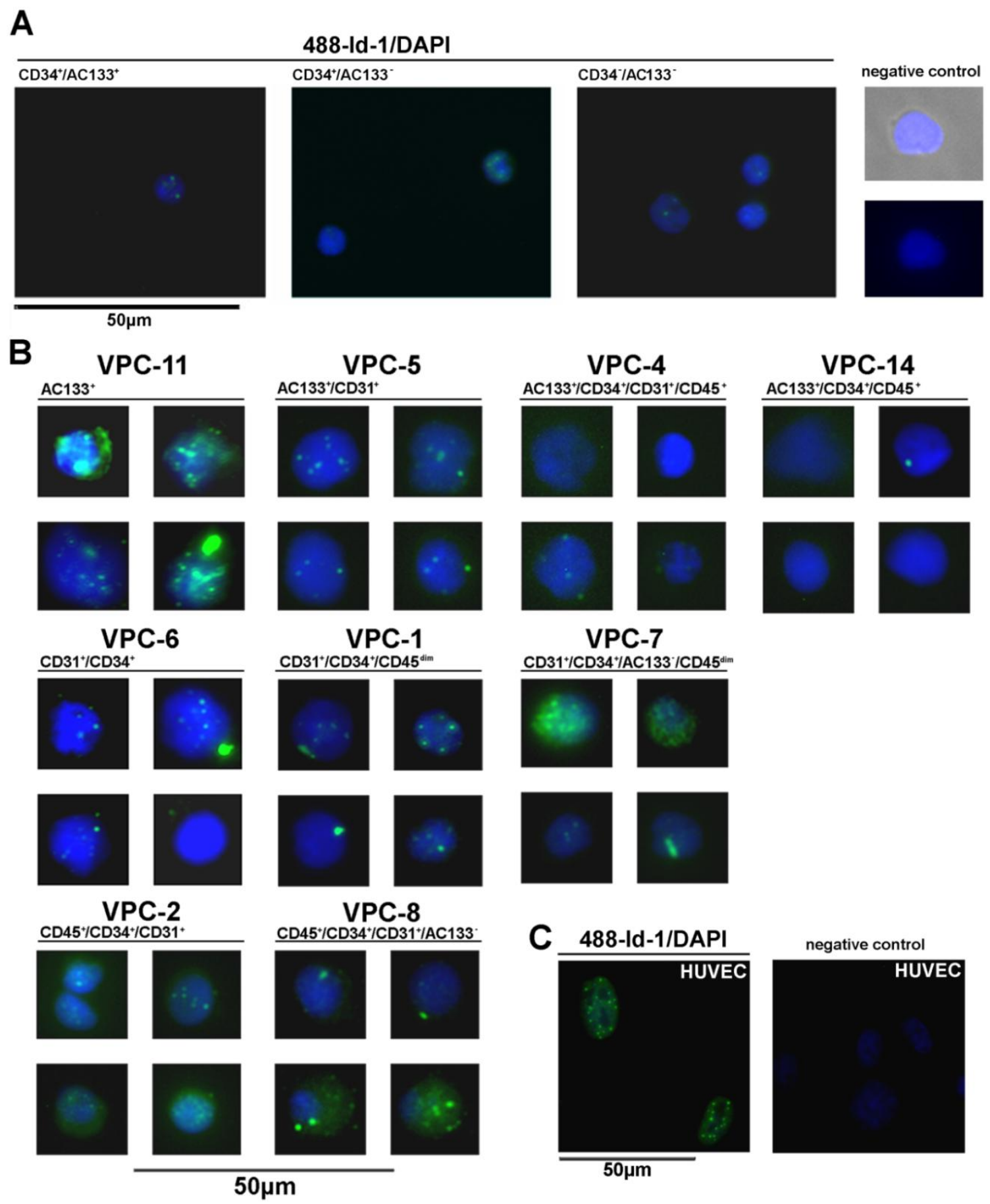

Figure 2. Abundance of Id-1 in populations of human blood progenitor cells.

(A) Fluorescence images (original magnification $60 \mathrm{x}$ ) of human blood CD $34^{+} / \mathrm{AC} 33^{+}$, $\mathrm{CD} 34^{+} / \mathrm{AC} 133^{-}$, and $\mathrm{CD} 34^{-} / \mathrm{AC} 133^{-}$cells. White blood cells were sorted by flow cytometry and fluorescence labeled with Alexa-488-Id-1 and DAPI. Phase-contrast and fluorescence images (left panel, original magnification $60 \mathrm{x}$ ) of human blood sorted for $\mathrm{CD} 31^{+} / \mathrm{CD} 34^{+} / \mathrm{CD} 45^{\mathrm{dim}}$. Cells were incubated with Alexa-488 secondary antibody (only) and DAPI. (B) Fluorescence single cell images (original magnification $60 \mathrm{x}$ ) of human 
blood cells sorted for VPC-11 $\left(\mathrm{AC}^{3} 33^{+}\right)$, VPC-5 $\left(\mathrm{AC} 133^{+} / \mathrm{CD} 31^{+}\right)$, VPC-4 $\left(\mathrm{AC} 133^{+} / \mathrm{CD} 34^{+} / \mathrm{CD} 31^{+} / \mathrm{CD} 45^{+}\right)$, VPC $-14\left(\mathrm{AC} 133^{+} / \mathrm{CD} 34^{+} / \mathrm{CD} 45^{+}\right)$, VPC-6 $\left(\mathrm{CD} 31^{+} / \mathrm{CD} 34^{+}\right), \mathrm{VPC}-1\left(\mathrm{CD} 31^{+} / \mathrm{CD} 34^{+} / \mathrm{CD} 45^{\mathrm{dim}}\right), \mathrm{VPC}-7$

$\left(\mathrm{CD} 31^{+} / \mathrm{CD} 34^{+} / \mathrm{CD} 45^{\mathrm{dim}} / \mathrm{AC} 133^{-}\right)$, VPC-2 (CD $\left.31^{+} / \mathrm{CD} 34^{+} / \mathrm{CD} 45^{+}\right)$, and VPC-8

$\left(\mathrm{CD} 31^{+} / \mathrm{CD} 34^{+} / \mathrm{CD} 45^{+} / \mathrm{AC} 133^{-}\right)$. Sorted cells were fluorescence labeled with Alexa-488Id-1 and DAPI and merged images of cells show colocalization of Id1 (Alexa-488-Id-1) with the nucleus (DAPI). (C) Fluorescence images (original magnification $60 \mathrm{x}$ ) of human umbilical vein endothelial cells (HUVEC) fluorescence labeled with Alexa-488Id-1 and DAPI (left image) or incubated with Alexa-488 secondary antibody (only) and DAPI (right).

\begin{tabular}{|c|c|c|c|}
\hline Variable & $\begin{array}{l}\text { Low FRS } \\
\text { Mean (SD) }\end{array}$ & $\begin{array}{l}\text { High FRS } \\
\text { Mean (SD) }\end{array}$ & p-va \\
\hline VPC $-1\left(C D 31^{+} / 34^{+} / 45^{\mathrm{dim}}\right)$ & $0.749(1.548)$ & $0.837(0.967)$ & $0.023^{* *}$ \\
\hline VPC-2 (CD31 $\left.134^{+} / 45^{+}\right)$ & $0.074(0.093)$ & $0.237(2.166)$ & 0.451 \\
\hline VPC-3 (CD $31^{+} / 34^{+} / 45^{\left.\mathrm{dim} / \mathrm{AC} 133^{+}\right)}$ & $0.208(0.291)$ & $0.480(0.641)$ & $0.008^{\star *}$ \\
\hline VPC-4 (CD31 $\left./ 34^{+} / 45^{+} / \mathrm{AC} 133^{+}\right)$ & $0.006(0.009)$ & $0.006(0.019)$ & 0.640 \\
\hline VPC-5 (CD31+/AC133+) & $2.984(8.901)$ & $1.240(2.131)$ & 0.239 \\
\hline VPC-6 $\left(\right.$ CD $\left.31^{+} / 34^{+}\right)$ & $1.073(1.824)$ & $1.391(4.055)$ & 0.240 \\
\hline VPC-7 (CD31+/34+/45 dim/AC133-) & $0.541(1.502)$ & $0.357(0.493)$ & 0.370 \\
\hline VPC-8 (CD31+ $\left./ 34^{+} / 45^{+} / A C 133^{-}\right)$ & $0.068(0.089)$ & $0.231(2.151)$ & 0.598 \\
\hline VPC-9 (CD34 $\left.{ }^{+}\right)$ & $1.346(2.609)$ & $1.536(4.949)$ & 0.539 \\
\hline VPC-10 (CD31+) & $214.4(198.8)$ & $227.6(227.9)$ & 0.997 \\
\hline VPC-11 (AC133+) & $2.995(8.898)$ & $1.608(2.966)$ & 0.834 \\
\hline VPC-12 (CD45 $)$ & $358.9(384.1)$ & $440.8(480.7)$ & 0.563 \\
\hline VPC-13 (CD $\left.34^{+} / \mathrm{AC} 133^{+}\right)$ & $0.247(0.296)$ & $0.493(0.625)$ & $0.020^{* *}$ \\
\hline VPC-14 (CD $\left.34^{+} / 45^{+} / \mathrm{AC} 133^{+}\right)$ & $0.005(0.013)$ & $0.004(0.013)$ & 0.198 \\
\hline VPC-15 (CD $34^{+} / 45^{\left.\mathrm{dim} / A C 133^{+}\right)}$ & $0.198(0.288)$ & $0.444(0.611)$ & $0.006^{* *}$ \\
\hline Fibrinogen & $309.8(81.27)$ & $357.8(109.5)$ & $0.006^{* *}$ \\
\hline Platelet mononuclear cell aggregates & $11.33(5.557)$ & $10.77(5.890)$ & 0.746 \\
\hline hsCRP & $4.704(4.587)$ & $4.905(4.700)$ & 0.800 \\
\hline
\end{tabular}

Table 2. Comparison between the low- and high- FRS risk populations.

The low FRS category has a FRS $<20$. The high FRS category has a FRS $\geq 20$ or has experienced a cardiovascular event. VPC counts per $\mu \mathrm{L}$ sample. Fibrinogen units $(\mathrm{mg} / \mathrm{dL})$. Platelet mononuclear cells are the percent total of cells CD $41^{+} / 45^{+}$. HsCRP units $(\mathrm{mg} / \mathrm{L}) . * *=$ significant at the 0.05 level. 


\begin{tabular}{|c|c|c|c|}
\hline Variable & $\begin{array}{l}\text { Low-Risk } \\
\text { Mean (SD) }\end{array}$ & $\begin{array}{l}\text { High-Risk } \\
\text { Mean (SD) }\end{array}$ & p-va \\
\hline VPC-1 (CD $\left.31^{+} / 34^{+} / 45^{\mathrm{dim}}\right)$ & $0.884(0.947)$ & $0.817(1.104)$ & 0.883 \\
\hline VPC-2 (CD31 $\left.1 / 34^{+} / 45^{+}\right)$ & $0.114(0.258)$ & $0.212(2.014)$ & 0.546 \\
\hline VPC-3 (CD $31^{+} / 34^{+} / 45^{\left.\mathrm{dim} / \mathrm{AC} 133^{+}\right)}$ & $0.330(0.430)$ & $0.436(0.610)$ & 0.411 \\
\hline VPC-4 (CD31 $\left./ 34^{+} / 45^{+} / \mathrm{AC} 133^{+}\right)$ & $0.003(0.008)$ & $0.006(0.018)$ & 0.704 \\
\hline VPC-5 (CD31+/AC133+) & $0.890(0.557)$ & $1.604(4.426)$ & 0.892 \\
\hline VPC-6 $\left(C D 31^{+} / 34^{+}\right)$ & $1.188(1.309)$ & $1.341(3.843)$ & 0.879 \\
\hline VPC-7 (CD31 ${ }^{+} / 34^{+} / 45^{\left.\mathrm{dim} / A C 133^{-}\right)}$ & $0.554(0.825)$ & $0.381(0.780)$ & 0.537 \\
\hline VPC-8 (CD31 $\left.+34^{+} / 45^{+} / A C 133^{-}\right)$ & $0.111(0.258)$ & $0.206(2.000)$ & 0.556 \\
\hline VPC-9 (CD34 $\left.{ }^{+}\right)$ & $1.193(1.316)$ & $1.520(4.730)$ & 0.642 \\
\hline VPC-10 (CD $\left.31^{+}\right)$ & $241.2(298.3)$ & $224.2(217.9)$ & 0.838 \\
\hline VPC-11 (AC133+) & $1.029(1.290)$ & $1.900(4.799)$ & 0.951 \\
\hline VPC-12 (CD45 $)$ & $384.5(500.7)$ & $428.2(463.5)$ & 0.787 \\
\hline VPC-13 (CD $\left.34^{+} / \mathrm{AC} 133^{+}\right)$ & $0.352(0.440)$ & $0.453(0.594)$ & 0.507 \\
\hline VPC-14 (CD $\left.34^{+} / 45^{+} / \mathrm{AC} 133^{+}\right)$ & $0.0002(0.001)$ & $0.005(0.014)$ & 0.267 \\
\hline 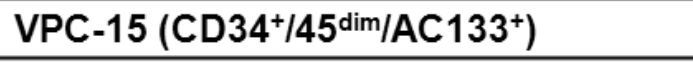 & $0.333(0.426)$ & $0.402(0.581)$ & 0.687 \\
\hline Fibrinogen & $321.9(82.58)$ & $349.6(107.2)$ & 0.363 \\
\hline Platelet mononuclear cell aggregates & $6.013(3.145)$ & $11.02(5.854)$ & $0.040^{* *}$ \\
\hline hsCRP & $2.963(4.071)$ & $4.986(4.685)$ & 0.130 \\
\hline
\end{tabular}

Table 3. Comparison between the low- and high- CVD risk factor populations.

The low-risk population has $\leq 1$ Framingham risk factor for CVD among age $\geq 40$ years, male gender, hypertension, hyperlipidemia, diabetes, and current smoking. The high-risk population has $\geq 2$ Framingham risk factors. VPC counts per $\mu \mathrm{L}$ sample. Fibrinogen units $(\mathrm{mg} / \mathrm{dL})$. Platelet mononuclear cells are the percent total of cells CD $41^{+} / 45^{+}$. HsCRP units $(\mathrm{mg} / \mathrm{L}) . * *=$ significant at the 0.05 level. 


\begin{tabular}{|c|c|c|c|c|c|}
\hline Categorical Variable - n (\%) & $\begin{array}{l}\text { Total } \\
n=183\end{array}$ & $\begin{array}{l}\text { Low VPC-3 } \\
n=(61)\end{array}$ & $\begin{array}{l}\text { Medium VPC-3 } \\
\mathrm{n}=(61)\end{array}$ & $\begin{array}{l}\text { High VPC-3 } \\
(n=61)\end{array}$ & p-value \\
\hline Gender & & & & & 0.389 \\
\hline Female & $85(46.4)$ & $30(49.2)$ & $31(50.8)$ & $24(39.3)$ & \\
\hline Male & $98(53.6)$ & $31(50.8)$ & $30(49.2)$ & $37(60.7)$ & \\
\hline Ethnicity & & & & & 0.708 \\
\hline Caucasian & $103(56.3)$ & $30(49.2)$ & $36(59.0)$ & $37(60.7)$ & \\
\hline African American & $76(41.5)$ & $29(47.5)$ & $24(39.3)$ & $23(37.7)$ & \\
\hline Hispanic & $4(2.2)$ & $2(3.3)$ & $1(1.6)$ & $1(1.6)$ & \\
\hline \multicolumn{6}{|l|}{ CVD Risk Factors } \\
\hline Hypertension & $148(82.2)$ & $48(78.7)$ & $50(84.7)$ & $50(83.3)$ & 0.661 \\
\hline Hyperlipidemia & $116(64.8)$ & $38(62.3)$ & $35(59.3)$ & $43(72.9)$ & 0.268 \\
\hline Diabetes & $46(25.6)$ & $14(23.0)$ & $14(23.7)$ & $18(30.0)$ & 0.624 \\
\hline $\mathrm{BMI} \geq 30$ & $106(59.6)$ & $31(54.4)$ & $38(62.3)$ & $37(61.7)$ & 0.627 \\
\hline Current smoker & $73(40.3)$ & $23(37.7)$ & $21(35.6)$ & $29(47.5)$ & 0.360 \\
\hline Never smoked & $44(24.3)$ & $15(24.6)$ & $17(28.8)$ & $12(19.7)$ & 0.505 \\
\hline Former smoker & $64(35.2)$ & $23(37.7)$ & $21(35.0)$ & $20(32.8)$ & 0.850 \\
\hline Environmental Smoke & $36(33.0)$ & $14(35.9)$ & $13(34.2)$ & $9(28.1)$ & 0.772 \\
\hline High FRS Category & $150(82.0)$ & $45(73.8)$ & $47(77.0)$ & $58(95.1)$ & $0.004^{\star *}$ \\
\hline \multicolumn{6}{|l|}{ Medical History } \\
\hline Myocardial Infarction & $64(35.4)$ & $21(34.4)$ & $17(28.8)$ & $26(40.6)$ & 0.281 \\
\hline Stroke & $18(9.9)$ & $4(6.6)$ & $7(11.9)$ & $7(11.5)$ & 0.553 \\
\hline CABG/ PCl/ Stents & $52(28.7)$ & $16(26.2)$ & $14(23.7)$ & $22(36.1)$ & 0.285 \\
\hline Heart Failure & $32(17.8)$ & $9(15.0)$ & $11(18.6)$ & $12(19.7)$ & 0.780 \\
\hline \multicolumn{6}{|l|}{ Medication } \\
\hline ACE inhibitor & $99(55.3)$ & $31(53.4)$ & $35(57.4)$ & $33(55.0)$ & 0.910 \\
\hline Angiotensin-receptor blockers & $12(6.7)$ & $3(5.2)$ & $4(6.6)$ & $5(8.3)$ & 0.789 \\
\hline Beta-blocker & $114(63.7)$ & $34(58.6)$ & $37(60.7)$ & $43(71.7)$ & 0.281 \\
\hline Calcium-channel blockers & $35(19.6)$ & $17(29.3)$ & $11(18.0)$ & $7(11.7)$ & 0.050 \\
\hline Diuretics & $71(39.7)$ & $22(37.9)$ & $19(31.1)$ & $30(50.0)$ & 0.100 \\
\hline Statins & $94(52.5)$ & $27(46.6)$ & $31(50.8)$ & $36(60.0)$ & 0.325 \\
\hline Aspirin & $105(58.7)$ & $30(51.7)$ & $31(50.8)$ & $44(73.3)$ & $0.018^{\star *}$ \\
\hline Vasodilator & $40(22.3)$ & $14(24.1)$ & $14(23.0)$ & $12(20.0)$ & 0.856 \\
\hline Continuous Variable - mean (SD) & Total & Low VPC-3 & Medium VPC-3 & High VPC-3 & p-value \\
\hline Age & $51.31(10.22)$ & $50.61(9.672)$ & $53.66(11.17)$ & $49.66(9.457)$ & 0.077 \\
\hline Cotinine & $501.1(719.3)$ & $457.7(629.4)$ & $480.3(811.7)$ & $566.4(713.0)$ & 0.697 \\
\hline FRS & $9.000(7.813)$ & $8.900(8.130)$ & $6.938(6.668)$ & $14.00(8.145)$ & 0.136 \\
\hline Lymphocyte count $\times 10^{4}$ & $13.10(8.828)$ & $10.57(7.080)$ & $12.11(7.199)$ & $16.62(10.69)$ & $<0.001^{* *}$ \\
\hline \multicolumn{6}{|l|}{ Thrombosis } \\
\hline Fibrinogen & $350.5(114.3)$ & $326.0(77.35)$ & $333.9(101.4)$ & $390.2(143.4)$ & $0.003^{\star *}$ \\
\hline Platelet mononuclear cell aggregates & $10.79(5.956)$ & $10.95(5.739)$ & $9.269(5.112)$ & $11.85(6.554)$ & 0.125 \\
\hline \multicolumn{6}{|l|}{ Inflammation } \\
\hline hsCRP & $4.998(4.691)$ & $4.678(4.447)$ & $4.507(4.497)$ & $5.852(5.085)$ & 0.250 \\
\hline Median household income & $30068(14796)$ & $28503(13450)$ & $31299(17614)$ & $30484(13320)$ & 0.611 \\
\hline
\end{tabular}

\section{Table 4. Demographic comparison stratified by VPC-3 tertile.}

Low VPC-3 mean $=-3095 \pm 980.15$, range $=--6075--2030$ (log-transformed VPC-3 normalized to uL sample $* 1000)$. Medium VPC-3 mean $=-1452 \pm 299.7$, range $=-2008-$ -878.5. High VPC-3 mean $=-143.2 \pm 532.2$, range $=-828.5-1589$. Current, never, and former smokers based on self-report. Environmental smoke is secondhand smoke exposure in self-reported non-smokers. FRS = Framingham Risk Score. High FRS 
category has a FRS $\geq 20$ or experienced a cardiovascular event. BMI = body mass index. $\mathrm{CABG}=$ coronary artery bypass graft. $\mathrm{PCI}=$ percutaneous coronary intervention. $\mathrm{ACE}=$ angiotensin-converting-enzyme. Age in years. Cotinine units $(\mathrm{ng} / \mathrm{mL})$. Fibrinogen units $(\mathrm{mg} / \mathrm{dL})$. HsCRP units $(\mathrm{mg} / \mathrm{L})$. Vasodilators included nitrates and hydralazine. Platelet mononuclear cells are the percent total of cells $\mathrm{CD} 41^{+} / 45^{+}$. Median household income in USD at the US Census block group level. $* *=$ significant at the 0.05 level. 


\begin{tabular}{|c|c|c|c|c|c|}
\hline Categorical Variable - n (\%) & $\begin{array}{l}\text { Total } \\
n=187\end{array}$ & $\begin{array}{l}\text { Low VPC-5 } \\
n=(62)\end{array}$ & $\begin{array}{l}\text { Medium VPC-5 } \\
n=(63)\end{array}$ & $\begin{array}{l}\text { High VPC-5 } \\
(n=62)\end{array}$ & p-value \\
\hline Gender & & & & & 0.490 \\
\hline Female & $88(47.1)$ & $27(43.5)$ & $28(44.4)$ & $33(53.2)$ & \\
\hline Male & $99(52.9)$ & $35(56.5)$ & $35(55.6)$ & $29(46.8)$ & \\
\hline Ethnicity & & & & & 0.303 \\
\hline Caucasian & $105(56.1)$ & $30(48.4)$ & $42(66.7)$ & $33(53.2)$ & \\
\hline African American & $78(41.7)$ & $30(48.4)$ & $20(31.7)$ & $28(45.2)$ & \\
\hline Hispanic & $4(2.1)$ & $2(3.2)$ & $1(1.6)$ & $1(1.6)$ & \\
\hline \multicolumn{6}{|l|}{ CVD Risk Factors } \\
\hline Hypertension & $152(82.6)$ & $51(85.0)$ & $48(76.2)$ & $53(86.9)$ & 0.244 \\
\hline Hyperlipidemia & $119(65.0)$ & $41(68.3)$ & $38(61.3)$ & $40(65.6)$ & 0.713 \\
\hline Diabetes & $47(25.5)$ & $16(26.7)$ & $11(17.5)$ & $20(32.8)$ & 0.143 \\
\hline $\mathrm{BMI} \geq 30$ & $107(58.8)$ & $33(55.9)$ & $33(53.2)$ & $41(67.2)$ & 0.249 \\
\hline Current smoker & $75(40.5)$ & $23(38.3)$ & $28(44.4)$ & $24(38.7)$ & 0.739 \\
\hline Never smoked & $45(24.3)$ & $13(21.7)$ & $18(28.6)$ & $14(22.6)$ & 0.622 \\
\hline Former smoker & 65 (34.9) & $24(39.3)$ & $17(27.0)$ & $24(38.7)$ & 0.264 \\
\hline Environmental Smoke & $36(32.4)$ & $14(36.8)$ & $13(37.1)$ & $9(23.7)$ & 0.364 \\
\hline High FRS Category & $152(81.3)$ & $48(77.4)$ & $57(90.5)$ & $47(75.8)$ & 0.070 \\
\hline \multicolumn{6}{|l|}{ Medical History } \\
\hline Myocardial Infarction & $66(35.7)$ & $22(36.7)$ & $24(38.1)$ & $20(32.3)$ & 0.778 \\
\hline Stroke & $18(9.7)$ & $6(10.0)$ & $6(9.5)$ & $6(9.5)$ & 0.996 \\
\hline CABG/ PCl/ Stents & $54(29.2)$ & $17(28.3)$ & $20(31.7)$ & $17(27.4)$ & 0.854 \\
\hline Heart Failure & $33(17.9)$ & $13(21.7)$ & $10(16.1)$ & $10(16.1)$ & 0.656 \\
\hline \multicolumn{6}{|l|}{ Medication } \\
\hline ACE inhibitor & $100(54.6)$ & $35(59.3)$ & $34(54.0)$ & $31(50.8)$ & 0.640 \\
\hline Angiotensin-receptor blockers & $12(6.6)$ & $2(3.4)$ & $3(4.8)$ & $7(11.5)$ & 0.157 \\
\hline Beta-blocker & $117(63.9)$ & $39(66.1)$ & $44(69.8)$ & $34(55.7)$ & 0.240 \\
\hline Calcium-channel blockers & $37(20.2)$ & $15(25.4)$ & $9(14.3)$ & $13(21.3)$ & 0.300 \\
\hline Diuretics & $73(39.9)$ & $21(35.6)$ & $26(41.3)$ & $26(42.6)$ & 0.707 \\
\hline Statins & $97(53.0)$ & $34(57.6)$ & $33(52.4)$ & $30(49.2)$ & 0.646 \\
\hline Aspirin & $108(59.0)$ & $32(54.2)$ & $39(61.9)$ & $37(60.7)$ & 0.656 \\
\hline Vasodilator & $41(22.4)$ & $17(28.8)$ & $12(19.0)$ & $12(19.7)$ & 0.356 \\
\hline Continuous Variable - mean (SD) & Total & Low VPC-5 & Medium VPC-5 & High VPC-5 & p-value \\
\hline Age & $51.39(10.16)$ & $51.98(10.85)$ & $51.05(9.351)$ & $51.13(10.38)$ & 0.852 \\
\hline Cotinine & $510.0(718.5)$ & $462.3(611.7)$ & $435.5(563.3)$ & $632.2(922.9)$ & 0.274 \\
\hline FRS & $8.822(7.682)$ & $7.411(7.690)$ & $10.00(8.350)$ & $9.550(7.633)$ & 0.635 \\
\hline Lymphocyte count $\times 10^{4}$ & $12.34(8.825)$ & $10.18(7.739)$ & $12.16(7.050)$ & $16.48(10.29)$ & $<0.001^{* *}$ \\
\hline \multicolumn{6}{|l|}{ Thrombosis } \\
\hline Fibrinogen & $350.7(113.5)$ & $339.7(82.34)$ & $338.0(83.85)$ & $374.0(155.7)$ & 0.139 \\
\hline Platelet mononuclear cell aggregates & $10.71(5.943)$ & $10.66(6.386)$ & $10.07(4.543)$ & $11.51(6.880)$ & 0.537 \\
\hline \multicolumn{6}{|l|}{ Inflammation } \\
\hline hsCRP & $5.002(4.689)$ & $4.925(4.794)$ & $4.451(4.146)$ & $5.638(5.090)$ & 0.383 \\
\hline Median household income & $30103(14762)$ & $30374(16023)$ & $31364(14071)$ & $28621(14256)$ & 0.622 \\
\hline
\end{tabular}

\section{Table 5. Demographic comparison stratified by VPC-5 tertile.}

Low VPC-5 mean $=-1414 \pm 655.1$, range $=-3361--631.5$ (log-transformed VPC-5

normalized to $\mathrm{uL}$ sample $* 1000$ ). Medium VPC-5 mean $=-233.5 \pm 201.2$, range $=-622.3$ -68.22 . High VPC-5 mean $=818.0 \pm 757.8$, range $=69.53-3968$. Current, never, and former smokers based on self-report. Environmental smoke is secondhand smoke exposure in self-reported non-smokers. FRS = Framingham Risk Score. High FRS category has a FRS $\geq 20$ or experienced a cardiovascular event. BMI = body mass index. $\mathrm{CABG}=$ coronary artery bypass graft. $\mathrm{PCI}=$ percutaneous coronary intervention. $\mathrm{ACE}=$ 
angiotensin-converting-enzyme. Age in years. Cotinine units $(\mathrm{ng} / \mathrm{mL})$. Fibrinogen units $(\mathrm{mg} / \mathrm{dL})$. HsCRP units $(\mathrm{mg} / \mathrm{L})$. Vasodilators included nitrates and hydralazine. Platelet mononuclear cells are the percent total of cells $\mathrm{CD} 41^{+} / 45^{+}$. Median household income in USD at the US Census block group level. ** = significant at the 0.05 level.

\begin{tabular}{|c|c|c|}
\hline VPC Population & $\boldsymbol{\beta}$ & p-value \\
\hline VPC-3 $\left(\mathrm{CD} 31^{+} / 34^{+} / 45^{\mathrm{dim}} / \mathrm{AC} 133^{+}\right)$ & 0.840 & $<0.001$ \\
\hline VPC-5 (CD31 $\left.{ }^{+} / \mathrm{AC} 133^{+}\right)$ & -0.679 & 0.003 \\
\hline VPC-13 (CD $\left.34^{+} / \mathrm{AC} 133^{+}\right)$ & 0.706 & 0.001 \\
\hline VPC-15 (CD $34^{+} / 45^{\left.\mathrm{dim} / A C 133^{+}\right)}$ & 0.864 & $<0.001$ \\
\hline
\end{tabular}

Table 6. Association between VPCs and FRS Category.

The $\beta$ presented is the adjusted $\beta$ for the FRS Category. Models were adjusted for ethnicity, alcohol, BMI, and SES. 


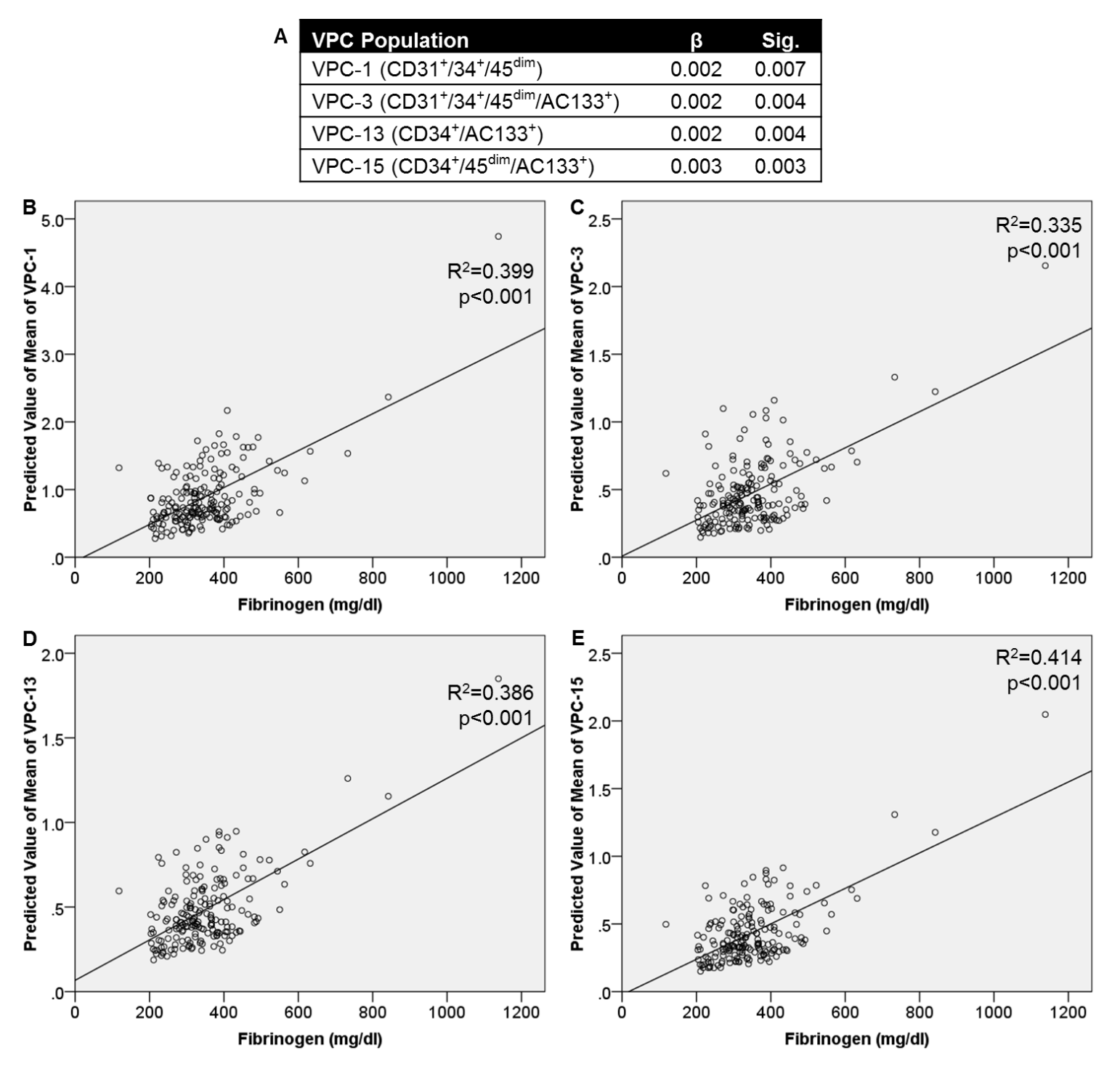

Figure 3. Adjusted association between VPCs and fibrinogen.

The $\beta$ presented is the adjusted $\beta$ for fibrinogen. (A) Models were adjusted for hypertension, hyperlipidemia, diabetes, smoking, age, ethnicity, alcohol, gender, BMI, and SES. (B) Predicted value of mean VPC-1 was calculated form the adjusted regression model. (C) Predicted value of mean VPC-3 was calculated form the adjusted regression model. (D) Predicted value of mean VPC-13 was calculated form the adjusted regression model. (E) Predicted value of mean VPC-15 was calculated form the adjusted regression model. 
A

\begin{tabular}{|c|c|c|}
\hline VPC Population & $\beta$ & p-value \\
\hline VPC-6 (CD31 $\left.{ }^{+} / 34^{+}\right)$ & 0.040 & 0.036 \\
\hline VPC-9 (CD34 $\left.{ }^{+}\right)$ & 0.044 & 0.026 \\
\hline VPC-14 (CD $\left.34^{+} / 45^{+} / \mathrm{AC} 133^{+}\right)$ & 0.118 & $<0.001$ \\
\hline
\end{tabular}

C

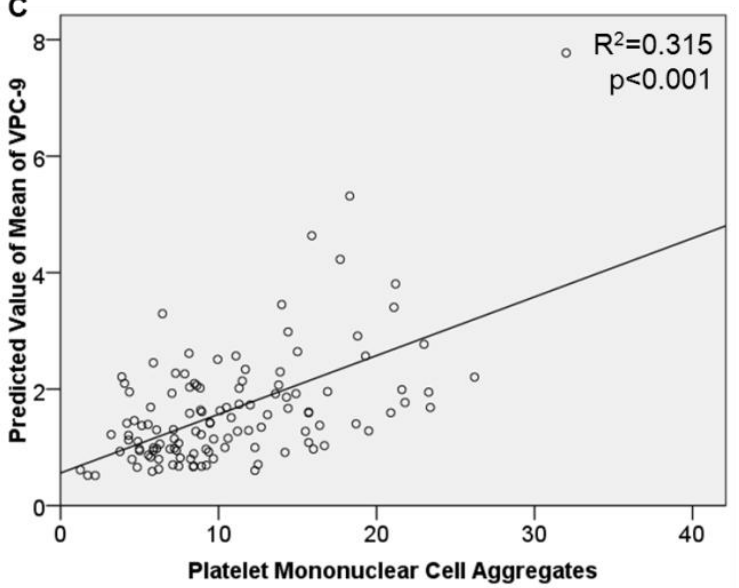

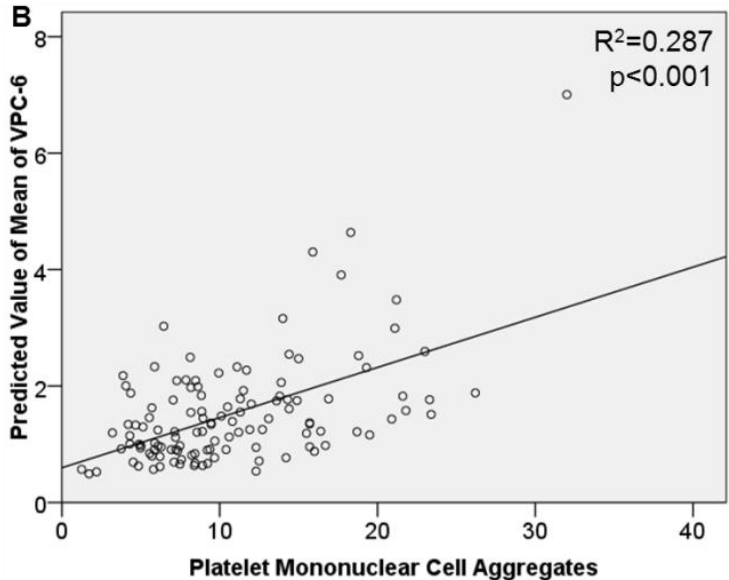

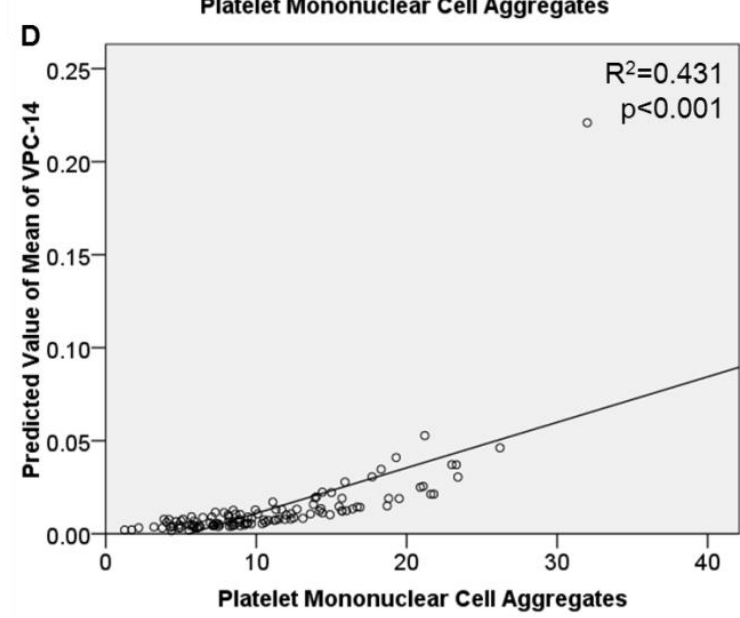

Figure 4. Adjusted association between VPCs and platelet mononuclear cell aggregates.

Platelet mononuclear cell aggregates are the percent total of cells $\mathrm{CD} 41^{+} / 45^{+}$. The $\beta$ presented is the adjusted $\beta$ for platelet mononuclear cell aggregates. (A) Models were adjusted for hypertension, hyperlipidemia, diabetes, smoking, age, ethnicity, alcohol, gender, BMI, and SES. (B) Predicted value of mean VPC-6 was calculated form the adjusted regression model. (C) Predicted value of mean VPC-9 was calculated form the adjusted regression model. (D) Predicted value of mean VPC-14 was calculated form the adjusted regression model. 

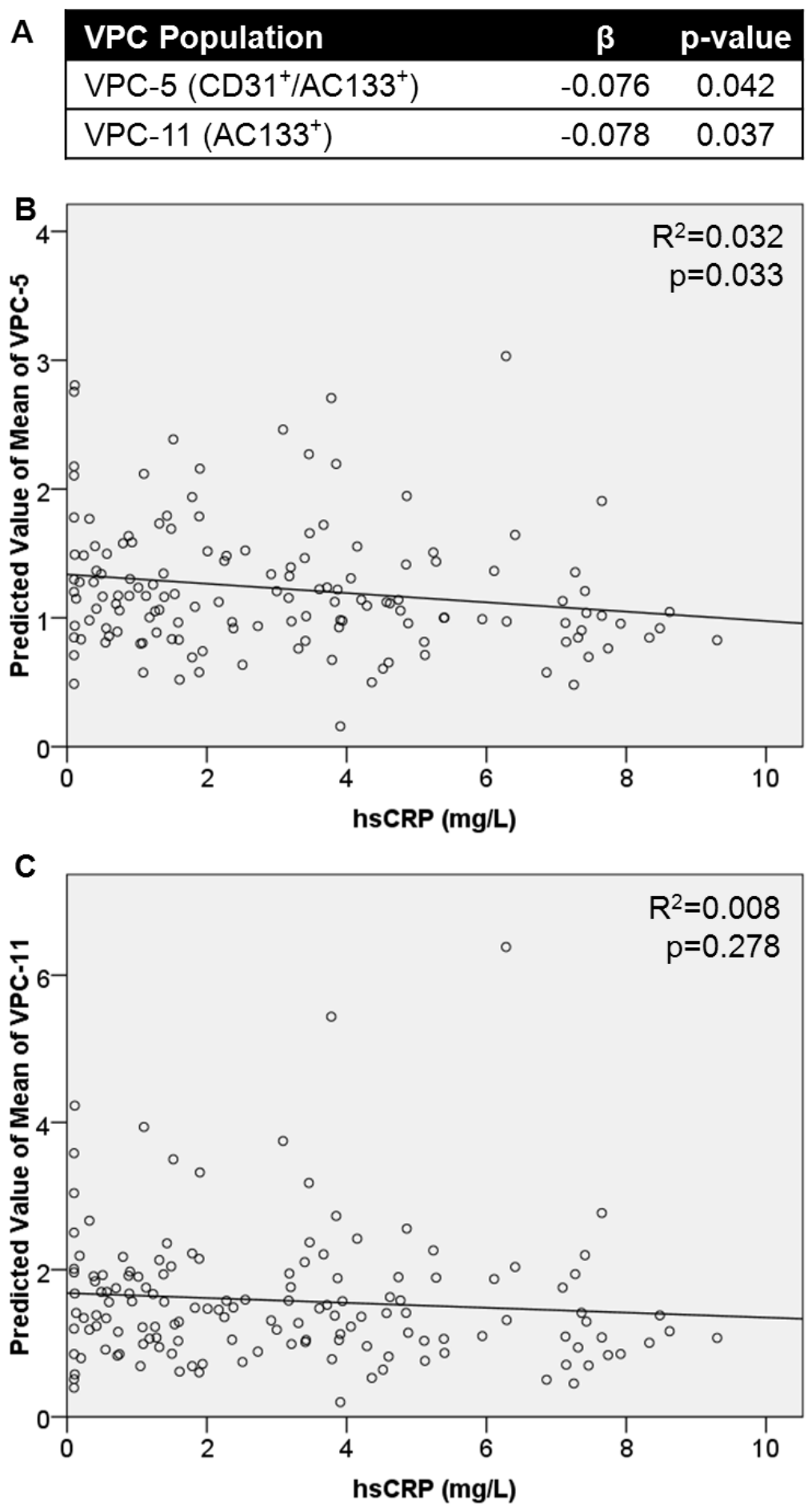

Figure 5. Adjusted association between VPCs and hsCRP.

People with hsCRP $>10$ were excluded from analysis $(n=19)$. The $\beta$ presented is the adjusted $\beta$ for hsCRP. (A) Models were adjusted for hypertension, hyperlipidemia, diabetes, smoking, age, ethnicity, alcohol, gender, BMI, and SES. (B) Predicted value of mean VPC-5 was calculated form the adjusted regression model. (C) Predicted value of mean VPC-11 was calculated form the adjusted regression model. 


\section{CHAPTER II}

\section{Contribution of Acrolein to Cardiovascular Disease Risk and Vascular Progenitor}

\section{Cell Levels}

\section{Introduction}

Cardiovascular disease (CVD) is the leading cause of death in the U.S. ${ }^{1}$. Vascular progenitor cells (VPCs) are suspected to be a sensitive indicator of vascular health. Several investigators have reported that decreased levels of circulating VPCs, cells that

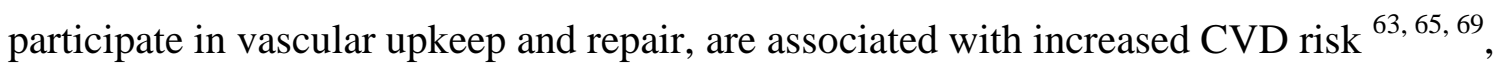
severity ${ }^{66,71-73}$, and mortality ${ }^{74}$. Exposure to ambient air pollution, including particulate matter, is associated with increased CVD incidence and mortality ${ }^{29}$, prompting a scientific statement from the American Heart Association indicating that air pollution exposure should be considered a modifiable risk factor for CVD ${ }^{32}$. It has been recently shown that exposure to elevated levels of combustion pollutants, including fine particulate matter in healthy young adults ${ }^{30}$ and acrolein in mice ${ }^{51}$, decrease circulating VPC levels. Therefore, we investigated the association between acrolein and VPC levels in humans.

Emerging evidence suggests that VPC populations may provide a mechanistic link between combustion pollutant exposure and CVD. The endothelium mediates vasodilatation and thrombosis. In mice, combustion pollutant exposure is associated with decreased endothelial-mediated vasodilation ${ }^{29}$. In humans, exposure to combustion pollutants is associated with vasoconstriction ${ }^{29}$, reduced brachial artery diameter ${ }^{102}$, and 
flow mediated vasodilation ${ }^{103,104}$. VPCs are necessary for upkeep and repair of the endothelium ${ }^{26}$, participating in revascularization. Decreased VPC levels are associated with endothelial dysfunction, a hallmark of atherosclerosis development and a key mechanism in myocardial infarction ${ }^{27}$. VPCs are heterogeneous populations, and understanding which phenotypically distinct population is associated with acrolein metabolism may be important in characterizing risk.

Acrolein exposure is ubiquitous and includes multiple sources of exposure, including tobacco smoke, vehicular exhaust, open fires, and industrial emissions ${ }^{51}$. Increased acrolein exposure is associated with increased CVD risk, including hypertension, atherogenesis, decreased plaque stability, suppression of cardiac flow, thrombosis, and cardiac contractility ${ }^{48}$. Acrolein exposure in mice is associated with dyslipidemia, decreased VPC levels, and endothelial dysfunction ${ }^{49-51}$. Additionally, protein-acrolein adducts have been found in atherosclerotic lesions in the vessels of acrolein-exposed mice ${ }^{51}$. While acrolein promotes atherogenesis via protein adduct formation and oxidation of thioredoxins in human endothelial cells, ${ }^{48}$ its effects on human VPCs are unknown. We explored the association between VPCs and acrolein using hydroxypropylmercapturic acid (HPMA), the acrolein metabolite found in highest quantity in the urine, and produced only by acrolein metabolism ${ }^{46}$. Because tobacco smoke is a source of acrolein exposure and a risk factor for CVD, we also measured urine cotinine, the primary nicotine metabolite, to reduce potential confounding.

Our objective was to examine the relationship between CVD risk and levels of the acrolein metabolite, HPMA. To characterize risk, we investigated VPC levels and markers of inflammation and thrombosis along with the Framingham Risk Score (FRS) to 
indicate clinical risk prediction - a novel assessment in the field. We hypothesized that acrolein metabolism is inversely associated with VPC levels, thereby contributing to CVD risk.

\section{Methods}

\section{Study Population}

See Overall Methods (Study Population).

\section{Case Definition}

See Overall Methods (Case Definition).

\section{Questionnaire}

See Overall Methods (Questionnaire).

\section{Biological Sample Collection and Processing}

See Overall Methods (Biological Sample Collection and Processing).

\section{VPC Quantification}

See Overall Methods (VPC Quantification).

\section{Platelet Mononuclear Cell Aggregate Identification}

See Overall Methods (Platelet Mononuclear Cell Aggregate Identification).

\section{HPMA Quantification}

We measured HPMA in urine using mass spectrometric analysis following the

methods described by Carmella et al. ${ }^{105}$ and modified by Conklin et al. ${ }^{46}$. One $\mathrm{mL}$ of urine was combined with $2.5 \mathrm{nmol}$ of $\mathrm{C}^{13}$ HPMA (internal standard) and added to an Oasis Max Solid Phase Extraction column for purification. The column protocol included

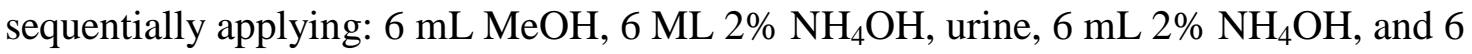
$\mathrm{mL} \mathrm{MeOH}$. The column was dried with $\mathrm{N}_{2}$ and then washed with $6 \mathrm{~mL} 2 \%$ formic acid. 
Finally, it was eluted with $30 \% \mathrm{MeOH}$ in $2 \%$ formic acid. The HPMA fraction was lyophilized and reconstituted in $1 \mathrm{~mL}$ of water. The solution was then syringe filtered and purified using high-performance liquid chromatography (HPLC). The HPMA fraction was lyophilized and subsequently derivitized with $40 \mu \mathrm{L}$ acetonitrile and $40 \mu \mathrm{L}$ N,OBis(trimethylsilyl)trifluoroacetamide (BSTFA) for 1 hour at $60^{\circ} \mathrm{C}$. One $\mu \mathrm{L}$ of the sample was applied to the gas chromatography / mass spectrometry (GC/MS) (Agilent 6890N)

for quantification. The ion fragments 366 (HPMA) and 369 ( ${ }^{13}$ HPMA) were compared for quantification. HPMA values were normalized to creatinine, which was measured in urine using the Cobas Mira 5600 Autoanalyzer.

\section{Cotinine Quantification}

Cotinine was measured in urine using GC/MS following the methods described by Man et al. ${ }^{56}$. See Overall Methods (Cotinine Quantification).

\section{Statistical Analysis}

Descriptive statistics were computed to describe the Healthy Heart Study population and are presented as n (\%) for categorical variables and mean (SD) for continuous variables. Population demographics, CVD risk factors, markers of thrombosis (fibrinogen and platelet mononuclear cell aggregates), and markers of inflammation (hsCRP) were compared among tertiles representing low, medium, and high HPMA levels. The tertiles were formed by dividing the population's HPMA levels into 3 even cut points. Population characteristics were compared using one-way analysis of variance (ANOVA) techniques for continuous variables and $\mathrm{X}$-squared analysis for dichotomous or categorical variables. 
VPC levels were compared among the HPMA tertiles using ANOVA techniques. The VPC levels assessed were log transformed for normality, consistent with previous literature ${ }^{74}$. VPC values presented are the VPC counts normalized to sample volume for consistency.

To explore the relationship between HPMA and smoking, independent sample ttest techniques were used to test for bivariate associations between self-reported smoking status and mean cotinine levels along with cotinine strata and mean HPMA levels. Cotinine was stratified into 2 strata representing low (cotinine $<200 \mathrm{ng} / \mathrm{mL}$ ) and high (cotinine $\geq 200 \mathrm{ng} / \mathrm{mL}$ ) smoking levels. These values are commonly used in the insurance industry to distinguish non-smokers from smokers. Additionally, HPMA was regressed against cotinine to verify the relationship between smoking and HPMA.

To explore the relationship between HPMA and CVD risk, HPMA was regressed against the FRS. In the current database, the FRS was only determined for the primary prevention population. As such, to include the secondary population, we divided the entire population into 2 FRS categories. The low FRS category includes the population with an FRS $<20$, while the high FRS population includes the population with an FRS $\geq$ 20 and the population that has experienced a cardiovascular event (i.e. the secondary preventive population). Independent samples t-tests were also used to examine differences in HPMA levels between the 2 FRS categories in both the whole population and subsequently for the subset of non-smokers.

Generalized Linear Modeling (GLM) techniques were used to examine whether the circulating VPC levels, markers of inflammation and thrombosis, and the FRS were associated with HPMA levels; after adjusting for age, gender, ethnicity, cotinine, alcohol 
consumption, body mass index (BMI), hypertension, diabetes, diuretics, and vasodilators. The FRS and FRS category were only adjusted for ethnicity, alcohol consumption, and BMI (the remaining variables are included in the FRS equation). Because the VPC levels appeared to follow a gamma distribution, GLMs that assessed VPCs as the dependent variable utilized the gamma probability distribution and the log link function. For FRS Category the binomial distribution was used. All other GLMs utilized the normal probability distribution and the identity link function. Traditional model fit statistics (loglikelihood) were used to develop the most parsimonious model. In addition we tested whether higher order modeling (e.g., exponential, cubic) improved model fit using traditional model-fit statistics (AIC, log-likelihood, etc.). Additionally, as an exploratory analysis, the aforementioned analysis was repeated in non-smokers to demonstrate the association with acrolein metabolism in the absence of smoke exposure.

\section{Results}

\section{Participant Characteristics}

The sample population was middle-aged (51 years old), majority male $(n=111$, $52.6 \%)$, Caucasian $(n=120,56.9 \%)$ and either a current smoker $(n=82,39.2 \%)$ or former smoker $(n=71,33.8 \%)$. A majority of the sample population had hypertension $(n=168$, $81.2 \%)$; hyperlipidemia $(n=131,63.6 \%)$; were obese $(B M I \geq 30, n=118,57.6 \%)$; or using angiotensin-converting-enzyme (ACE) inhibitors $(n=112,54.4 \%)$, beta-blockers $(n=129$, $62.6 \%)$, or statins $(\mathrm{n}=109,52.9 \%)$ (Table 7$)$.

\section{Non-smoking Participant Characteristics}

The non-smokers in the sample population were middle-aged (53 years old), a majority male $(n=68,53.5 \%)$, Caucasian $(n=73,57.5 \%)$, and were either a former smoker 
$(n=71,55.9 \%)$ or a never smoker $(n=56,44.1 \%)$. A majority of the non-smoking sample

population had hypertension $(n=103,81.7 \%)$; hyperlipidemia $(n=78,61.4 \%)$; were obese $(\mathrm{BMI} \geq 30, \mathrm{n}=74,59.7 \%)$; or using angiotensin-converting-enzyme (ACE) inhibitors $(n=68,55.3 \%)$, beta-blockers $(n=79,64.2 \%)$, or statins $(n=64,52.0 \%)($ Table 8$)$.

\section{Demographic Comparison}

Differences between the characteristics of the populations within low, medium, and high HPMA tertiles are shown in Table 7. There were no significant differences between HPMA tertile and gender; hypertension; hyperlipidemia; diabetes mellitus; environmental tobacco smoke; myocardial infarction; stroke; heart failure; most medications except diuretics; age; the FRS (in primary preventive patients); lymphocyte count; thrombosis, inflammation, and median household income. Caucasians were more likely to have higher HPMA than African Americans ( $p=0.005)$. Obese (BMI $\geq 30)$ participants had lower HPMA ( $\mathrm{p}=0.015)$. Smoking demonstrated highly significant associations with HPMA; high HPMA was associated with self-report of being a current smoker $(\mathrm{p}<0.001)$, inversely associated with having never smoked $(\mathrm{p}=0.001)$ and being a former smoker $(\mathrm{p}<0.001)$, and was associated with higher cotinine levels $(\mathrm{p}<0.001)$. Participants in the high FRS category (FRS $\geq 20$ or experienced a cardiovascular event) had significantly higher HPMA $(\mathrm{p}=0.006)$. Participants with revascularization including coronary artery bypass graft $(\mathrm{CABG})$, percutaneous coronary intervention (PCI), or stents also had higher HPMA ( $\mathrm{p}=0.040)$ Participants who were taking diuretics had lower HPMA $(\mathrm{p}=0.005)$. 


\section{Non-smoking Demographic Comparison}

Differences between the characteristics of the non-smoking population within low, medium, and high HPMA tertiles are shown in Table 8. Obese (BMI $\geq 30)$ participants were less likely to have high HPMA ( $\mathrm{p}=0.033)$. People with high HPMA were more likely to self-report having never smoked $(\mathrm{p}=0.015)$ and less likely to be a former smoker $(\mathrm{p}=0.015)$, and more likely to have higher cotinine $(\mathrm{p}<0.001)$. Participants that were taking diuretics were more likely to have low HPMA $(\mathrm{p}=0.023)$. People with low HPMA had a significantly a higher mean hsCRP level ( $\mathrm{p}=0.004)$.

\section{Association between VPCs and CVD Risk with HPMA Tertile}

Results of the ANOVA comparison between HPMA tertile and VPC levels are shown in Table 9. VPC-2 $\left(\left(\mathrm{CD} 31^{+} / 34^{+} / 45^{+}\right) ; \mathrm{p}=0.030\right)$, and VPC-8 $\left(\left(\mathrm{CD} 31^{+} / 34^{+} / 45^{+} / \mathrm{AC} 133^{-}\right), \mathrm{p}=0.035\right)$ were inversely associated with HPMA levels. When stratified into self-reported non-smokers, none of the VPC populations were significantly associated with HPMA tertile (Table 10).

\section{Association between Smoking and HPMA}

Associations between smoking and HPMA are illustrated in Figure 6. Mean cotinine levels were significantly higher in smokers when compared to non-smokers $(1033.79 \pm 93.84$ v. $142.26 \pm 37.78, \mathrm{p}<0.001)$. Mean HPMA levels were significantly higher in the population with high cotinine $(<200 \mathrm{ng} / \mathrm{mL})$ than low cotinine $(\geq 200$ $\mathrm{ng} / \mathrm{mL})$, with values of $726.49 \pm 74.61$ and $144.93 \pm 16.40 \mu \mathrm{g} / \mathrm{g}$ creatine $(\mathrm{p}<0.001)$, respectively. Regression analysis results confirmed that HPMA levels were positively associated with cotinine $\left(\beta=0.257, \mathrm{R}^{2}=0.422, \mathrm{p}<0.001\right)$. 


\section{Association between CVD Risk and HPMA}

Association between the FRS and HPMA are shown in Figure 7. A scatterplot demonstrates that HPMA levels increase as the FRS increases in the primary prevention population $\left(\mathrm{R}^{2}=0.101, \mathrm{p}=0.021\right)$. In a scatterplot of the primary preventive population of non-smokers, there is no significant association between HPMA and FRS $\left(\mathrm{R}^{2}=0.010\right.$, $\mathrm{p}=0.595)$. The population in the low FRS category $(\mathrm{FRS}<20)$ demonstrates significantly lower HPMA than the high FRS category (FRS $\geq 20$ or experienced a cardiovascular event) with values of $181.45 \pm 46.74$ and $458.73 \pm 30.04 \mu \mathrm{g} / \mathrm{g}$ creatine $(\mathrm{p}<0.001)$, respectively. When stratified into the non-smoking population, although HPMA was about half that of the total population, HPMA remained significantly higher in the high FRS category with mean values of $105.16 \pm 23.04$ and $220.87 \pm 26.69 \mu \mathrm{g} / \mathrm{g}$ creatine $(\mathrm{p}=0.001)$ for the low and high FRS categories, respectively.

\section{Adjusted Association of CVD Risk and HPMA}

The adjusted GLM results of CVD risk and HPMA are shown in Table 11. The associations were adjusted for age, gender, ethnicity, cotinine, alcohol, BMI, hypertension, diabetes, and diuretics. VPC-2 $\left(\left(\mathrm{CD} 31^{+} / 34^{+} / 45^{+}\right), \beta=-0.002, \mathrm{p}<0.001\right)$, VPC-8 ((CD31 $\left.\left.{ }^{+} / 34^{+} / 45^{+} / \mathrm{AC} 133^{-}\right), \beta=-0.002, \mathrm{p}<0.001\right), \mathrm{VPC}-11\left(\left(\mathrm{AC} 133^{+}\right), \beta=-0.001\right.$, $\mathrm{p}=0.046)$, and VPC-14 $\left(\left(\mathrm{CD} 34^{+} / 45^{+} / \mathrm{AC} 133^{+}\right), \beta=-0.002, \mathrm{p}=0.029\right)$ were inversely associated with HPMA. Platelet mononuclear cell aggregates $\left(\mathrm{CD} 41^{+} / 45^{+}\right)$were positively associated with HPMA $(\beta=0.003, \mathrm{p}=0.030)$. The FRS was associated with HPMA $(\beta=0.012, p<0.001)$ after adjustment for ethnicity, alcohol, and BMI (the remaining variables are reflected in the FRS). The FRS category, also adjusted for 
ethnicity, alcohol, and BMI, demonstrated a positive association with HPMA where the low FRS category had lower HPMA $(\beta=-0.003, \mathrm{p}=0.002)$.

\section{Adjusted Association of CVD Risk and HPMA in Non-smokers}

The adjusted GLM results of CVD risk and HPMA in non-smokers are shown in Table 12. The associations were adjusted for age, gender, ethnicity, cotinine, alcohol, BMI, hypertension, diabetes, and diuretics. VPC-2 $\left(\left(\mathrm{CD} 31^{+} / 34^{+} / 45^{+}\right), \beta=-0.003\right.$, $\mathrm{p}<0.001), \mathrm{VPC}-8\left(\left(\mathrm{CD} 31^{+} / 34^{+} / 45^{+} / \mathrm{AC} 133^{-}\right), \beta=-0.003, \mathrm{p}<0.001\right), \mathrm{VPC}-9\left(\mathrm{CD} 34^{+} ; \beta=-\right.$ $0.001, \mathrm{p}=0.024)$, and VPC-14 $\left(\left(\mathrm{CD} 34^{+} / 45^{+} / \mathrm{AC} 133^{+}\right), \beta=-0.011, \mathrm{p}=0.001\right)$ were inversely associated with HPMA; however, VPC-11 ((AC133 $\left.\left.{ }^{+}\right), \beta<0.001, \mathrm{p}=0.793\right)$ was no longer associated with HPMA. Platelet mononuclear cell aggregates $\left(\mathrm{CD} 41^{+} / 45^{+}\right)$were no longer associated with HPMA $(\beta=0.004, p=0.245)$. The FRS was no longer associated with HPMA $(\beta=0.010, p=0.097)$ after adjustment for ethnicity, alcohol, and BMI. The FRS category was no longer associated with HPMA $(\beta=-0.004, p=0.069)$.

\section{Discussion}

While associations between acrolein exposure and CVD risk have been shown in mice, this is the first study to examine the association between the primary urine acrolein metabolite, HPMA, and VPC levels as a measure of CVD risk in humans. The current results demonstrate a significant association with HPMA and ethnicity. Obese individuals were more likely to have low HPMA. Additionally, an inverse association between HPMA and use of diuretics was observed. Comparison between HPMA tertiles demonstrated that VPC-2 $\left(\mathrm{CD} 31^{+} / 34^{+} / 45^{+}\right)$and VPC-8 $\left(\mathrm{CD} 31^{+} / 34^{+} / 45^{+} / \mathrm{AC} 133^{-}\right)$levels significantly decrease as HPMA levels increase. We verified that smokers have significantly higher HPMA levels, which was expected because cigarette smoke is a 
source of acrolein. Our results demonstrated that HPMA is positively associated with the FRS and the FRS categories, indicating that HPMA levels significantly increase as risk increases. This association was consistent among FRS categories in non-smokers, suggesting that the association is not driven solely by tobacco smoke exposure. In the fully adjusted models, we determined that HPMA was significantly inversely associated with VPC-2, VPC-8, VPC-11 (AC133 $\left.{ }^{+}\right)$, and VPC-14 $\left(\mathrm{CD} 34^{+} / 45^{+} / \mathrm{AC} 133^{+}\right)$.

Additionally, HPMA was significantly positively associated with thrombosis (platelet mononuclear cell aggregate levels), the FRS, and FRS categories. VPC-2, VPC-8, VPC-9 $\left(\mathrm{CD} 34^{+}\right)$, and VPC-14 and significantly associated with HPMA when the models included non-smokers only.

One particularly interesting finding was that Caucasians are more likely to have higher HPMA than African Americans in the Healthy Heart Study population. There was not a significant difference between smoking (empirical or self-reported) and ethnicity among the study participants. African Americans participants were also more likely to be obese, and HPMA levels decreased as BMI increased. The likely link between HPMA and ethnicity is diuretic use. There is a significantly higher proportion of African Americans using diuretics compared to Caucasians in the Healthy Heart Study, and we found that diuretic use decreased as HPMA tertile increased. There was not a significant association between smoking and BMI, and there was no association between HPMA and self-reported exercise. There was an association between BMI and diuretics, where obese patients were significantly more likely to be taking diuretics. When the population using diuretics is excluded from analysis, there is no longer a significant association between HPMA and BMI. Therefore, our adjusted regression model included diuretics as a 
potential confounder. Future research should investigate other factors among different ethnicities and relating to BMI that may contribute to differences in HPMA levels.

VPC-2 (CD31 $\left.1^{+} / 34^{+} / 45^{+}\right)$, VPC-8 (CD31 $\left.1^{+} / 34^{+} / 45^{+} / \mathrm{AC} 133^{-}\right)$, and VPC-14 $\left(\mathrm{CD} 34^{+} / 45^{+} / \mathrm{AC} 133^{+}\right)$levels were inversely associated with HPMA in both the total population and non-smokers. O'Toole et al. found that VPC-2 was inversely associated with increased exposure to $\mathrm{PM}_{2.5}{ }^{30}$. Because VPC- 8 is a sub-population of VPC-2, it is likely that VPC-8 is driving the association seen with VPC-2; therefore, the true association appears to be with VPC-8 and HPMA. The VPC-8 population should be assessed in future environmental research as a sensitive indicator of CVD risk and combustion pollution exposure, which could potentially provide insight into environmental mechanisms of vascular toxicity.

We found that platelet mononuclear cell aggregates were positively associated with HPMA, suggesting that thrombosis increases as acrolein (a combustion pollutant) exposure increases. These results were similar to the finding by O'Toole et al. that increased combustion pollutant exposure ( $\left.\mathrm{PM}_{2.5}\right)$ was associated with increased platelet mononuclear cell aggregates in healthy young adults ${ }^{30}$. Our population of middle-aged adults with increased CVD risk demonstrated a similar association with acrolein metabolism.

This is the first investigation to report an association between HPMA and FRS. Because the FRS includes smoking, and smoking is a source of acrolein, we also analyzed the association with the FRS and HPMA in non-smokers. The positive association between HPMA and FRS category remained in the non-adjusted comparisons in the whole population as well as the non-smoking population. This suggests that the 
association between HPMA and FRS may not be driven entirely by tobacco smoke exposure, but also possibly by acrolein through the environment, endogenous exposure, or in food. In the adjusted analyses, HPMA no longer remained significantly lower in the low FRS category when assessing the whole population nor the non-smoking population. To further understand the environmental contribution, ambient or personal monitoring of acrolein will be necessary.

Strengths of the current study include the large study population with a wide range of CVD risk factors, allowing us to investigate how differences in risk factors are associated with HPMA. Additionally, our study includes multiple phenotypically different VPC populations to understand which cell types are associated HPMA. This expands on past VPC research by understanding differences in the phenotypes associated with environmental exposures. The endothelial cell $\left(\mathrm{CD} 31^{+}\right)$, stem cell $\left(\mathrm{CD} 34^{+}\right)$, hematopoietic cell $\left(\mathrm{CD} 45^{+}\right)$, and early and late stem cell $\left(\mathrm{AC}_{133^{+/}}\right)$phenotypes demonstrated significantly lower levels with increased HPMA concentrations. The progenitor cell populations with the non-hematopoietic $\left(\mathrm{CD} 45^{\mathrm{dim}}\right)$ cell phenotype were not associated with acrolein metabolism, a novel finding in combustion pollution-linked vascular research. An added benefit of our study was that we were able to account for potential confounding by measuring cotinine levels, the primary urine nicotine metabolite, in addition to collecting data on self-reported smoking. We adjusted for potential confounding due to diuretic use, which was associated with ethnicity and BMI.

One potential limitation in this study is the lack of ambient acrolein measurements. Acrolein is highly volatile, and the stationary acrolein monitors are not widely dispersed throughout Jefferson County, KY to attain a valid estimation of 
exposure levels in our study population. An additional limitation is that investigations of urine metabolites generally collect urine at the first catch. Our study collected urine (for HPMA and cotinine) and blood (for VPCs and markers of inflammation and thrombosis) at the time of the visit (between 9 am and $5 \mathrm{pm}$ ). Similarly, some of the research on VPCs indicates that they demonstrate diurnal variations and recommend that blood should be collected at the same point each day ${ }^{64}$. Our collection of blood and urine at the same time point did allow a snapshot of collective exposures and risk from that corresponding point in time. Some of the limitations to the investigation involve the type of study we have selected. Cross-sectional studies are limited in their ability to demonstrate causality, but are useful to identify associations that can be used to generate hypotheses for future cohort studies. Moreover, none of the recruiting personnel fluently spoke languages other than English; therefore, some potential participants without a translator present were not able to provide consent for the study or participate in the interview questionnaire. In addition, based on the recruitment being entirely from cardiology clinics, we lacked a true population-based sample, but rather an at-risk population. This poses a limitation in being able to generalize the results to the larger community.

For future directions of this research, it would be beneficial to measure ambient acrolein levels, in order to determine the portion of HPMA that may be attributed to environmental exposure. Understanding the basis for the differences in HPMA among different ethnicities and obesity will be valuable in characterizing risk. We could also investigate other biomarkers of environmental exposures to determine how they affect CVD risk and VPC levels. A future case-control study with controls that have no CVD 
and are non-smokers would be beneficial to better understand differences in risk and acrolein metabolite levels.

In summary, these findings suggest that increased HPMA levels are associated with increased CVD risk. The major finding in the current study is that acrolein metabolism appears to be associated with vascular injury, as reflected by reduced VPC levels. This is accompanied by increased CVD risk and thrombosis. VPC-2 and VPC-8 levels were significantly lower with increased HPMA levels. Because VPC-8 is a subpopulation of VPC-2, it is likely that VPC-8 (specifically the AC133- late stem cell phenotype) is driving the association. Additionally, VPC-11 and VPC-14 were inversely associated with HPMA. A marker of thrombosis was significantly higher with increased HPMA. Lastly, as the FRS increased, HPMA levels increased. The associations seen in VPC-2, VPC-8, VPC-9, and VPC-14 were associated among the non-smoking population, suggesting that environmental exposure to acrolein poses additional endothelial risk that is detectable through these VPC populations. 
Figures and Tables

\begin{tabular}{|c|c|c|c|c|c|}
\hline Categorical Variable - n (\%) & $\begin{array}{l}\text { Total } \\
\mathrm{n}=211\end{array}$ & $\begin{array}{l}\text { Low HPMA } \\
n=(70)\end{array}$ & $\begin{array}{l}\text { Medium HPMA } \\
\mathrm{n}=(71)\end{array}$ & $\begin{array}{l}\text { High HPMA } \\
(n=70)\end{array}$ & p-value \\
\hline Gender & & & & & 0.863 \\
\hline Female & $100(47.4)$ & $32(45.7)$ & $33(46.5)$ & $35(50.0)$ & \\
\hline Male & $111(52.6)$ & $38(54.3)$ & $38(53.5)$ & $35(50.0)$ & \\
\hline Ethnicity & & & & & $0.005^{\star \star}$ \\
\hline Caucasian & $120(56.9)$ & $35(50.0)$ & $34(47.9)$ & $51(72.9)$ & \\
\hline African American & $87(41.2)$ & $32(45.7)$ & $37(52.1)$ & $18(25.7)$ & \\
\hline Hispanic & $4(1.9)$ & $3(4.3)$ & $0(0.0)$ & $1(1.4)$ & \\
\hline \multicolumn{6}{|l|}{ CVD Risk Factors } \\
\hline Hypertension & $168(81.2)$ & $61(88.4)$ & $55(79.7)$ & $52(75.4)$ & 0.137 \\
\hline Hyperlipidemia & $131(63.6)$ & $40(58.0)$ & $46(66.7)$ & $45(66.2)$ & 0.492 \\
\hline Diabetes & $55(26.4)$ & $18(26.1)$ & $23(32.9)$ & $14(20.3)$ & 0.243 \\
\hline $\mathrm{BMI} \geq 30$ & $118(57.6)$ & $45(66.2)$ & $44(62.9)$ & $29(43.3)$ & $0.015^{\star *}$ \\
\hline Current smoker (self-reported) & $82(39.2)$ & $8(11.6)$ & $22(31.4)$ & $52(74.3)$ & $<0.001^{\star *}$ \\
\hline Never smoked (self-reported) & $56(26.8)$ & $19(27.5)$ & $28(40.0)$ & $9(12.9)$ & $0.001^{\star *}$ \\
\hline Former smoker (self-reported) & $71(33.8)$ & $42(60.9)$ & $20(28.2)$ & $9(12.9)$ & $<0.001^{\star *}$ \\
\hline Environmental Smoke & $41(53.4)$ & $19(30.6)$ & $13(27.7)$ & $8(44.4)$ & 0.419 \\
\hline High FRS Category & $168(79.6)$ & $49(70.0)$ & $55(77.5)$ & $64(91.4)$ & $0.006^{* *}$ \\
\hline \multicolumn{6}{|l|}{ Medical History } \\
\hline Myocardial Infarction & $73(34.9)$ & $19(27.5)$ & $25(35.7)$ & $29(41.4)$ & 0.225 \\
\hline Stroke & $22(10.5)$ & $7(10.1)$ & $9(12.9)$ & $6(8.6)$ & 0.705 \\
\hline CABG/ PCl/ Stents & $58(27.8)$ & $14(20.3)$ & $17(24.3)$ & $27(38.6)$ & $0.040^{\star *}$ \\
\hline Heart Failure & $36(17.4)$ & $11(15.9)$ & $17(24.6)$ & $8(11.6)$ & 0.120 \\
\hline \multicolumn{6}{|l|}{ Medication } \\
\hline ACE inhibitor & $112(54.4)$ & $35(52.2)$ & $42(59.2)$ & $35(51.5)$ & 0.604 \\
\hline Angiotensin-receptor blockers & $12(5.8)$ & $6(9.0)$ & $4(5.6)$ & $2(2.9)$ & 0.328 \\
\hline Beta-blocker & $129(62.6)$ & $40(59.7)$ & $42(59.2)$ & $47(69.1)$ & 0.400 \\
\hline Calcium-channel blockers & $45(21.8)$ & $17(25.4)$ & $15(21.1)$ & $13(19.1)$ & 0.668 \\
\hline Diuretics & $81(39.3)$ & $32(47.8)$ & $33(46.5)$ & $16(23.5)$ & $0.005^{\star \star}$ \\
\hline Statins & $109(52.9)$ & $33(49.3)$ & $37(52.1)$ & $39(57.4)$ & 0.632 \\
\hline Aspirin & $117(56.8)$ & $37(55.2)$ & $38(53.5)$ & $42(61.8)$ & 0.588 \\
\hline Vasodilator & $47(22.8)$ & $10(14.9)$ & $20(28.2)$ & $17(25.0)$ & 0.157 \\
\hline Continuous Variable - mean (SD) & Total & Low HPMA & Medium HPMA & High HPMA & p-value \\
\hline Age & $51(10.3)$ & $53(10.8)$ & $50(10.2)$ & $50(9.8)$ & 0.134 \\
\hline Cotinine & $503(779.7)$ & $37(83.0)$ & $383(584.5)$ & $1107(952)$ & $<0.001^{\star *}$ \\
\hline FRS & $9(7.6)$ & $7(6.6)$ & $8(7.2)$ & $13(9.3)$ & 0.110 \\
\hline Lymphocyte Count X $10^{4}$ & $13(9.3)$ & $12(7.8)$ & $14(9.7)$ & $14(10.1)$ & 0.434 \\
\hline \multicolumn{6}{|l|}{ Thrombosis } \\
\hline Fibrinogen & $344.9(107.8)$ & $334.3(92.0)$ & $360.8(140.6)$ & $339.6(81.4)$ & 0.310 \\
\hline Platelet Mononuclear Cell Aggregates & $10.8(5.9)$ & $10.3(5.6)$ & $11.1(5.7)$ & $10.9(6.2)$ & 0.818 \\
\hline \multicolumn{6}{|l|}{ Inflammation } \\
\hline hsCRP & $4.7(4.6)$ & $5.5(5.1)$ & $4.8(4.4)$ & $3.8(4.3)$ & 0.106 \\
\hline Median Household Income & $30774(17786)$ & $31360(18222)$ & $30188(19771)$ & 30795 (15032) & 0.937 \\
\hline
\end{tabular}

Table 7. Demographic comparison stratified by HPMA tertile.

Low HPMA mean $=54.89 \pm 17.76$, range $=19.11-87.29 \mu \mathrm{g} / \mathrm{g}$ creatinine. Medium HPMA mean $=202.50 \pm 100.37$, range $=87.81-405.23 \mu \mathrm{g} / \mathrm{g}$ creatinine. High HPMA mean $=$ $940.12 \pm 693.73$, range $=424.03-4908.19 \mu \mathrm{g} / \mathrm{g}$ creatinine. Current, never, and former 
smokers based on self-report. Environmental smoke is secondhand smoke exposure in self-reported non-smokers. BMI = body mass index. FRS $=$ Framingham Risk Score. High FRS category has a FRS $\geq 20$ or experienced a cardiovascular event. $\mathrm{CABG}=$ coronary artery bypass graft. $\mathrm{PCI}=$ percutaneous coronary intervention. $\mathrm{ACE}=$ angiotensin-converting-enzyme. Age in years. Cotinine units $(\mathrm{ng} / \mathrm{mL})$. Fibrinogen units $(\mathrm{mg} / \mathrm{dL})$. HsCRP units $(\mathrm{mg} / \mathrm{L})$. Vasodilators included nitrates and hydralazine. Platelet mononuclear cells are the percent total of cells $\mathrm{CD}_{4} 1^{+} / 45^{+}$. Median household income in USD at the US Census block group level. $* *=$ significant at the 0.05 level. 


\begin{tabular}{|c|c|c|c|c|c|}
\hline Categorical Variable - n (\%) & $\begin{array}{l}\text { Total } \\
n=127\end{array}$ & $\begin{array}{l}\text { Low HPMA } \\
n=61\end{array}$ & $\begin{array}{l}\text { Medium HPMA } \\
n=48\end{array}$ & $\begin{array}{l}\text { High HPMA } \\
n=18\end{array}$ & p-value \\
\hline Gender & & & & & 0.739 \\
\hline Female & $59(46.5)$ & $30(49.2)$ & $22(45.8)$ & $7(38.9)$ & \\
\hline Male & $68(53.5)$ & $31(50.8)$ & $26(54.2)$ & $11(61.1)$ & \\
\hline Ethnicity & & & & & 0.061 \\
\hline Caucasian & $73(57.5)$ & $32(52.5)$ & $26(54.2)$ & $15(83.3)$ & \\
\hline African American & $51(40.2)$ & $27(44.3)$ & $22(45.8)$ & $2(11.1)$ & \\
\hline Hispanic & $3(2.4)$ & $2(3.3)$ & $0(0.0)$ & $1(5.6)$ & \\
\hline \multicolumn{6}{|l|}{ CVD Risk Factors } \\
\hline Hypertension & $103(81.7)$ & $53(86.9)$ & $37(78.7)$ & $13(72.2)$ & 0.292 \\
\hline Hyperlipidemia & $78(61.4)$ & $34(55.7)$ & $31(64.6)$ & $13(72.2)$ & 0.383 \\
\hline Diabetes & $40(31.5)$ & $15(24.6)$ & $20(41.7)$ & $5(27.8)$ & 0.152 \\
\hline $\mathrm{BMI} \geq 30$ & $74(59.7)$ & $40(67.8)$ & $28(59.6)$ & $6(33.3)$ & $0.033^{\star \star}$ \\
\hline Never smoked (self-reported) & $56(44.1)$ & $19(31.1)$ & $28(58.3)$ & $9(50.0)$ & $0.015^{\star \star}$ \\
\hline Former smoker (self-reported) & $71(55.9)$ & $42(68.9)$ & $20(41.7)$ & $9(50.0)$ & $0.015^{\star *}$ \\
\hline Environmental Smoke & $40(31.7)$ & $19(31.1)$ & $13(27.7)$ & $8(44.4)$ & 0.425 \\
\hline High FRS Category & $99(78.0)$ & $43(70.5)$ & $39(81.3)$ & $17(94.4)$ & 0.077 \\
\hline \multicolumn{6}{|l|}{ Medical History } \\
\hline Myocardial Infarction & $47(37.0)$ & $18(29.5)$ & $20(41.7)$ & $9(50.0)$ & 0.200 \\
\hline Stroke & $12(9.4)$ & $6(9.8)$ & $5(10.4)$ & $1(5.6)$ & 0.826 \\
\hline CABG/ PCl/ Stents & $33(26.0)$ & $13(21.3)$ & $13(27.1)$ & $7(38.9)$ & 0.320 \\
\hline Heart Failure & $25(20.0)$ & $10(16.4)$ & $12(25.5)$ & $3(17.6)$ & 0.483 \\
\hline \multicolumn{6}{|l|}{ Medication } \\
\hline ACE inhibitor & $68(55.3)$ & $30(51.7)$ & $30(62.5)$ & $8(47.1)$ & 0.412 \\
\hline Angiotensin-receptor blockers & $8(6.5)$ & $6(10.3)$ & $2(4.2)$ & $0(0.0)$ & 0.221 \\
\hline Beta-blocker & $79(64.2)$ & $33(56.9)$ & $32(66.7)$ & $14(82.4)$ & 0.141 \\
\hline Calcium-channel blockers & $30(24.4)$ & $16(27.6)$ & $10(20.8)$ & $4(23.5)$ & 0.720 \\
\hline Diuretics & $52(42.3)$ & $27(46.6)$ & $23(47.6)$ & $2(11.8)$ & $0.023^{\star *}$ \\
\hline Statins & $64(52.0)$ & $29(50.0)$ & $23(47.9)$ & $12(70.6)$ & 0.251 \\
\hline Aspirin & $71(57.7)$ & $33(56.9)$ & $27(56.3)$ & $11(64.7)$ & 0.819 \\
\hline Vasodilator & $27(22.0)$ & $9(15.5)$ & $12(25.0)$ & $6(35.3)$ & 0.180 \\
\hline Continuous Variable - mean (SD) & Total & Low HPMA & Medium HPMA & High HPMA & p-value \\
\hline Age & $53(10.7)$ & $54(11.4)$ & $51(9.9)$ & $54(10.6)$ & 0.450 \\
\hline Cotinine & $148(428.7)$ & $29(73.9)$ & $149(385.7)$ & $572(855)$ & $<0.001^{\star *}$ \\
\hline FRS & $6(6.4)$ & $7(6.5)$ & $3(2.2)$ & $14(12.0)$ & 0.116 \\
\hline Lymphocyte Count X $10^{4}$ & $14(9.6)$ & $12(7.9)$ & $14(9.7)$ & $17(13.1)$ & 0.164 \\
\hline \multicolumn{6}{|l|}{ Thrombosis } \\
\hline Fibrinogen & $345(111.7)$ & $339(95.6)$ & $363(139.4)$ & $320(75.1)$ & 0.329 \\
\hline Platelet Mononuclear Cell Aggregates & $11(5.6)$ & $10(5.4)$ & $11(5.9)$ & $11(5.3)$ & 0.637 \\
\hline \multicolumn{6}{|l|}{ Inflammation } \\
\hline hsCRP & $5(4.7)$ & $6(5.1)$ & $5(4.4)$ & $1(1.2)$ & $0.004^{\star \star}$ \\
\hline Median Household Income & $31687(20121)$ & 30787 (17573) & $31428(22878)$ & $35786(21392)$ & 0.711 \\
\hline
\end{tabular}

Table 8. Demographic comparison stratified by HPMA tertile in non-smokers. Low HPMA mean $=54.89 \pm 17.76$, range $=19.11-87.29 \mu \mathrm{g} / \mathrm{g}$ creatinine. Medium HPMA mean $=202.50 \pm 100.37$, range $=87.81-405.23 \mu \mathrm{g} / \mathrm{g}$ creatinine. High HPMA mean $=$ $940.12 \pm 693.73$, range $=424.03-4908.19 \mu \mathrm{g} / \mathrm{g}$ creatinine. Current, never, and former smokers based on self-report. Environmental smoke is secondhand smoke exposure in self-reported non-smokers. BMI = body mass index. FRS = Framingham Risk Score. High FRS category has a FRS $\geq 20$ or experienced a cardiovascular event. $\mathrm{CABG}=$ 
coronary artery bypass graft. $\mathrm{PCI}=$ percutaneous coronary intervention. $\mathrm{ACE}=$ angiotensin-converting-enzyme. Age in years. Cotinine units $(\mathrm{ng} / \mathrm{mL})$. Fibrinogen units $(\mathrm{mg} / \mathrm{dL})$. HsCRP units $(\mathrm{mg} / \mathrm{L})$. Vasodilators included nitrates and hydralazine. Platelet mononuclear cells are the percent total of cells $\mathrm{CD} 41^{+} / 45^{+}$. Median household income in USD at the US Census block group level. $* *=$ significant at the 0.05 level.

\begin{tabular}{|c|c|c|c|c|}
\hline Variable & $\begin{array}{l}\text { Low HPMA } \\
\text { Mean (SD) }\end{array}$ & $\begin{array}{l}\text { Medium HPMA } \\
\text { Mean (SD) }\end{array}$ & $\begin{array}{l}\text { High HPMA } \\
\text { Mean (SD) }\end{array}$ & p-value \\
\hline VPC-1 (CD $\left.31^{+} / 34^{+} / 45^{-}\right)$ & $0.792(0.926)$ & $0.889(1.414)$ & $0.812(1.005)$ & 0.903 \\
\hline VPC-2 $\left(C D 31^{+} / 34^{+} / 45^{+}\right)$ & $0.555(3.555)$ & $0.058(0.092)$ & $0.047(0.079)$ & $0.030^{* *}$ \\
\hline VPC-3 (CD31 $\left./ 34^{+} / 45^{-} / \mathrm{AC} 133^{+}\right)$ & $0.355(0.399)$ & $0.438(0.617)$ & $0.506(0.760)$ & 0.523 \\
\hline VPC-4 (CD31 $\left.+34^{+} / 45^{+} / \mathrm{AC} 133^{+}\right)$ & $0.010(0.028)$ & $0.004(0.007)$ & $0.004(0.011)$ & 0.599 \\
\hline VPC-5 (CD $\left.31^{+} / A C 133^{+}\right)$ & $2.697(7.521)$ & $1.265(1.548)$ & $0.983(1.019)$ & 0.224 \\
\hline VPC-6 $\left(C D 31^{+} / 34^{+}\right)$ & $1.910(6.480)$ & $1.173(1.630)$ & $1.038(1.275)$ & 0.546 \\
\hline VPC-7 (CD31+/34+/45-IAC133-) & $0.437(0.778)$ & $0.451(1.164)$ & $0.306(0.276)$ & 0.809 \\
\hline VPC-8 (CD31 $\left.+/ 34^{+} / 45^{+} / A C 133^{-}\right)$ & $0.545(3.530)$ & $0.054(0.087)$ & $0.043(0.074)$ & $0.035^{\star \star}$ \\
\hline VPC-9 (CD34 $)$ & $2.267(7.971)$ & $1.324(2.201)$ & $1.079(1.271)$ & 0.254 \\
\hline VPC-10 (CD31 $\left.{ }^{+}\right)$ & $215.4(182.1)$ & $210.7(151.4)$ & $254.5(311.7)$ & 0.843 \\
\hline VPC-11 (AC133) & $3.200(8.057)$ & $1.539(1.963)$ & $1.180(1.201)$ & 0.287 \\
\hline VPC-12 (CD45 $)$ & $376.9(315.1)$ & $421.3(425.6)$ & $505.9(623.8)$ & 0.541 \\
\hline VPC-13 (CD $\left.34^{+} / \mathrm{AC} 133^{+}\right)$ & $0.407(0.412)$ & $0.473(0.632)$ & $0.478(0.709)$ & 0.905 \\
\hline VPC-14 (CD34 $\left.{ }^{+} / 45^{+} / \mathrm{AC} 133^{+}\right)$ & $0.009(0.021)$ & $0.002(0.008)$ & $0.002(0.007)$ & 0.195 \\
\hline VPC-15 (CD34 $\left.{ }^{+} / 45^{-} / \mathrm{AC} 133^{+}\right)$ & $0.342(0.396)$ & $0.411(0.601)$ & $0.448(0.708)$ & 0.381 \\
\hline
\end{tabular}

Table 9. Comparison of VPC levels among HPMA tertiles. VPC counts per $\mu \mathrm{L}$ sample. $* *=$ significant at the 0.05 level. 


\begin{tabular}{|c|c|c|c|c|}
\hline Variable & $\begin{array}{l}\text { Low HPMA } \\
\text { Mean (SD) }\end{array}$ & $\begin{array}{l}\text { Medium HPMA } \\
\text { Mean (SD) }\end{array}$ & $\begin{array}{l}\text { High HPMA } \\
\text { Mean (SD) }\end{array}$ & p-value \\
\hline VPC-1 (CD31+/34+/45-) & $0.794(0.934)$ & $1.01(1.656)$ & $0.903(0.976)$ & 0.854 \\
\hline VPC-2 (CD31+ $\left./ 34^{+} / 45^{+}\right)$ & $0.633(3.834)$ & $0.044(0.080)$ & $0.034(0.048)$ & 0.101 \\
\hline VPC-3 (CD31+/34 $\left./ 45-/ A C 133^{+}\right)$ & $0.338(0.386)$ & $0.466(0.701)$ & $0.561(0.708)$ & 0.556 \\
\hline VPC-4 (CD $\left.31^{+} / 34^{+} / 45^{+} / \mathrm{AC} 133^{+}\right)$ & $0.009(0.028)$ & $0.002(0.005)$ & $0.004(0.009)$ & 0.317 \\
\hline VPC-5 (CD31+/AC133 $\left.{ }^{+}\right)$ & $2.866(8.082)$ & $0.993(1.092)$ & $1.208(0.908)$ & 0.225 \\
\hline VPC-6 (CD31+/34+) & $2.056(6.974)$ & $1.241(1.908)$ & $1.101(1.134)$ & 0.312 \\
\hline VPC-7 (CD $\left.31^{+} / 34^{+} / 45-/ A C 133^{-}\right)$ & $0.456(0.820)$ & $0.545(1.385)$ & $0.341(0.296)$ & 0.806 \\
\hline VPC-8 (CD31+/34+/45+/AC133-) & $0.624(3.807)$ & $0.041(0.076)$ & $0.030(0.040)$ & 0.111 \\
\hline VPC-9 (CD34 $\left.{ }^{+}\right)$ & $2.470(8.580)$ & $1.413(2.600)$ & $1.110(1.140)$ & 0.106 \\
\hline VPC-10 (CD31+) & $217.4(180.1)$ & $218.0(164.5)$ & $197.6(156.7)$ & 0.539 \\
\hline VPC-11 (AC133+) & $2.933(8.044)$ & $1.247(1.576)$ & $1.511(1.305)$ & 0.350 \\
\hline VPC-12 (CD45+) & $396.0(324.7)$ & $434.4(416.2)$ & $449.3(410.6)$ & 0.465 \\
\hline VPC-13 (CD34+/AC133+) & $0.389(0.393)$ & $0.487(0.717)$ & $0.434(0.428)$ & 0.762 \\
\hline VPC-14 (CD $\left.34^{+} / 45^{+} / \mathrm{AC} 133^{+}\right)$ & $0.007(0.017)$ & $0.001(0.003)$ & $0.001(0.005)$ & 0.389 \\
\hline VPC-15 (CD34+/45-IAC $\left.133^{+}\right)$ & $0.328(0.392)$ & $0.448(0.691)$ & $0.397(0.416)$ & 0.704 \\
\hline
\end{tabular}

Table 10. Comparison of VPC levels among HPMA tertiles in non-smokers. VPC counts per $\mu \mathrm{L}$ sample. $* *=$ significant at the 0.05 level. 
A

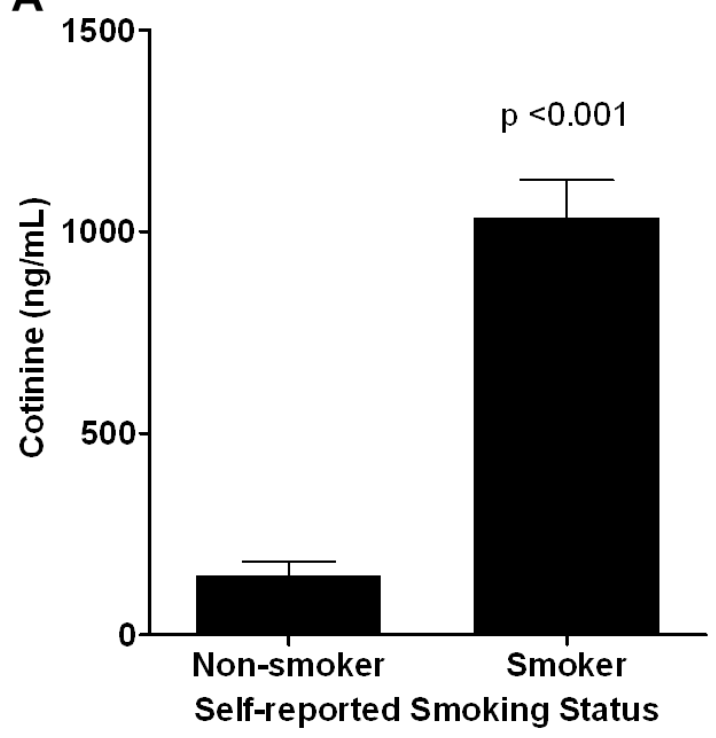

B

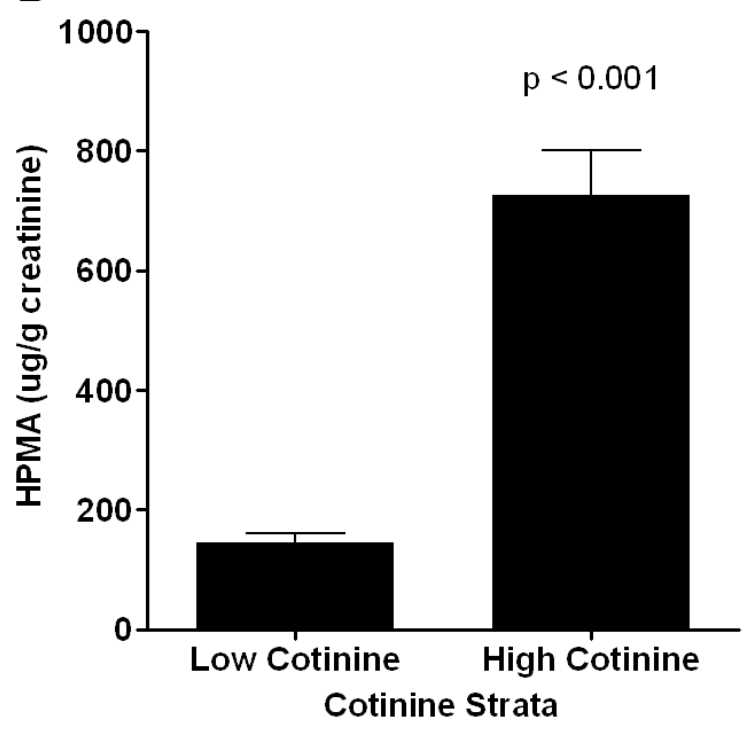

C

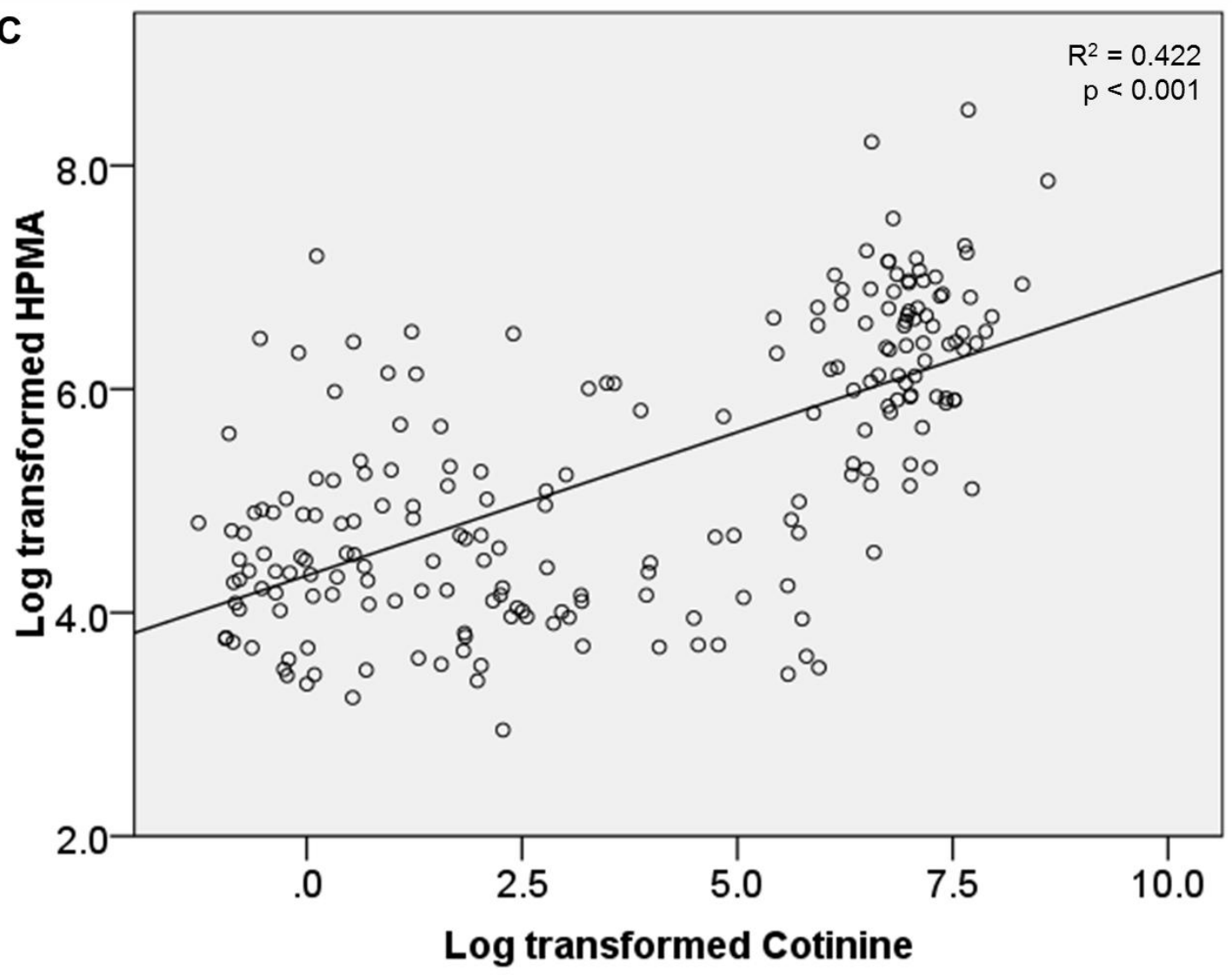

Figure 6. Association between HPMA and smoking.

(A) Mean cotinine for self-reported non-smokers was $145.26 \pm 37.78$ and $1033.79 \pm$ $93.84 \mathrm{ng} / \mathrm{mL}$ for smokers. (B) Mean HPMA levels for low $(<200 \mathrm{ng} / \mathrm{mL})$ and high $(\geq 200$ $\mathrm{ng} / \mathrm{mL}$ ) cotinine strata were $144.93 \pm 16.40$ and $726.49 \pm 74.61 \mathrm{ug} / \mathrm{g}$ creatinine, respectively. (C) HPMA regressed against cotinine levels. 
A

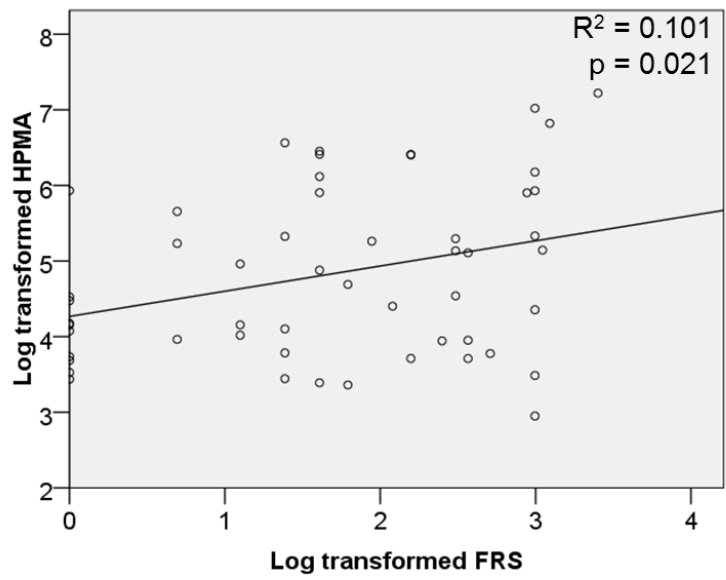

C

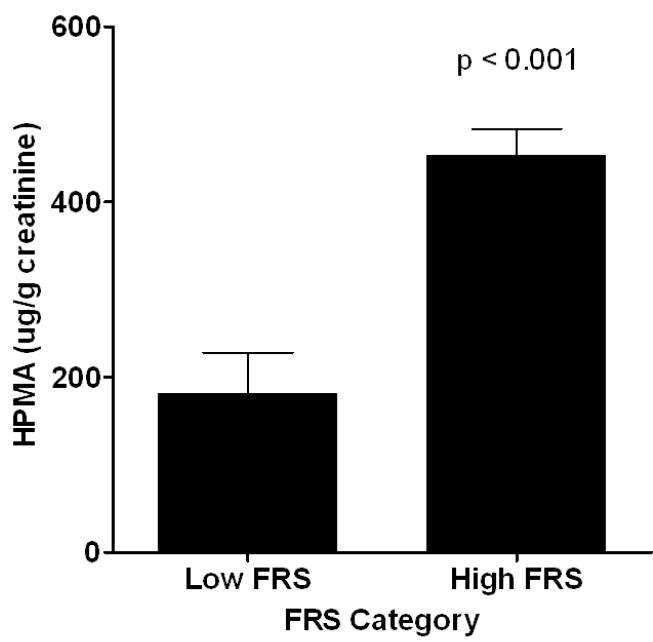

B

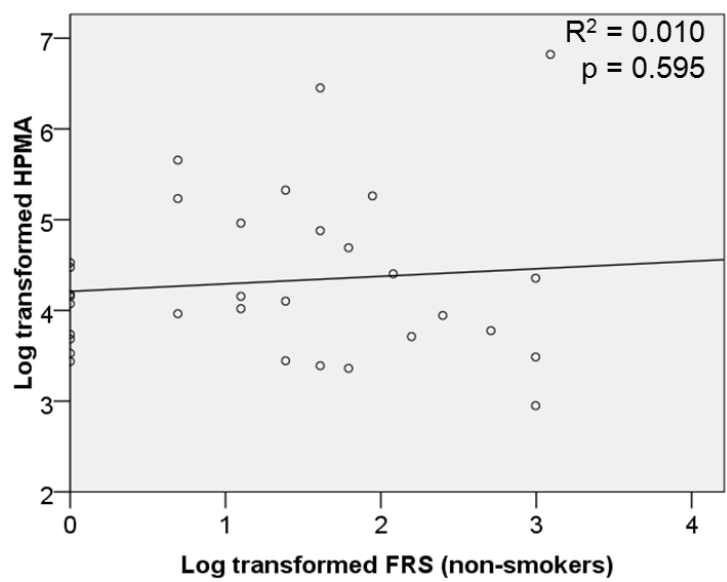

D

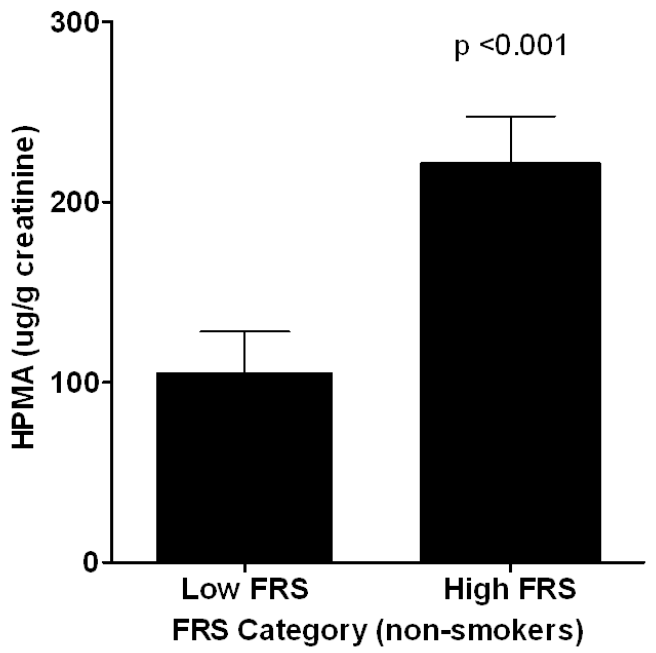

Figure 7. Association between HPMA and the FRS.

A) Scatterplot of HPMA and FRS. (B) Scatterplot of HPMA and FRS in self-reported non-smokers. (C) Mean HPMA levels for low (FRS $<20$ ) and high $(F R S \geq 20$ ) or experienced a cardiovascular event FRS category were $181.45 \pm 46.74$ and $453.73 \pm$ $30.04 \mu \mathrm{g} / \mathrm{g}$ creatinine, respectively. (D) Mean HPMA levels for low and high FRS categories in self-reported non-smokers were $105.16 \pm 23.04$ and $220.87 \pm 26.69 \mu \mathrm{g} / \mathrm{g}$ creatinine, respectively. 


\begin{tabular}{|c|c|c|}
\hline Variable & $\beta$ & p-value \\
\hline VPC-2 $\left(C D 31^{+} / 34^{+} / 45^{+}\right)$ & -0.002 & $<0.001$ \\
\hline VPC-8 (CD $\left.31^{+} / 34^{+} / 45^{+} / A C 133^{-}\right)$ & -0.002 & $<0.001$ \\
\hline VPC-11 (AC133+) & -0.001 & 0.046 \\
\hline VPC-14 (CD $\left.34^{+} / 45^{+} / \mathrm{AC}^{2} 133^{+}\right)$ & -0.002 & 0.029 \\
\hline Platelet Mononuclear Cell Aggregates (CD41 ${ }^{+} / \mathrm{CD}^{2} 5^{+}$) & 0.003 & 0.030 \\
\hline FRS & 0.012 & $<0.001$ \\
\hline FRS Category & -0.003 & 0.002 \\
\hline
\end{tabular}

Table 11. Adjusted association between HPMA and CVD Risk.

Models were adjusted for age, gender, ethnicity, cotinine, alcohol, BMI, hypertension, diabetes, and diuretics. FRS = Framingham Risk Score. GLMs that assessed VPCs as the dependent variable utilized the gamma probability distribution and the log link function. GLMs for platelet mononuclear cell aggregates and the FRS were assessed using normal probability distribution and the identity link function. The GLM for FRS category was analyzed using the binomial distribution. The FRS and FRS Category were only adjusted for ethnicity, alcohol, and BMI.

\begin{tabular}{|c|c|c|}
\hline Variable & $\beta$ & p-value \\
\hline VPC-2 (CD31+ $\left./ 34^{+} / 45^{+}\right)$ & -0.003 & $<0.001$ \\
\hline VPC-8 (CD31 $\left./ 34^{+} / 45^{+} / \mathrm{AC} 133^{-}\right)$ & -0.003 & $<0.001$ \\
\hline VPC-9 (CD34 $\left.{ }^{+}\right)$ & -0.001 & 0.024 \\
\hline VPC-11 (AC133+) & $<0.001$ & 0.793 \\
\hline VPC-14 (CD34 $\left.4^{+} / 45^{+} / \mathrm{AC} 133^{+}\right)$ & -0.011 & 0.001 \\
\hline Platelet Mononuclear Cell Aggregates (CD41 $\left.{ }^{+} / \mathrm{CD} 45^{+}\right)$ & 0.004 & 0.245 \\
\hline FRS & 0.010 & 0.097 \\
\hline FRS Category & -0.004 & 0.069 \\
\hline
\end{tabular}

Table 12. Adjusted association between HPMA and CVD Risk in non-smokers. Models were adjusted for age, gender, ethnicity, cotinine, alcohol, BMI, hypertension, diabetes, and diuretics in self-reported non-smokers. FRS = Framingham Risk Score. GLMs that assessed VPCs as the dependent variable utilized the gamma probability distribution and the log link function. GLMs for platelet mononuclear cell aggregates and the FRS were assessed using normal probability distribution and the identity link function. The GLM for FRS category was analyzed using the binomial distribution. The FRS and FRS Category were only adjusted for ethnicity, alcohol, and BMI. 


\section{CHAPTER III}

\section{The Association of Residential Proximity to Roadway with Circulating Vascular Progenitor Cell Levels}

\section{Introduction}

Cardiovascular disease (CVD) is the top cause of death in the United States, responsible for 1 in every 3 deaths ${ }^{1}$. Vascular progenitor cells (VPCs) are suspected to be a sensitive indicator of vascular health. Several investigators have reported that decreased levels of circulating VPCs, cells that participate in vascular upkeep and repair, are inversely associated with increased CVD risk ${ }^{63,65,69}$, severity ${ }^{66,71-73}$, and mortality ${ }^{74}$. Growing evidence of the associations between particulate matter exposure and CVD risk led to a scientific statement from the American Heart Association indicating that air pollution exposure should be considered a modifiable risk factor for CVD ${ }^{32}$. It has been recently shown that exposure to elevated levels of vehicular exhaust pollutants, including fine particulate matter in healthy young adults ${ }^{30}$ and acrolein in mice ${ }^{51}$, were associated with decreased circulating VPC levels. Therefore, the association between traffic pollution exposure and VPC levels should be explored, particularly in a susceptible population of adults at increased risk for CVD.

Traffic emissions include a mixture of particulate, gaseous, and volatile pollutants. It is assumed that people living closer to major roadways bear more exposure to these emissions. Epidemiological research indicates that living in close proximity to a major roadway, a common measure used to indicate traffic pollution exposure, is 
associated with increased risk of CVD and CVD mortality. Close proximity to roadways has been associated with increased coronary heart disease mortality ${ }^{37,106,107}$, myocardial infarction ${ }^{38,108}$, heart failure ${ }^{109}$, deep vein thrombosis ${ }^{110}$, and stroke mortality ${ }^{111}$. Creactive protein (CRP), a clinical risk indicator, is positively associated with traffic density ${ }^{112}$. In addition, inverse associations have been determined between roadway proximity and sub-clinical risk including coronary artery calcification ${ }^{39}$ and oxidized low-density lipoprotein (LDL) ${ }^{113}$. Investigation of the association between traffic pollution exposure and vascular outcomes at the cellular level may provide a greater understanding of the environment's role in cardiovascular disease risk.

Multiple studies have confirmed that traffic pollutants decrease in quantity as distance to roadway increases. Roorda-Knape et al. demonstrated that black smoke and $\mathrm{NO}_{2}$ background levels are reached at $300 \mathrm{~m}$ of a roadway carrying a mean of $80,000-$ 152,000 vehicles/day ${ }^{114}$. Zhu et al. 2002 reported that $\mathrm{CO}$ and particulate matter (PM) background concentrations were reached at $150 \mathrm{~m}$ of a freeway with a mean of 13,900 vehicles/hour ${ }^{115}$. A meta-analysis determined that background concentrations are reached at $100-400 \mathrm{~m}$ for $\mathrm{PM}, 200-500 \mathrm{~m}$ for $\mathrm{NO}_{2}$, and $100-300 \mathrm{~m}$ for ultrafine particulate matter (UPM) from mobile sources ${ }^{116}$. Studies finding associations between roadway proximity and adverse cardiovascular outcomes generally consider people to be exposed within: $100 \mathrm{~m}$ of a limited-access highway or multilane highway ${ }^{108} ; 300 \mathrm{~m}$ of an interstate, state highway, or major arterial ${ }^{106}$; and $50 \mathrm{~m}$ of major arterial and $100 \mathrm{~m}$ of an interstate or state highway ${ }^{117}$. Our investigation provides a missing link in by examining associations within close proximity to a major roadway that carries a moderate mean number of vehicles per day (5000). We consider people within 50m of the roadway to be exposed. 
While a substantial body of research has established that living in close proximity to a major roadway is associated with increased CVD morbidity and mortality, the impact of exposure to traffic pollution on VPC levels has not been assessed. Our objective was to investigate the association between residential proximity to a roadway and VPC levels as a measure of CVD risk. We hypothesized that residential proximity to roadway is associated with VPC levels in a population at increased risk for CVD. Residential addresses were geocoded to determine distance to roadway in a population of individuals at increased risk for CVD. VPC levels for 15 different antigenically-defined VPC populations were measured by flow cytometry to determine associations with residential proximity to a major roadway. This investigation evaluated the established association between roadway proximity and CVD risk through investigation of VPC levels, a novel assessment.

\section{Methods}

\section{Study Population}

See Overall Methods (Study Population).

\section{Case Definition}

See Overall Methods (Case Definition).

\section{Questionnaire}

See Overall Methods (Questionnaire).

\section{Biological Sample Collection and Processing}

See Overall Methods (Biological Sample Collection and Processing).

\section{VPC Quantification}

See Overall Methods (VPC Quantification). 


\section{Platelet Mononuclear Cell Aggregate Identification}

See Overall Methods (Platelet Mononuclear Cell Aggregate Identification).

\section{Residential Proximity to Roadway}

Residential addresses of study participants were provided during the patient interview questionnaire or through the review of medical records. Distance to roadway measurements were carried out using Geographic Information System (GIS) ArcMap 9.3 (ESRI, Redlands, CA). Data for geocoding addresses was provided by the Louisville/Jefferson County Information Consortium (LOJIC) composite locator in ArcGIS. Subject addresses were first examined for flaws including spelling errors, invalid characters, and invalid format, etc. Addresses that could not be geocoded were cross-referenced with other known addresses, or attempts were made to manually place the points. The records were examined for duplicates, which were most often apartments, condominiums, and mobile home communities. We examined aerial imagery and excluded records where the geocoded point was not at the residential location; many of these were mobile home communities or postal office boxes. Road vehicle counts were provided by the Kentucky Transportation Cabinet. Major roadway was defined as a road carrying an annual mean of 5,000 or more vehicles/day. Roadway proximity was entered into the statistical model as dichotomous data indicating living within $50 \mathrm{~m}$ of a major roadway. Socioeconomic status (SES), estimated using the proxy variable "median household income," was provided at the block group level from the 2000 U.S. Census. "Residential duration", which indicates the length of time the home was owned by the current owner, was also included in the model. These housing records were available through the Jefferson County, KY Property Valuation Administrator via LOJIC. The final 
model only included the population that had a residential duration at their current home of at least 6 months.

\section{$\mathbf{P M}_{2.5}$ Estimation}

Fine particulate matter (particulate matter with an aerodynamic diameter less than $2.5 \mu \mathrm{m} ; \mathrm{PM}_{2.5}$ ) levels are collected hourly at 5 ambient monitoring stations within Jefferson County, KY. $\mathrm{PM}_{2.5}$ values were assigned by zip codes of the Healthy Heart Study participants. The $\mathrm{PM}_{2.5}$ monitor closest to the residential zip code was assigned to each participant. The hourly levels were averaged over 1 day prior to the sample collection.

\section{Statistical Analysis}

Independent samples t-tests (for normally distributed continuous variables), Wilcoxon methods (for non-normal continuous variables) and chi-square analysis (for categorical or dichotomous variables) were used to test for differences in the dichotomized version of the distance to a major roadway variable among gender, ethnicity, smoking status, CVD risk, CVD history, age, and median household income within the study population.

Initially, independent sample t-test techniques were used to test for bivariate associations between the dichotomized version of distance to roadway and VPC levels,

markers of thrombosis (platelet mononuclear cell aggregates and fibrinogen), markers of inflammation (hsCRP), the sum of risk factors (age $\geq 40$ years, male gender, hypertension, hyperlipidemia, diabetes, and current smoking), and the Framingham Risk Score (FRS). VPCs were log-transformed $* 1000$ for normality in the t-test analysis, and the significance is reported. The mean cell levels, normalized to sample volume, are 
presented in the results, consistent with the literature. The factors that were significantly associated with distance to roadway in the bivariate analysis were entered into the adjusted regression model below.

Generalized Linear Modeling (GLM) techniques were used to examine whether the VPC values were associated with distance to a major roadway, adjusting for age, gender, body mass index (BMI), cigarette smoking, median household income (SES), and 24-hour average $\mathrm{PM}_{2.5}$. Only the population with a residential duration of at least 6 months was included in the final analysis to control for exposure misclassification. GLM models that assessed VPCs as the dependent variable utilized the gamma probability distribution and the log link function. GLMs that assessed the sum of risk factors utilized the normal probability distribution and the identity link function. Traditional model-fit statistics (log-likelihood) were used to develop the most parsimonious model. In addition we tested whether higher order modeling (e.g., exponential, cubic) improved model-fit using traditional model-fit statistics (AIC, log-likelihood, etc.).

\section{Results}

\section{Participant Characteristics}

The sample population was middle-aged ( $51 \pm 10$ years old), majority male $(n=110,54.2 \%)$, Caucasian $(n=106,52.2 \%)$ and was either a current smoker $(n=78$, $38.8 \%)$ or former smoker $(n=67,33.2 \%)$. A majority of the sample population had hypertension $(n=162,81.4 \%)$; hyperlipidemia $(n=126,63.6 \%)$; were obese $(B M I \geq 30$, $\mathrm{n}=118,59.6 \%)$; and using angiotensin-converting-enzyme (ACE) inhibitors $(\mathrm{n}=111$, $55.5 \%)$, beta-blockers $(n=127,63.5 \%)$, and statins $(n=101,50.5 \%)($ Table 13$)$. We successfully geocoded $n=203,84.6 \%$ of the patient addresses. 


\section{Participant Characteristics of the Population with a Residential Proximity of 6}

\section{Months}

The non-smoking sample population was middle-aged (52 years old), a majority male $(n=57,57 \%)$, Caucasian $(n=53,53.0 \%)$ and was either a current smoker $(n=38$, $38 \%)$ or former smoker $(n=37,37 \%)$. A majority of the sample population had hypertension $(n=84,84.8 \%)$; hyperlipidemia $(n=66,68 \%)$; were obese $(B M I \geq 30, n=61$, $62.9 \%)$; and using angiotensin-converting-enzyme (ACE) inhibitors $(n=57,57.6 \%)$, betablockers $(n=72,72.7 \%)$, and statins $(n=61,61.6 \%)$ (Table 14). Patients with cancer were excluded from the analysis $(n=6)$.

\section{Geographic Distribution}

The geographic distribution of Healthy Heart Study participants in Jefferson County. KY is shown in Figure 8. The patients are largely concentrated in the northwestern region of Jefferson County known as West Louisville. It is also well known that this area suffers disproportionately from cardiovascular disease and air pollution exposure.

\section{Demographic Comparison}

Differences between the characteristics of the population living within $50 \mathrm{~m}$ of a major roadway were compared to people living more than $50 \mathrm{~m}$ from a major roadway are shown in Table 13. There were no significant differences between distance from a major road and the following factors: age, gender, ethnicity, hypertension, hyperlipidemia, diabetes mellitus, obesity, environmental tobacco smoke exposure, empirical smoke exposure (cotinine), myocardial infarction, stroke, coronary artery bypass graft (CABG)/ percutaneous coronary intervention (PCI)/ or stents, heart failure, or medication use. 
People within 50m of a major road were more likely to self-report being a current smoker (53.8\% vs. $35.2 \%, \mathrm{p}=0.043)$ and less likely to report having never smoked (12.8\% vs. $31.5 \%, \mathrm{p}=0.027)$. People with closer roadway proximity also had significantly higher lymphocyte counts $(167,394$ vs. $121,368, p=0.033)$ and significantly lower incomes (\$23,560 vs. $\$ 32,944, \mathrm{p}=0.002)$.

\section{Demographic Comparison of the Population with a Residential Proximity of 6}

\section{Months}

Differences between the characteristics of the population that lived within $50 \mathrm{~m}$ of a major roadway were compared to people that lived more than $50 \mathrm{~m}$ from a major roadway are shown in Table 14 . People within $50 \mathrm{~m}$ of a major road were more likely to self-report being a current smoker $(71.4 \%$ vs. $32.6 \%, \mathrm{p}=0.008)$, less likely to report having never smoked (0.0\% vs.29.1\%, p=0.019), and more likely to have a higher mean cotinine $(1,059 \pm 1,136 . \mathrm{vs} .456 \pm 870 \mathrm{ng} / \mathrm{mL}, \mathrm{p}=0.037)$. Heart failure patients were significantly less likely to live near a major road $(0.0 \%$ vs. $24.4 \%, \mathrm{p}=0.037)$. People that lived in close proximity to a major road also had significantly lower incomes $(\$ 23,595 \pm$ $\$ 6,900$ vs. $\$ 34,457 \pm \$ 19,277, \mathrm{p}=0.040)$.

\section{Association between VPCs and CVD Risk with Distance to Roadway}

Results of the independent-sample t-test comparison between dichotomized distance to roadway and VPC levels, markers of thrombosis (platelet mononuclear cell aggregates and fibrinogen), markers of inflammation (hsCRP), and CVD risk scores are shown in Table 15. VPC-4 $\left(\left(\mathrm{CD} 31^{+} / 34^{+} / 45^{+} / \mathrm{AC} 133^{+}\right) ; \mathrm{p}=0.047\right)$, VPC-5

$\left(\left(\mathrm{CD} 31^{+} / \mathrm{AC} 133^{+}\right), \mathrm{p}=0.007\right), \mathrm{VPC}-11\left(\left(\mathrm{AC} 133^{+}\right), \mathrm{p}=0.013\right)$, and $\mathrm{VPC}-14$ $\left(\left(\mathrm{CD} 34^{+} / 45^{+} / \mathrm{AC} 133^{+}\right), \mathrm{p}=0.030\right)$ were significantly associated with distance to roadway; 
these VPC levels were higher in the population that lived closer to a major roadway. The sum of CVD risk factors was inversely associated with residential proximity to roadway $(\mathrm{p}=0.017)$

\section{Association between VPCs and CVD Risk with Distance to Roadway in the Population with a Residential Proximity of 6 Months}

Results of the independent-sample t-test comparison between dichotomized distance to roadway and VPC levels, markers of thrombosis (platelet mononuclear cell aggregates and fibrinogen), markers of inflammation (hsCRP), and CVD risk scores are

shown in Table 16. There was no significant association between distance to roadway and VPC levels, thrombosis, inflammation, or CVD risk in the population with a 6 month residential duration.

\section{Adjusted Association of VPCs and Distance to Roadway for the Total Population}

The adjusted GLM results of VPCs and distance to roadway are shown in Table 17. The associations were adjusted for age, gender, BMI, cigarette smoking, median household income, and 24-hour $\mathrm{PM}_{2.5}$. VPC-5 $\left(\left(\mathrm{CD} 31^{+} / \mathrm{AC} 133^{+}\right), \beta=-0.648, \mathrm{p}=0.003\right)$, $\mathrm{VPC}-11\left(\left(\mathrm{AC} 133^{+}\right), \beta=-0.469, \mathrm{p}=0.033\right)$, and VPC-14 $\left(\left(\mathrm{CD} 34^{+} / 45^{+} / \mathrm{AC} 133^{+}\right), \beta=-1.138\right.$, $\mathrm{p}=0.018$ ) were significantly associated with distance to roadway. VPC levels in these populations were higher in the population that lived closer to a major roadway, as inferred from a negative regression coefficient. VPC-4 $\left(\left(\mathrm{CD} 31^{+} / 34^{+} / 45^{+} / \mathrm{AC} 133^{+}\right), \beta=-\right.$ 0.611, $\mathrm{p}=0.083$ ) was not significantly associated with distance to roadway. The sum of CVD risk factors was inversely associated with residential proximity to roadway $(\beta=-$ 0.517, $\mathrm{p}=0.021$ ), after adjustment for BMI, median household income, and 24-hour $\mathrm{PM}_{2.5}$ (not age, gender, smoking which are risk factors themselves). 


\section{Adjusted Association of VPCs and Distance to Roadway in the Population with a Residential Proximity of 6 Months}

As previously described, only the population with a residential duration of at least 6 months was included in the final analysis. The adjusted GLM results of VPCs and distance to roadway among individuals who resided in their homes for at least 6 months are shown in Table 18. The associations were adjusted for age, gender, BMI, cigarette smoking, median household income, and 24-hour $\mathrm{PM}_{2.5}$. Patients with cancer were excluded from the analysis. Among the population with a residential duration of at least 6 months $(\mathrm{n}=80), \mathrm{VPC}-4\left(\left(\mathrm{CD} 31^{+} / 34^{+} / 45^{+} / \mathrm{AC} 133^{+}\right), \beta=-1.333, \mathrm{p}=0.005\right), \mathrm{VPC}-5$ $\left(\left(\mathrm{CD} 31^{+} / \mathrm{AC} 133^{+}\right), \beta=-0.835, \mathrm{p}=0.015\right)$, and $\mathrm{VPC}-14\left(\left(\mathrm{CD} 34^{+} / 45^{+} / \mathrm{AC} 133^{+}\right), \beta=-1.037\right.$, $\mathrm{p}=0.015$ ) remained significantly associated with distance to roadway. VPC levels in these populations were higher in the population that lived closer to a major roadway. VPC$11\left(\left(\mathrm{AC} 133^{+}\right), \beta=-0.588, \mathrm{p}=0.130\right)$, and the sum of CVD risk factors $(\beta=-0.687, \mathrm{p}=0.070$ (only adjusted for BMI, median household income, and 24-hour $\mathrm{PM}_{2.5}$ (not adjusted for age, gender, smoking which are risk factors themselves))) were no longer significantly associated with distance to roadway when stratifying by residential duration of at least 6 months. These results held consistent when the model was adjusted for residential duration as a continuous variable, residential duration was entered as a dichotomous variable for 1 year residency, or stratified to include only the population with a residential duration of 1 year or more.

\section{Discussion}

Multiple investigators have reported inverse associations between residential proximity to roadways and CVD risk. However, the association between residential 
proximity to a major roadway and VPC levels has not been investigated. Among a panel of 15 antigenically defined VPCs, we found that VPC-4 (CD31 $\left.1^{+} / 34^{+} / 45^{+} / \mathrm{AC} 133^{+}\right)$, VPC$5\left(\mathrm{CD} 31^{+} / \mathrm{AC} 133^{+}\right), \mathrm{VPC}-11\left(\mathrm{AC} 133^{+}\right), \mathrm{VPC}-14\left(\mathrm{CD} 34^{+} / 45^{+} / \mathrm{AC} 133^{+}\right)$, and the sum of CVD risk factors were significantly higher in the population living in close proximity to a major roadway. In the adjusted analysis of the population with 6-month residency at their current home, VPC-4, VPC-5, and VPC-14 remained significantly higher in the population residing closer to the roadway.

The results of the current study demonstrated that individuals that lived closer to the roadway had a higher number of CVD risk factors. This is consistent with previous studies which determined that individuals in close residential proximity to major roads have higher CVD risk ${ }^{37,38,106-108}$. Moreover, the aforementioned result remained after adjustment for $\mathrm{PM}_{2.5}$, but not after stratification for 6 month residential duration. This suggests that CVD risk is associated with roadway proximity, independent of $\mathrm{PM}_{2.5}$ level.

These results regarding VPC increases with decreased road proximity are biologically plausible. It has been demonstrated that inhalation of $\mathrm{PM}_{2.5}$ may cause pulmonary oxidative stress and inflammation, autonomic nervous system imbalance, and hemodynamic imbalances ${ }^{32,118}$. Each of these pathways causes vascular outcomes that may result in mobilization of early progenitors (following acute exposure) or possibly depletion of VPCs after prolonged exposure. Our findings suggest that the associations with distance to roadway and VPCs are mostly seen in cells that are $\mathrm{AC} 33^{+}$, the early stem marker. This could indicate that with a population at risk for CVD, living closer to the roadway leads to mobilization of early VPCs, possibly as a protective mechanism against environmental insults. 
VPC levels increase following a vascular insult. They are mobilized into circulation to the site of injury to achieve their role in vascular repair. Faidini et al. described that as atherosclerosis progresses to an event in low risk populations, VPCs are mobilized into circulation, but this action can be limited in high risk populations where VPCs have been depleted ${ }^{80}$. Furthermore, as the number of risk factors increase, it is more likely that individuals are being treated for primary prevention of CVD through statins which increase VPC levels ${ }^{64,81,87,88}$ and VPC mobilization. ${ }^{89-91}$.

Although we determined that VPC levels are significantly increased in the population living in closer proximity to a major roadway, the adjusted regression model did find that $\mathrm{PM}_{2.5}$ was inversely associated with VPC levels in the population with 6 month residency (cancer patients excluded), adjusted for age, gender, smoking, BMI, SES, and distance to a major roadway. VPC-5 ( $\beta=-0.048, p=0.009)$, VPC-11 $(\beta=-0.063$, $\mathrm{p}=0.003)$, VPC-14 $(\beta=-0.062, \mathrm{p}=0.047)$ were inversely associated with $\mathrm{PM}_{2.5}$. O'Toole et al. also determined that VPC levels were inversely associated with $\mathrm{PM}_{2.5}$ exposure during temperature inversions in Provo, $\mathrm{UT}^{30}$. While the current population was relatively unhealthy in terms of CVD risk, the population in the study by O'Toole et al. was comprised of healthy collegiate athletes. The current study demonstrated VPC decreases associated just as the O'Toole et al. investigation. However, the current study was able to determine this with lower $\mathrm{PM}_{2.5}$ exposure levels. This suggests that even at lower $\mathrm{PM}_{2.5}$ exposure levels, there are still detectable VPC reductions.

Among the strengths of our study include the large study population. The range of CVD risk factors within our study population make it a diverse group to study. Additionally, our study includes multiple phenotypically distinct VPC populations to 
understand which populations are associated with distance to roadway. We were able to account for potential confounding by measuring cotinine levels, the primary urine nicotine metabolite, in addition to collecting data on self-reported smoking. Cancer patients were excluded from the final analysis because VPCs are recruited in tumor angiogenesis ${ }^{75-77}$, which may increase VPC levels (we did not find significantly different associations when including or excluding cancer patients in the final analysis). Including the residential duration in our sub-analysis allowed additional benefit in our understanding of VPC associations with road proximity because it allowed for reduced exposure misclassification in the population that had not resided at their homes for a long-term duration.

One important limitation includes not accounting for some potential confounders in traffic exposure, including traffic noise, which has been associated with higher blood pressure $^{119}$ and increased risk of adverse cardiovascular outcomes ${ }^{120,121}$. It is also associated with distance to roadway; therefore, it is an important factor to consider in roadway proximity studies. Additionally, land use and tree cover, factors that can mediate or exacerbate traffic pollution exposure, were also not accounted for in the current study. Moreover, $\mathrm{PM}_{2.5}$ exposures were assigned by zip code, rather than inverse distance weighting or other interpolation methods. The use of road proximity as an indicator of exposure to traffic pollutants assumes that study participants spend much of their time at home. Therefore, it does not account for the duration of time individuals spend outside their home and road proximity during other activities. There was also no account for time spent in vehicles or participation in traffic, which has been associated with increased cardiovascular risk ${ }^{35}$. Socioeconomic status (SES) is an important consideration in 
cardiovascular research because of its association with adverse cardiovascular risk. The foremost measure of SES is maternal education, which was not assessed in the study questionnaire. We assessed median household income for the Census block group of the participant's residential address to approximate SES. The duration of home ownership was helpful to account for exposure misclassification; however, we were unable to account for the population that rents property because that variable was not included in our study questionnaire. Additional limitations include the study design: a cross-sectional analysis of a convenience sample recruited from cardiology clinics. Therefore, the findings represent the CVD risk population in Louisville, KY and cannot be extrapolated to represent the general population, even in Louisville, KY.

Future directions from this research should involve the inclusion of a CVD-free control population. More detailed information on residential address history and duration would be helpful to define exposures and inclusion of multiple study sites would be beneficial in understanding the differences between roads with higher or lower mean annual vehicles. Additionally, research into the mechanism by which traffic pollution exposure influences circulating VPC levels is needed. Determining which component of vehicular traffic pollution influences circulating VPC levels might also broaden our understanding of how the environment contributes to CVD.

\section{Conclusions}

The sum of CVD risk factors along with VPC-4 $\left(\mathrm{CD} 31^{+} / 34^{+} / 45^{+} / \mathrm{AC} 133^{+}\right)$, VPC-5 $\left(\mathrm{CD} 31^{+} / \mathrm{AC} 33^{+}\right), \mathrm{VPC}-11\left(\mathrm{AC} 133^{+}\right)$, and $\mathrm{VPC}-14\left(\mathrm{CD} 34^{+} / 45^{+} / \mathrm{AC} 133^{+}\right)$were elevated in the population that resided in closer proximity to the roadway. VPCs with the $\mathrm{AC} 133^{+}$ phenotype were higher in people who lived closer to a major road, suggesting that the 
effects of traffic pollutants on the vascular system may be associated with increased circulation of $\mathrm{AC} 133^{+}$cells as a means of vasoprotection. The finding that the population in closer proximity to the road has higher levels of early progenitors is intriguing given our finding that CVD risk decreases with increased roadway distance. This suggests that the population living in close proximity to the road has higher risk and this may have stimulated VPCs into circulation. This is biologically plausible because increased risk alone may stimulate VPCs into circulation. 
Figures and Tables

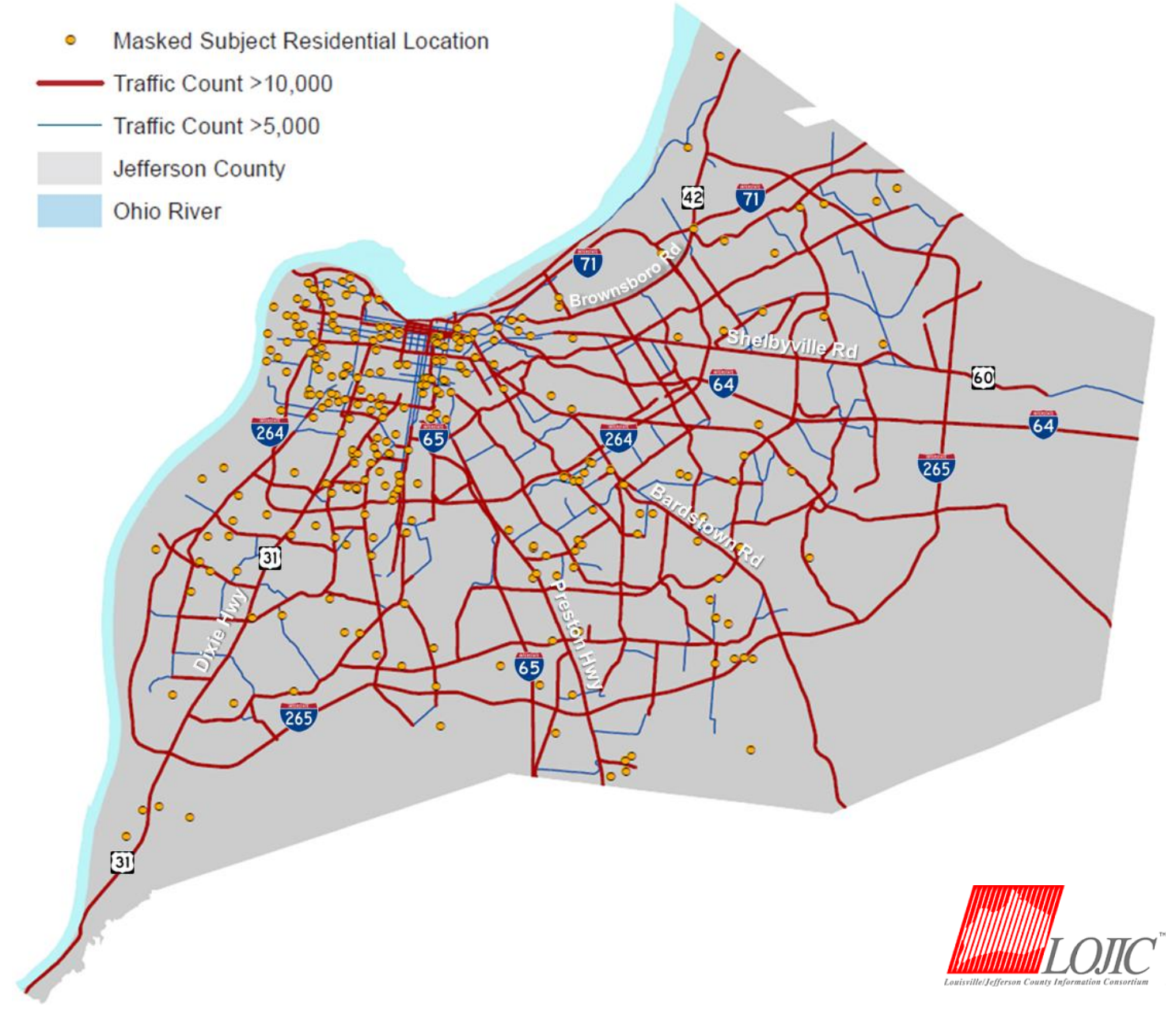

Figure 8. Patients' residential locations in Jefferson County, KY.

Patient addresses are geographically masked. 


\begin{tabular}{|c|c|c|c|c|}
\hline Characteristic & $\begin{array}{l}\text { Total } \\
n=203\end{array}$ & $\begin{array}{l}<50 m \text { from } \\
\text { major road } \\
n=39(\%)\end{array}$ & $\begin{array}{l}\geq 50 m \text { from } \\
\text { major road } \\
n=164(\%)\end{array}$ & p-value \\
\hline Age - mean (SD) & $51(10)$ & $52(8)$ & $51(10)$ & 0.754 \\
\hline Gender - n (\%) & & & & 0.114 \\
\hline Female & $93(45.8)$ & $14(35.9)$ & $79(48.2)$ & \\
\hline Male & $110(54.2)$ & $25(64.1)$ & $85(51.8)$ & \\
\hline Ethnicity - n (\%) & & & & 0.558 \\
\hline Caucasian & $106(52.2)$ & $22(56.4)$ & $84(51.2)$ & \\
\hline African American & $93(45.8)$ & $17(43.6)$ & $76(46.3)$ & \\
\hline Hispanic & $4(2.0)$ & $0(0.0)$ & $4(2.4)$ & \\
\hline \multicolumn{5}{|l|}{ CVD Risk Factors - n (\%) } \\
\hline Hypertension & $162(81.4)$ & $32(82.1)$ & $130(81.3)$ & 1.000 \\
\hline Hyperlipidemia & $126(63.6)$ & $24(61.5)$ & $102(64.2)$ & 0.853 \\
\hline Diabetes & $55(27.5)$ & $14(35.9)$ & $41(25.5)$ & 0.230 \\
\hline $\mathrm{BMI} \geq 30$ & $118(59.6)$ & $20(52.6)$ & $98(61.3)$ & 0.361 \\
\hline Current smoker & $78(38.8)$ & $21(53.8)$ & $57(35.2)$ & $0.043^{\star \star}$ \\
\hline Never smoked & $56(27.9)$ & $5(12.8)$ & $51(31.5)$ & $0.027^{\star \star}$ \\
\hline Former smoker & $67(33.2)$ & $13(33.3)$ & $54(33.1)$ & 1.000 \\
\hline Environmental Smoke & $41(33.3)$ & $5(27.8)$ & $36(34.3)$ & 0.788 \\
\hline Cotinine - mean (SD) & $495(787)$ & $680(908)$ & $453(755)$ & 0.135 \\
\hline \multicolumn{5}{|l|}{ Medical History - n (\%) } \\
\hline Myocardial Infarction & $74(36.8)$ & $16(41.0)$ & $58(35.8)$ & 0.581 \\
\hline Stroke & $22(10.9)$ & $6(15.4)$ & $16(9.9)$ & 0.389 \\
\hline CABG/ PCl/ Stents & $58(28.9)$ & $13(33.3)$ & $45(27.8)$ & 0.556 \\
\hline Heart Failure & $38(19.1)$ & $5(13.5)$ & $33(20.4)$ & 0.487 \\
\hline \multicolumn{5}{|l|}{ Medication - n (\%) } \\
\hline ACE inhibitors & $111(55.5)$ & $23(59.0)$ & $88(54.7)$ & 0.720 \\
\hline Beta-blockers & $127(63.5)$ & $26(66.7)$ & $101(62.7)$ & 0.713 \\
\hline Diuretics & $80(40.0)$ & $15(38.5)$ & $65(40.4)$ & 0.858 \\
\hline Statins & $101(50.5)$ & $21(53.8)$ & $80(49.7)$ & 0.722 \\
\hline Vasodilators & $45(22.5)$ & $12(30.8)$ & $33(20.5)$ & 0.200 \\
\hline $\begin{array}{l}\text { Lymphocyte Count } \times 10^{4} \\
\text { - mean (SD) }\end{array}$ & $13(9.1)$ & 17 (11.5) & $12(8.3)$ & $0.033^{\star \star}$ \\
\hline $\begin{array}{l}\text { Median Household Income } \\
\text { - mean (SD) }\end{array}$ & $31114(17516)$ & $23560(13258)$ & $32944(17690)$ & $0.002^{\star \star}$ \\
\hline
\end{tabular}

Table 13. Demographics and CVD risk history stratified by roadway proximity. Current, never, and former smokers are based on self-report. Environmental smoke is self-reported secondhand smoke exposure in non-smokers only. BMI = body mass index. Cotinine units $(\mathrm{ng} / \mathrm{mL})$. CABG $=$ coronary artery bypass graft. $\mathrm{PCI}=$ percutaneous coronary intervention. ACE = angiotensin-converting-enzyme. Vasodilators include nitrates and hydralazine. Median household income in USD at the US Census block group level. $* *=$ significant at the 0.05 level. 


\begin{tabular}{|c|c|c|c|c|}
\hline Characteristic & $\begin{array}{l}\text { Total } \\
\mathrm{n}=100\end{array}$ & $\begin{array}{l}<50 m \text { from } \\
\text { major road } \\
n=14(\%)\end{array}$ & $\begin{array}{l}\geq 50 m \text { from } \\
\text { major road } \\
n=86(\%)\end{array}$ & p-value \\
\hline Age - mean (SD) & $52(10.4)$ & $49(6.5)$ & $52(10.9)$ & 0.360 \\
\hline Gender - n (\%) & & & & 0.383 \\
\hline Female & $43(43.0)$ & $4(28.6)$ & $39(45.3)$ & \\
\hline Male & $57(57.0)$ & $10(71.4)$ & $47(54.7)$ & \\
\hline Ethnicity - n (\%) & & & & 0.299 \\
\hline Caucasian & $53(53.0)$ & $10(71.4)$ & $43(50.0)$ & \\
\hline African American & $44(44.0)$ & $4(28.6)$ & $40(46.5)$ & \\
\hline Hispanic & $3(3.0)$ & $0(0.0)$ & $3(3.5)$ & \\
\hline \multicolumn{5}{|l|}{ CVD Risk Factors - n (\%) } \\
\hline Hypertension & $84(84.8)$ & $11(78.6)$ & $73(85.9)$ & 0.441 \\
\hline Hyperlipidemia & $66(68.0)$ & $10(71.4)$ & $56(67.5)$ & 1.000 \\
\hline Diabetes & $25(25.3)$ & $4(28.6)$ & $21(24.7)$ & 0.747 \\
\hline $\mathrm{BMI} \geq 30$ & 61 (62.9) & $8(61.5)$ & $53(63.1)$ & 1.000 \\
\hline Current smoker & $38(38.0)$ & $10(71.4)$ & $28(32.6)$ & $0.008^{\star \star}$ \\
\hline Never smoked & $25(25.0)$ & $0(0.0)$ & $25(29.1)$ & $0.019^{\star *}$ \\
\hline Former smoker & $37(37.0)$ & $4(28.6)$ & $33(38.4)$ & 0.563 \\
\hline Environmental Smoke & $21(33.3)$ & $3(75.0)$ & $18(30.5)$ & 0.104 \\
\hline Cotinine - mean (SD) & $543(930)$ & $1059(1136)$ & $456(870)$ & $0.037^{\star \star}$ \\
\hline \multicolumn{5}{|l|}{ Medical History - n (\%) } \\
\hline Myocardial Infarction & $40(40.0)$ & $6(42.9)$ & $34(39.5)$ & 1.000 \\
\hline Stroke & $14(14.0)$ & $2(14.3)$ & $12(14.0)$ & 1.000 \\
\hline CABG/ PCl/ Stents & $36(36.0)$ & $6(42.9)$ & $30(34.9)$ & 0.563 \\
\hline Heart Failure & $21(21.0)$ & $0(0.0)$ & $21(24.4)$ & $0.037^{\star \star}$ \\
\hline \multicolumn{5}{|l|}{ Medication - n (\%) } \\
\hline ACE inhibitors & $57(57.6)$ & $9(64.3)$ & $48(56.5)$ & 0.772 \\
\hline Beta-blockers & $72(72.7)$ & $8(57.1)$ & $64(75.3)$ & 0.197 \\
\hline Diuretics & $40(40.4)$ & $4(28.6)$ & $36(42.4)$ & 0.391 \\
\hline Statins & $61(61.6)$ & $9(64.3)$ & $52(61.2)$ & 1.000 \\
\hline Vasodilators & $25(25.3)$ & $6(42.9)$ & $19(22.4)$ & 0.180 \\
\hline $\begin{array}{l}\text { Lymphocyte Count X } 10^{4} \\
\text { - mean (SD) }\end{array}$ & $14(9.1)$ & $18(10.2)$ & $13(8.4)$ & 0.068 \\
\hline $\begin{array}{l}\text { Median Household Income } \\
\text { - mean (SD) }\end{array}$ & $32920(18424)$ & $23595(6990)$ & 34457 (19277) & $0.040^{\star *}$ \\
\hline
\end{tabular}

Table 14. Demographics and CVD risk history stratified by roadway proximity in people with a residential duration of 6 months.

Cancer patients $(n=6)$ were excluded from this analysis. Current, never, and former smokers are based on self-report. Environmental smoke is self-reported secondhand smoke exposure in non-smokers only. BMI = body mass index. Cotinine units $(\mathrm{ng} / \mathrm{mL})$. $\mathrm{CABG}=$ coronary artery bypass graft. $\mathrm{PCI}=$ percutaneous coronary intervention. $\mathrm{ACE}=$ angiotensin-converting-enzyme. Vasodilators include nitrates and hydralazine. Median household income in USD at the US Census block group level. $* *=$ significant at the 0.05 level. 


\begin{tabular}{|c|c|c|c|}
\hline Variable & $\begin{array}{l}<50 \mathrm{~m} \text { from } \\
\text { major road } \\
\text { Mean (SD) }\end{array}$ & $\begin{array}{l}\geq 50 \mathrm{~m} \text { from } \\
\text { major road } \\
\text { Mean (SD) }\end{array}$ & p-value \\
\hline VPC-1 (CD $\left.31^{+} / 34^{+} / 45^{\mathrm{dim}}\right)$ & $0.974(1.124)$ & $0.813(1.162)$ & 0.211 \\
\hline VPC-2 (CD $\left.31^{+} / 34^{+} / 45^{+}\right)$ & $0.058(0.056)$ & $0.262(2.330)$ & 0.552 \\
\hline VPC-3 (CD $31^{+} / 34^{+} / 45^{\left.\mathrm{dim} / \mathrm{AC} 133^{+}\right)}$ & $0.541(0.719)$ & $0.416(0.600)$ & 0.193 \\
\hline VPC-4 (CD $\left.31^{+} / 34^{+} / 45^{+} / \mathrm{AC} 133^{+}\right)$ & $0.009(0.016)$ & $0.005(0.018)$ & $0.047^{\star \star}$ \\
\hline VPC-5 (CD31+/AC133+) & $2.728(4.384)$ & $1.416(4.644)$ & $0.007^{\star \star}$ \\
\hline VPC-6 (CD31+/34+) & $1.257(1.359)$ & $1.422(4.403)$ & 0.491 \\
\hline VPC-7 (CD31+/34+/45 dim/AC133-) & $0.432(0.599)$ & $0.396(0.881)$ & 0.778 \\
\hline VPC-8 (CD31+/34+/45+/AC133-) & $0.049(0.045)$ & $0.257(2.313)$ & 0.674 \\
\hline VPC-9 (CD34+) & $1.336(1.353)$ & $1.623(5.436)$ & 0.428 \\
\hline VPC-10 (CD31+) & $251.7(204.3)$ & $222.3(239.9)$ & 0.382 \\
\hline VPC-11 (AC133+) & $2.940(4.395)$ & $1.768(5.117)$ & $0.013^{\star \star}$ \\
\hline VPC-12 (CD45+) & $490.0(411.7)$ & $410.6(485.2)$ & 0.302 \\
\hline VPC-13 (CD34+/AC133+) & $0.605(0.738)$ & $0.421(0.568)$ & 0.065 \\
\hline VPC-14 (CD $\left.34^{+} / 45^{+} / \mathrm{AC} 133^{+}\right)$ & $0.009(0.022)$ & $0.004(0.011)$ & $0.030^{* \star}$ \\
\hline VPC-15 (CD34 $+45^{\left.\mathrm{dim} / \mathrm{AC} 133^{+}\right)}$ & $0.519(0.702)$ & $0.379(0.565)$ & 0.134 \\
\hline Fibrinogen & $368.1(122.9)$ & $343.2(107.6)$ & 0.227 \\
\hline Platelet mononuclear cell aggregates & $11.51(6.824)$ & $10.83(5.665)$ & 0.608 \\
\hline hsCRP & $4.770(4.836)$ & $4.692(4.556)$ & 0.931 \\
\hline Sum of CVD risk factors & $3.920(1.178)$ & $3.380(1.270)$ & $0.017^{\star \star}$ \\
\hline Framingham Risk Score & $9.385(8.096)$ & $8.000(7.283)$ & 0.564 \\
\hline
\end{tabular}

Table 15. Comparison of VPC levels, thrombosis, inflammation, and CVD risk between roadway proximities.

VPC counts per $\mu \mathrm{L}$ sample. Fibrinogen units (mg/dL). Platelet mononuclear cell aggregates are the percent of total cells $\mathrm{CD} 41^{+} / 45^{+}$. HsCRP units (mg/L). The sum of CVD risk factors includes the following Framingham risk factors: age $\geq 40$ years, male gender, current smoker, hypertension, hyperlipidemia, and diabetes. $* *=$ significant at the 0.05 level. 


\begin{tabular}{|c|c|c|c|}
\hline Variable & $\begin{array}{l}<50 \text { m from } \\
\text { major road } \\
\text { Mean (SD) }\end{array}$ & $\begin{array}{l}\geq 50 \mathrm{~m} \text { from } \\
\text { major road } \\
\text { Mean (SD) }\end{array}$ & p-value \\
\hline VPC-1 (CD $\left.31^{+} / 34^{+} / 45^{\mathrm{dim}}\right)$ & $0.763(0.608)$ & $0.883(1.234)$ & 0.749 \\
\hline VPC-2 (CD31+/34+/45+) & $0.055(0.048)$ & $0.054(0.108)$ & 0.372 \\
\hline VPC-3 (CD31+/34+/45 dim/AC133+) & $0.477(0.407)$ & $0.445(0.505)$ & 0.393 \\
\hline VPC-4 (CD $\left.31^{+} / 34^{+} / 45^{+} / \mathrm{AC} 133^{+}\right)$ & $0.008(0.013)$ & $0.003(0.006)$ & 0.091 \\
\hline VPC-5 (CD31+/AC133+) & $2.095(4.016)$ & $1.602(6.442)$ & 0.212 \\
\hline VPC-6 (CD $\left.31^{+} / 34^{+}\right)$ & $0.945(0.615)$ & $1.147(1.431)$ & 0.640 \\
\hline VPC-7 (CD31+/34+/45 dim/AC133-) & $0.285(0.243)$ & $0.437(1.062)$ & 0.675 \\
\hline VPC-8 (CD $\left.31^{+} / 34^{+} / 45^{+} / \mathrm{AC} 133^{-}\right)$ & $0.047(0.038)$ & $0.051(0.106)$ & 0.417 \\
\hline VPC-9 (CD34 $)$ & $0.978(0.613)$ & $1.281(1.976)$ & 0.717 \\
\hline VPC-10 (CD31+) & $216.3(106.0)$ & $203.0(186.7)$ & 0.291 \\
\hline VPC-11 (AC133+) & $2.349(4.043)$ & $2.064(7.073)$ & 0.307 \\
\hline VPC-12 (CD45+) & $410.3(216.1)$ & $362.1(368.4)$ & 0.224 \\
\hline VPC-13 (CD34+/AC133+) & $0.544(0.404)$ & $0.433(0.434)$ & 0.226 \\
\hline VPC-14 (CD34+/45+/AC133 $\left.{ }^{+}\right)$ & $0.006(0.013)$ & $0.002(0.007)$ & 0.207 \\
\hline VPC-15 (CD34 $+/ 45^{\left.\mathrm{dim} / A C 133^{+}\right)}$ & $0.458(0.410)$ & $0.401(0.425)$ & 0.360 \\
\hline Fibrinogen & $366.2(105.3)$ & $348.3(119.5)$ & 0.614 \\
\hline Platelet mononuclear cell aggregates & $10.14(7.746)$ & $10.76(5.843)$ & 0.789 \\
\hline hsCRP & $5.426(5.516)$ & $4.722(4.519)$ & 0.653 \\
\hline Sum of CVD risk factors & $4.143(1.231)$ & $3.477(1.299)$ & 0.076 \\
\hline Framingham Risk Score & $10.00(8.660)$ & $7.810(8.501)$ & 0.681 \\
\hline
\end{tabular}

Table 16. Comparison of VPC levels, thrombosis, inflammation, and CVD risk between roadway proximities in people with a residential duration of at least 6 months.

Cancer patients $(\mathrm{n}=6)$ were excluded from analysis. VPC counts per $\mu \mathrm{L}$ sample.

Fibrinogen units $(\mathrm{mg} / \mathrm{dL})$. Platelet mononuclear cell aggregates are the percent of total cells $\mathrm{CD} 41^{+} / 45^{+}$. HsCRP units $(\mathrm{mg} / \mathrm{L})$. The sum of CVD risk factors includes the following Framingham risk factors: age $\geq 40$ years, male gender, current smoker, hypertension, hyperlipidemia, and diabetes. ${ }^{* *}=$ significant at the 0.05 level. 


\begin{tabular}{|c|c|c|}
\hline Variable & $\beta$ & p-value \\
\hline VPC-4 (CD31 $\left.1^{+} / 34^{+} / 45^{+} / \mathrm{AC} 133^{+}\right)$ & -0.611 & 0.083 \\
\hline VPC-5 (CD31+ $\left./ A C 133^{+}\right)$ & -0.648 & 0.003 \\
\hline VPC-11 (AC133+) & -0.469 & 0.033 \\
\hline VPC-14 (CD34 $\left.{ }^{+} / 45^{+} / \mathrm{AC} 133^{+}\right)$ & -1.138 & 0.018 \\
\hline Sum of CVD risk factors & -0.517 & 0.021 \\
\hline
\end{tabular}

Table 17. Association between roadway proximity, VPC levels, and CVD risk. Samples were adjusted for age, gender, BMI, cigarette smoking, median household income, and 24-hour $\mathrm{PM}_{2.5}$. GLMs that assessed VPCs as the dependent variable utilized the gamma probability distribution and the log link function. GLMs that assessed the sum of risk factors utilized the normal probability distribution and the identity link function.

\begin{tabular}{|lll|}
\hline Variable & $\boldsymbol{\beta}$ & $\boldsymbol{p}$-value \\
\hline VPC-4 (CD31+/34+/45+/AC133+) & -1.333 & 0.005 \\
\hline VPC-5 (CD31 $/$ /AC133+) & -0.835 & 0.015 \\
\hline VPC-14 (CD34 ${ }^{+} / \mathbf{4 5}^{+} /$AC133 $\left.^{+}\right)$ & -1.037 & 0.015 \\
\hline
\end{tabular}

Table 18. Association between roadway proximity and VPC levels in people with a residential duration of at least 6 months.

Samples were adjusted for age, gender, BMI, cigarette smoking, median household income, and 24-hour PM 2.5 . GLMs that assessed VPCs as the dependent variable utilized the gamma probability distribution and the $\log$ link function. Cancer patients $(n=6)$ were excluded from this analysis. 


\section{OVERALL DISCUSSION}

\section{Highlights}

These chapters describe how VPC levels are associated with CVD risk and environmental pollution exposure. In the first chapter, it was determined that VPC levels are associated with increased CVD risk, possibly through recruitment in thrombosis and suppression in inflammation. Previous investigators reported mixed results in describing the associations between risk and VPC levels. Because VPCs are a heterogeneous population containing cells of different angiogenic potential, investigation of the large panel of VPCs in the current study more accurately described which VPCs subpopulations are associated with increased CVD risk in an at-risk population. In the second chapter, it was described that the acrolein metabolite, HPMA, was associated with reduced VPC levels: suggesting that exposure to acrolein is associated with decreased VPCs. Additionally, HPMA was associated with increased thrombosis and increased FRS. The associations between acrolein exposure and VPC levels and thrombosis had been demonstrated in mice, but not in humans. In the final chapter, individuals who lived closer to a major roadway had a higher number of risk factors for CVD and higher VPC levels. This was a novel assessment in the field and the findings suggest that VPC levels are increased as a means of vasoprotection in either roadway exposure or increased CVD risk, or both. Ultimately, these investigations revealed that environmental pollution exposure is associated with VPC levels, which may also contribute to CVD risk. 


\section{Strengths}

\section{Population size}

There are multiple strengths of these investigations. First, there was a large population recruited for this study, ranking us among the largest VPC investigations of at-risk individuals. Many investigations of VPCs and CVD risk have investigated associations in less than 100 people ${ }^{52,63,65,67,69-72,122,123}$. Most of these investigations utilized a case-control design. The current study utilized a cross-sectional design, which requires more study participants for more strength of association. Werner et al. investigated a large population $(n=507)$ using a prospective cohort ${ }^{74}$. Kunz et al. investigated a cross-section of 122 patients undergoing diagnostic cardiac catheterization

${ }^{66}$. Xiao et al. investigated a cross-section of 574 low-risk individuals ${ }^{64}$. The current study includes a population of 240 individuals (189 with VPC levels) with risk factors for CVD. The current study was statistically powered to detect associations with VPC levels. With an effect size of $20 \%, 10$ predictors, and statistical significance of 0.05 , there is a $1 \%$ chance that our conclusion that VPC levels are associated with CVD risk factors and environmental exposures is invalid and they are actually not associated.

\section{Susceptible population}

Previous research of vascular progenitor cells and the association with CVD risk have included both healthy and unhealthy individuals, in terms of CVD risk. The environmental investigation of VPCs and risk, however, investigated VPC levels in healthy young adults ${ }^{30}$. It is important to add to the literature an investigation of susceptible individuals and their VPC levels associated with environmental exposures. Older individuals are more susceptible to the effects of environmental exposures. In 
addition, older individuals are more likely to have heart disease. Moreover, patients with heart disease may be more susceptible to the effects of environmental exposures ${ }^{38}$. Investigating a susceptible population that includes both older individuals and a population who have heart disease allows for greater understanding of cardiovascular risks of environmental exposures, determined through VPC levels.

\section{Antigenic markers}

The current study used antigenic markers $\mathrm{CD} 31^{+}, \mathrm{CD} 34^{+}, \mathrm{CD} 45^{+/ \mathrm{dim}}$, and $\mathrm{CD}_{133^{+/}}$to define VPCs. These markers are useful in defining circulating VPCs. Some previous investigations used markers which were not highly specific to VPCs, including 1,1'-dioctadecyl-3,3,3',3'-tetramethyl-indocarbocyanine perchlorate labeled acetylated low-density lipoprotein (DiI-Ac-LDL) and lectin. In addition to using validated antigenic markers, the current study also verified that selected populations were positive for the transcription factor inhibitor of DNA binding 1, Id1, indicating that they are endothelial progenitor cells.

\section{VPC measurement}

Some previous studies investigated VPCs using culture and colony forming unit assays. These assays are beneficial in determining the growth and functional capacity of VPCs ${ }^{64,65}$, however, they are less suitable in determining levels of circulating VPCs. The current study quantifies VPCs using flow cytometry, a superior method for circulating VPC identification and quantification. Additionally, flow cytometry allows for multiple measurements with rapid speed. This methodology is beneficial for future clinical use of VPC quantification. If a proper cell type is identified to be useful in detection of CVD, 
the clinical staff will be able to have flow cytometry results, using the current study's methodology, within hours.

\section{VPC population specificity}

VPCs are a heterogeneous population of cells with different angiogenic potential. The current study measured 15 antigenically distinct populations of VPCs. Results from this investigation have scientific significance because of the determination of specific cell types and sub-populations that are associated with CVD risk and environmental exposures. O'Toole et al. determined that $\mathrm{CD} 31^{+} / 34^{+} / 45^{+}$cells are inversely associated with $\mathrm{PM}_{2.5}$ exposure ${ }^{30}$. The current study also determined that $\mathrm{CD} 31^{+} / 34^{+} / 45^{+}$cells were inversely associated with HPMA, but the results also demonstrated that a sub-population of those cells were also inversely associated, $\mathrm{CD} 31^{+} / 34^{+} / 45^{+} / \mathrm{AC} 133^{-}$: suggesting that depletion of the late progenitor $\left(\mathrm{AC}^{-3} 3^{-}\right)$, rather than the more immature progenitor cell population $\left(\mathrm{AC} 33^{+}\right)$, drives the association demonstrated in $\mathrm{CD} 31^{+} / 34^{+} / 45^{+}$cells. By assessing a large number of VPCs, in some cases a more specific marker population that is affected can be determined. This is beneficial for future mechanistic investigations, allowing for future investigations to be targeted at more specific cell types, and for greater understanding of which cell differentiation state is influenced by pollution exposure and CVD risk.

\section{Minimizing exposure misclassification}

To reduce exposure misclassification, multiple efforts were employed including the use of biomarkers. Measuring urine HPMA concentrations allows for a reliable measure of individual acrolein exposure. Estimating acrolein exposure using ambient monitoring would not provide as much benefit if used instead of metabolism 
quantification because estimates would be more specific to a community rather than an individual and the difficulties in determining the amount of time individuals are exposed. HPMA is the primary urine metabolite of acrolein, and it is specific to acrolein exposure ${ }^{46}$, making it the most reliable marker to quantify acrolein exposure. With this measurement, the current study was able to determine the HPMA levels of a person at the timing that coincides with the timing of the individual's VPC and cotinine levels. This way, the snapshot of exposures occurs at the same time of the outcome measure, VPCs.

Cotinine was also a biomarker utilized in the current study to reduce exposure misclassification in self-reported smoking. Additionally, cotinine is a continuous variable that allows quantification of the exposure to tobacco smoke. It accounts for both primary and environmental exposure to tobacco smoke.

Exposure misclassification in the association between VPCs and distance to a major roadway was minimized through including only individuals who had a residential duration at their current home of at least 6 months. This reduced attributing long-term exposures to persons with short-term residency.

\section{Limitations}

\section{Convenience sample}

The results of the current study are valuable because they add knowledge about the association of environmental exposures with VPC levels, which may contribute to CVD risk. These associations were determined in a population with increased risk factors for CVD, which poses a limitation in being able to generalize the results to the whole population. Each participant was recruited during cardiology clinic visits, therefore, their clinic visit was related to cardiology concerns. This implies that the population has poor 
cardiovascular health. Additionally, when reviewing our population characteristics, $24.6 \%(n=59)$ of the study population were primary preventive patients, and $75.4 \%$ $(n=181)$ were secondary preventive patients, indicating that $75 \%$ of the participants had overt CAD. For these results to be generalizable beyond a high-CVD risk population, more people who are low-risk must be included in the population. A comparison population with 1 or less risk factors would be ideal to include for understanding the differences between VPC levels among risk scores and risk factors. Future direction should include age- and sex-matched controls with no additional risk factors (outside of age and gender).

\section{Recruitment}

In addition to the convenience sample from the cardiology clinics posing a possible limitation, recruiting a sample population that is representative of the clinic patient demographics may be another limitation. The population of the current study may not entirely represent the clinic population demographics. For example, none of the recruiters for the current study fluently spoke any languages other than English; therefore, participants who were not English-speaking and did not have a translator present could not participate in the study. Possibly as a result, only $1.7 \%(n=4)$ individuals in the current study were Hispanic.

It is estimated that $75 \%$ of the individuals that were recruited enrolled in the study. Many of those that did not enroll explained that they had time limitations, were uncomfortable with the biological sample collection, or were not interested. At the onset of the study, limitations included retaining study participants after the questionnaire administration to provide biological samples following their appointment. Initially, the 
recruiters would ask patients to meet them at the phlebotomy lab immediately following their appointment for biological sample collection. This had poor retention outcomes because some patients were unable to locate the lab, some may have forgotten, and some may have changed their minds about providing samples. The current study was able to change this trend by increasing the number of recruitment personnel and assigning recruiters to specific patients and escorting them to the lab to provide samples. An additional challenge involved individuals that had "rolling" veins or veins that were difficult to locate. In these scenarios, multiple sticks may have been required for an adequate blood draw, adding to the patient's discomfort.

\section{Misclassification}

Measuring cotinine levels to minimize exposure misclassification in tobacco smoke exposure provided a strength in the study by allowing for quantification of smoke exposure. Ironically, it also provided as an additional means for exposure

misclassification. In some assessments, smoke exposure was associated with an outcome, but cotinine was not: although self-reported smoking and cotinine were highly correlated. If, for example, a study participant reported that they were a smoker, but had not had a cigarette in 20 hours, their cotinine levels may represent a non-smoker's cotinine level.

Assessing only the population with a residential duration of at least 6 months was

a great step toward reducing exposure misclassification. Narrowing the population to the individuals with at least 6 month home ownership, however, may have misclassified renters in the study population. If a renter has been in their current home for more than 6 months, but the property owner changed less than 6 months prior, they would have been 
misclassified. If, on the other hand, renters had recently moved to the property, but the owner had not changed, their exposure measurement would also be misclassified.

Determining whether or not an individual was a smoker may have possibly led to misclassification. Some study participants indicated that they were current nonsmokers, but had only quit smoking weeks prior to the questionnaire. Additionally, some individuals described themselves as current smokers, but only smoked a few cigarettes a week or just socially. Some investigations only consider individuals to be nonsmokers if they have abstained for 6 months. Because of the difficulties in quantifying exposure, we also measured cotinine levels. The difficulty in quantifying smoke exposure is similar to other variables in the current dataset including alcohol consumption and exercise. Instead of quantifying the amount of exercise or alcohol, these variables were entered as dichotomous data, possibly leaving heavy consumers of alcohol in the same category as individuals who consume infrequently.

\section{Outcome measurement}

Some patients were not able to provide blood samples that were needed to measure VPCs. Patients that had engaged in past intravenous drug use that caused their veins to be damaged (or others that were not able to provide samples from their arm) occasionally provided blood samples from their hands, which may have resulted in slower blood flow into the vacutainer tubes. The cell preparation tube (CPT) separator vacutainer required $8 \mathrm{~mL}$ of blood for VPC measurement; some patients were not able to provide this amount, possibly resulting in cell levels that were too low to be counted by the flow cytometer. 
There is potential bias in the measurement of VPCs. Although the operator was blinded to the disease status and risk factors of the patient, it could have been assumed that most study participants are diseased because of their recruitment from cardiology clinics. This may have influenced the flow cytometric interpretation through operator bias. Additionally, the gating of cell properties in flow cytometry can appear somewhat arbitrary and possibly differ from investigator to investigator. Therefore, one investigator directed and verified the gating for consistency. Additionally, the $\mathrm{CD} 31^{+}$antigenic marker is considered to be less specific in indicating the endothelial phenotype than the kinase insert domain receptor $\left(\mathrm{KDR}^{+}\right)$(vascular endothelial growth factor receptor- $2^{+}$ $\left(\mathrm{VEGFR}^{+} 2^{+}\right.$) is also known as $\left.\mathrm{KDR}^{+}\right)$. To address not marking for $\mathrm{KDR}^{+}$rather than $\mathrm{CD} 31^{+}$, we verified the endothelial progenitor cell phenotype with the presence of Id $1^{+}$ cells that were $\mathrm{CD} 31^{+}$.

VPCs are useful to investigate because they are specific to the vascular and cardiovascular systems and are sensitive to environmental exposures. It is important to control for many factors in human VPC assessments because many factors influence levels of circulating VPCs. Gender influences VPC levels; VPC levels fluctuate during the menstrual cycle in women. A study limitation is that the current investigation did not account for what phase of menstruation female participants were undergoing. To account for this, the current study stratified by gender to determine whether associations changed, and the direction of associations did not change. Additionally, differences were compared between VPC levels among genders, and no significant differences were found between VPC levels and gender. Models in the current study were adjusted for gender to account for any undetermined differences between men and women (except models with FRS or 
FRS category because gender is weighted in the risk score). Additionally, exercise influences VPC levels by mobilizing VPCs from the bone marrow into circulation. The questionnaire item for exercise was not robust enough to adequately quantify exercise within the study population. Adjusting the models for exercise did not appear to provide additional benefit over adjusting for BMI, in terms of statistical significance. Therefore, BMI (a continuous variable) was entered into the selected adjusted regression models. BMI provides an additional limitation in that it has been reported that waist circumference and waist-to-hip ratio are more closely related to adverse cardiovascular health $^{124,125}$.

An additional limitation in the outcome measurement is the lack of adjusting our

analyses for multiple comparisons. Associations between each VPC and the exposure and risk factor were assessed individually, one model for each VPC - 15 total. The current study investigated each cell separately to understand the associations between each VPC and the exposures and risk factors individually. If there is a 5\% chance of error for each model, this increases the likelihood that there will be an association determined within 15 models that is erroneous.

\section{CVD risk/ exposure measurement}

A crude measure of risk included in our assessments was the "sum of CVD risk factors" variable. This variable allowed for greater understanding of how increases in cumulative risk factors are associated with VPC levels. This measure is less valid to assessing risk because it does not weight for different risk factors. Ultimately, CVD risk is predicted by the FRS and FRS category in the current study. The FRS predicts future myocardial infarction and cardiac mortality. Some criticism of the FRS is due to the 
original study cohort being unrepresentative of the general population: completely Caucasian and middle class. The Framingham Heart Study now includes multiple ethnicities in its subsequent cohorts ${ }^{126}$, and the FRS has been validated against other ethnicities ${ }^{127}$. Additional criticism of the FRS involves the lack of accurate prediction for women and individuals in the intermediate risk category (FRS 10-20) ${ }^{22}$. This poses a limitation where women and individuals with intermediate risk may not have an appropriate risk score. In fact, cardiovascular events can occur without an individual having any Framingham risk factors. The Reynolds Risk Score (RRS) is another risk algorithm predicting risk of adverse cardiovascular outcomes. The RRS predicts heart attack, stroke, coronary revascularization, and cardiovascular death. It was derived to better estimate risk in women and intermediate risk populations. The RRS includes Framingham risk factors (age, hypertension, hyperlipidemia, diabetes, smoking, and gender) along with family history and C-reactive protein (CRP). The current study was unable to investigate the RRS due to incomplete family history data. Investigating risk in terms of the RRS in its association with VPC levels will be a beneficial and novel approach in future assessments. Because the current investigation determined that VPC levels were inversely associated with hsCRP in an at-risk population, it would be interesting to understand the association with the RRS. Ultimately, the RRS may be a better predictor of VPCs suppressed in inflammation, while the FRS may better predict VPCs recruited in thrombosis. More research would be required to investigate the potential associations.

Additional cardiovascular risk scores that may provide added benefit in understanding the association between VPCs and risk include the Systematic COronary 
Risk Evaluation (SCORE), which measures the risk of fatal CVD with an algorithm including age, gender, total cholesterol, systolic blood pressure, and smoking ${ }^{128}$. The Prospective Cardiovascular Münster (PROCAM) Study score assesses risk of myocardial infarction and cardiac death through an algorithm that includes age, low-density lipoprotein (LDL) cholesterol, high-density lipoprotein (HDL) cholesterol, smoking, systolic blood pressure, family history, diabetes, and triglycerides ${ }^{129}$. The DiamondForrester score predicts significant CAD through age, sex, and chest pain ${ }^{130}$. Because these scores measure different outcomes, their association with VPC levels may be helpful for greater understanding of the role of these cells in CVD risk.

HPMA is a marker of acrolein metabolism, but it is not possible to attribute the acrolein exposure only to the environment. There are environmental sources of acrolein exposure (combustion of fossil fuels, open fire, industrial emissions, vehicular exhaust, and tobacco smoke), but there is also endogenous acrolein exposure as well as exposure to acrolein in food and alcohol consumption. It is not known what portion of our acrolein exposures are endogenous compared to environmental. Therefore, to better estimate environmental acrolein exposure, in addition to HPMA levels, it would have also been beneficial to have ambient acrolein levels as well. Personal samplers would be best because they would remain with a person wherever their daily activities lead them. However, these additionally provide limitations because individuals may not wear them properly or wear them at all. Some find these uncomfortable, and they are an added expense for the investigator. In-home monitors would also be beneficial, but that may not be where the participants spend most of their time. There are also complaints of the noise and space they impose. Ambient air monitoring stations throughout the study area would 
be beneficial, but there are not enough acrolein monitors distributed widely across Jefferson County, KY to provide a valid estimation of such a volatile chemical.

Roadway proximity studies operate with the assumption that study participants spend a majority of their time at home. A better estimation would involve geocoding the distance to roadway of both the home and work addresses and accounting for the time spent at both. Additionally, inclusion of a variable that accounts for efficiency and insulation in homes, possibly estimated by the age of the home, would provide benefit in attributing exposures.

\section{Future Directions}

Because of the multiple implications of examining whether a population with increased CVD risk has vascular progenitor cell levels that are associated with CVD risk and environmental exposures, there are many directions in which the current study results can be expanded and applied. The results of the current study should be assessed in animal models. Mechanistic explorations in animals will add greater understanding of the associations between the environment and CVD risk, detected by VPC levels.

One key goal is to determine the best VPC population to be measured in a clinical setting for diagnostic purposes in CVD. As described before, VPC levels can be quantified within hours, allowing for a quick turn-around on information. Future investigations should determine whether VPC levels provide additional benefit to determining risk in the population within the intermediate FRS category (FRS $10-20$ ). Understanding which VPC populations are associated with specific risk factors will be helpful in determining targets for therapeutic interventions. Determining, for example, the VPC population associated with hypertension will allow for future investigations that 
mobilize these VPCs in hypertensive patients. In the current study, VPC levels are suppressed in patients with inflammation. Future investigation of mechanistic means to increase VPC-5 $\left(\mathrm{CD} 31^{+} / \mathrm{AC} 133^{+}\right)$in patients with inflammation may minimize or prevent vascular damage, improving patient cardiovascular outcomes.

In an effort to determine populations that are most associated with risk, we divided the cell populations into groupings based on the single antigenic markers and possible sub-populations. Possibly because there is much overlap between the cell populations and many are correlated with each other, we did not find trends in associations on this basis (with the exception of VPCs and proximity to a major roadway). Future directions should consider the antigenic marker similarities common to the risk factor or exposures and develop hypotheses on that basis to guide future understanding.

Because it has now been determined that VPCs decrease in humans exposed to acrolein, understanding the mechanism of VPC depletion in animals will give better understanding of the role of acrolein exposure in vascular damage. Because the population living closer to the roadway had a higher number of risk factors and higher number of VPCs, future investigations should explore whether the VPCs are increased in the population living closer to the road because increased CVD risk results in these cells being mobilized into circulation, environmental insults are stimulating VPC mobilization, or both. 


\section{OVERALL SUMMARY}

Taken together, these chapters describe how environmental pollution exposure is associated with VPC levels, contributing to CVD risk. In the first chapter, the objective was to describe the associations between VPC levels and cardiovascular disease risk. VPCs in circulation are suspected to be a sensitive indicator of cardiovascular health. Several investigators have suggested that circulating VPC levels are decreased in populations with CVD; however, some positive associations with CVD have been demonstrated. Likely reasons for the mixed results may be due to the use of cellular definitions that were non-specific to VPCs and assays not specific to quantifying circulating levels of these cells. Therefore, the current study evaluated the relationship between CVD risk and VPC levels using antigentically defined VPCs with angiogenic potential. CVD history and risk factors, blood, and urine were collected in a crosssectional assessment of 240 patients in the Louisville, KY Healthy Heart Study receiving primary or secondary preventive treatment for CVD. Fifteen VPC populations measured in peripheral blood using VPC-specific antigenic markers of $\mathrm{CD}^{+} 1^{+}$(endothelial cell), $\mathrm{CD}_{4} 4^{+}$(stem cell), CD45 ${ }^{+/ \mathrm{dim}}$ (hematopoietic/ non-hematopoietic), AC133 ${ }^{+/}$(early/ late progenitor cell) were quantified using flow cytometry. Generalized Linear Modeling (GLM) techniques were utilized to describe associations between VPC levels, traditional CVD risk factors, the Framingham Risk Score (FRS), plasma levels of fibrinogen, and platelet mononuclear cell aggregates in whole blood (markers of thrombosis), and serum levels of high sensitivity C-reactive protein (hsCRP; a marker of inflammation). FRS 
category was inversely associated with VPC-5 $\left(\mathrm{CD} 31^{+} / \mathrm{AC} 133^{+}\right)$and positively associated with VPC-3 $\left(\mathrm{CD} 31^{+} / 34^{+} / 45^{\mathrm{dim}} / \mathrm{AC} 133^{+}\right)$, VPC-13 (CD34 $\left./ \mathrm{AC} 133^{+}\right)$, and VPC$15\left(\mathrm{CD} 34^{+} / 45^{\mathrm{dim}} / \mathrm{AC} 133^{+}\right)$. Fibrinogen was positively associated with VPC-1 $\left(\mathrm{CD} 31^{+} / 34^{+} / 45^{\mathrm{dim}}\right)$, VPC-3, VPC-13, and VPC-15. Platelet mononuclear cell aggregates were positively associated with VPC-6 (CD31 $\left.{ }^{+} / 34^{+}\right)$, VPC-9 $\left(\mathrm{CD} 34^{+}\right)$, and VPC-14 $\left(\mathrm{CD} 34^{+} / 45^{+} / \mathrm{AC} 133^{+}\right)$. HsCRP was inversely associated with VPC-5 and VPC-11 $\left(\mathrm{AC} 133^{+}\right)$levels. These results suggest that VPC-5 levels decrease as risk increases, possibly through suppression during inflammation. Results also indicate that VPC-3, VPC-13, and VPC-15 increase as risk increases, possibly due to their role in resolving venous thrombus. Results from this investigation described how VPC levels are associated with CVD risk in a population at increased risk for CVD. Future direction from the current investigation should involve the verification of these results in animal models to understand the mechanism behind these associations. Additionally, future planned research will investigate these associations beyond an at-risk population.

In the second chapter, the association between acrolein exposure and VPC levels was assessed to understand how the environment contributes to CVD risk. Combustion pollutants, including acrolein, are associated with decreased VPC levels in mice; however, this was the first investigation of the association between acrolein exposure and VPC levels in humans. To estimate acrolein exposure, the primary urine acrolein metabolite HPMA was quantified using gas chromatography / mass spectrophotometric analysis (GC/MS). Additionally, urine levels of the nicotine metabolite, cotinine, were determined by GC/MS. The associations between HPMA concentrations and smoking, VPC levels, the FRS, and the markers of thrombosis and inflammation were assessed 
using GLM techniques. HPMA levels were positively associated with tobacco smoke exposure. After adjustment for traditional risk factors and potential confounders, VPC-2 $\left(\mathrm{CD} 31^{+} / 34^{+} / 45^{+}\right)$, VPC-8 $\left(\mathrm{CD} 31^{+} / 34^{+} / 45^{+} / \mathrm{AC} 33^{-}\right)$, VPC- 11 , and VPC-14 were inversely associated with HPMA. Platelet mononuclear cell aggregates were positively associated with HPMA. The FRS and FRS category were positively associated with HPMA. VPC-2, VPC-8, VPC-9, and VPC-14 were inversely associated with HPMA after stratification for non-smokers. The major finding of this study is that exposure to acrolein is associated with vascular outcomes, determined through reductions in circulating levels of VPCs. Additionally, as acrolein exposure increases (detected by acrolein metabolism), a marker for thrombosis (platelet mononuclear cell aggregates) and CVD risk increase.

Implications of these results are of added value because the current study found these associations in a population with increased risk for CVD, a population more susceptible to the effects of environmental exposures.

The third chapter presented the association between proximity to a major roadway and VPC levels as an added analysis in understanding the environmental contribution to VPC levels and CVD risk. A substantial body of research has established that living in close proximity to a major roadway is associated with increased CVD morbidity and mortality; however, this is the first investigation of the impact of exposure to traffic pollution on VPC levels. Vehicular exhaust is a source of acrolein exposure, and distance to roadway is a common measure of exposure to traffic-related pollution. The objective was to investigate the association between residential proximity to a major roadway (an indicator of traffic pollution exposure) and circulating VPC levels indicating CVD risk. Residential addresses were geocoded in a Geographic Information System (GIS), with 
major roadways defined as roads carrying an annual mean of 5,000 or more vehicles/ day. Individuals were considered exposed if they resided within $50 \mathrm{~m}$ of a major roadway. The association between roadway proximity and VPC levels, CVD risk factors, the FRS, and markers of thrombosis and inflammation was assessed using GLM techniques, and the models were adjusted for traditional covariates along with potential confounders. Only the population with a residential duration of at least 6 months was included in the final analysis. A large portion of study participants resided in the northwestern portion of Jefferson County, KY, called, "West Louisville," which has disproportionately high CVD mortality rates and environmental exposures. Levels of VPC-4 $\left(\mathrm{CD} 31^{+} / 34^{+} / 45^{+} / \mathrm{AC} 133^{+}\right)$, VPC-5, and VPC-14 were significantly higher in the population in close proximity to the roadway after adjustment for potential confounders. VPCs with the $\mathrm{AC} 133^{+}$(early progenitor cell) marker were higher in people who lived closer to a major road, suggesting that the effects of traffic pollutants on the vascular system result in increased circulation of early (immature) progenitors as a means of vasoprotection. Because the population living closer to the roadway had a higher number of risk factors and higher VPC levels, future investigations should explore whether the VPCs are increased in the population living closer to the road because increased CVD risk results in these cells being mobilized into circulation, environmental insults to the vasculature are stimulating VPC mobilization, or both.

Taken together, these chapters describe an important aspect of the influence of the environment on CVD risk, assessed by VPC levels. The first chapter is significant because it accurately defined VPC populations to assess potential VPC associations with CVD risk factors in a population at increased risk for CVD. The second chapter expanded 
scientific knowledge through quantifying individual levels of the primary acrolein metabolite to determine its association with adverse cardiovascular health in humans, a novel investigation. The third chapter advanced the field of environmental cardiology by evaluating the established association between roadway proximity and CVD risk through investigation of VPC levels, a novel assessment in the field. Results of these investigations provide insights for future mechanistic assessments of VPCs, and add additional information to drive future investigations for VPCs in interventional therapies for CVD risk factors and environmental exposures. 


\section{REFERENCES}

1. Go AS, Mozaffarian D, Roger VL, Benjamin EJ, Berry JD, Borden WB, Bravata DM, Dai S, Ford ES, Fox CS, Franco S, Fullerton HJ, Gillespie C, Hailpern SM, Heit JA, Howard VJ, Huffman MD, Kissela BM, Kittner SJ, Lackland DT, Lichtman JH, Lisabeth LD, Magid D, Marcus GM, Marelli A, Matchar DB, McGuire DK, Mohler ER, Moy CS, Mussolino ME, Nichol G, Paynter NP, Schreiner PJ, Sorlie PD, Stein J, Turan TN, Virani SS, Wong ND, Woo D, Turner MB. Heart disease and stroke statistics—2013 update: A report from the american heart association. Circulation. 2013;127:e6-e245

2. Lozano R, Naghavi M, Foreman K, Lim S, Shibuya K, Aboyans V, Abraham J, Adair T, Aggarwal R, Ahn SY, AlMazroa MA, Alvarado M, Anderson HR, Anderson LM, Andrews KG, Atkinson C, Baddour LM, Barker-Collo S, Bartels DH, Bell ML, Benjamin EJ, Bennett D, Bhalla K, Bikbov B, Abdulhak AB, Birbeck G, Blyth F, Bolliger I, Boufous S, Bucello C, Burch M, Burney P, Carapetis J, Chen H, Chou D, Chugh SS, Coffeng LE, Colan SD, Colquhoun S, Colson KE, Condon J, Connor MD, Cooper LT, Corriere M, Cortinovis M, de Vaccaro KC, Couser W, Cowie BC, Criqui MH, Cross M, Dabhadkar KC, Dahodwala N, De Leo D, Degenhardt L, Delossantos A, Denenberg J, Des Jarlais DC, Dharmaratne SD, Dorsey ER, Driscoll T, Duber H, Ebel B, Erwin PJ, Espindola P, Ezzati M, Feigin V, Flaxman AD, Forouzanfar MH, Fowkes FGR, Franklin R, Fransen M, Freeman MK, Gabriel SE, Gakidou E, Gaspari F, Gillum 
RF, Gonzalez-Medina D, Halasa YA, Haring D, Harrison JE, Havmoeller R, Hay RJ, Hoen B, Hotez PJ, Hoy D, Jacobsen KH, James SL, Jasrasaria R, Jayaraman S, Johns N, Karthikeyan G, Kassebaum N, Keren A, Khoo J-P, Knowlton LM, Kobusingye O, Koranteng A, Krishnamurthi R, Lipnick M, Lipshultz SE, Ohno SL, Mabweijano J, MacIntyre MF, Mallinger L, March L, Marks GB, Marks R, Matsumori A, Matzopoulos R, Mayosi BM, McAnulty JH, McDermott MM, McGrath J, Memish ZA, Mensah GA, Merriman TR, Michaud C, Miller M, Miller TR, Mock C, Mocumbi AO, Mokdad AA, Moran A, Mulholland K, Nair MN, Naldi L, Narayan KMV, Nasseri K, Norman P, O'Donnell M, Omer SB, Ortblad K, Osborne R, Ozgediz D, Pahari B, Pandian JD, Rivero AP, Padilla RP, Perez-Ruiz F, Perico N, Phillips D, Pierce K, Pope lii CA, Porrini E, Pourmalek F, Raju M, Ranganathan D, Rehm JT, Rein DB, Remuzzi G, Rivara FP, Roberts T, De León FR, Rosenfeld LC, Rushton L, Sacco RL, Salomon JA, Sampson U, Sanman E, Schwebel DC, Segui-Gomez M, Shepard DS, Singh D, Singleton J, Sliwa K, Smith E, Steer A, Taylor JA, Thomas B, Tleyjeh IM, Towbin JA, Truelsen T, Undurraga EA, Venketasubramanian N, Vijayakumar L, Vos T, Wagner GR, Wang M, Wang W, Watt K, Weinstock MA, Weintraub R, Wilkinson JD, Woolf AD, Wulf S, Yeh P-H, Yip P, Zabetian A, Zheng Z-J, Lopez AD, Murray CJL. Global and regional mortality from 235 causes of death for 20 age groups in 1990 and 2010: A systematic analysis for the global burden of disease study 2010. The Lancet. 2012;380:2095-2128

3. Mensah GA, Brown DW. An overview of cardiovascular disease burden in the united states. Health Affairs. 2007;26:38-48 
4. Stampfer MJ, Hu FB, Manson JE, Rimm EB, Willett WC. Primary prevention of coronary heart disease in women through diet and lifestyle. New England Journal of Medicine. 2000;343:16-22

5. Kahn R, Robertson RM, Smith R, Eddy D. The impact of prevention on reducing the burden of cardiovascular disease. Circulation. 2008:1-10

6. Risk factors and coronary heart disease. Heart.org. 2010

7. Lloyd-Jones DM, Nam B-H, D'Agostino Sr RB, Levy D, Murabito JM, Wang TJ, Wilson PW, O'Donnell CJ. Parental cardiovascular disease as a risk factor for cardiovascular disease in middle-aged adults. Journal of the American Medical Association. 2004;291:2204-2211

8. Lloyd-Jones D, Adams R, Carnethon M, De Simone G, Ferguson TB, Flegal K, Ford E, Furie K, Go A, Greenlund K, Haase N, Hailpern S, Ho M, Howard V, Kissela B, Kittner S, Lackland D, Lisabeth L, Marelli A, McDermott M, Meigs J, Mozaffarian D, Nichol G, O'Donnell C, Roger V, Rosamond W, Sacco R, Sorlie P, Stafford R, Steinberger J, Thom T, Wasserthiel-Smoller S, Wong N, WylieRosett J, Hong Y. Heart disease and stroke statistics - 2009 update. A report from the american heart association statistics committee and stroke statistics subcommittee. Circulation. 2008;119:e1-e161

9. $\quad$ AHA. What is high blood pressure? 2012;2013

10. Daviglus ML, Liu K, Pirzada A, Yan LL, Garside DB, Feinglass J, Guralnik JM, Greenland P, Stamler J. Favorable cardiovascular risk profile in middle age and health-related quality of life in older age. Archives of Internal Medicine. 2003;163:2460-2468 
11. Cardiovascular disease risk factors. OSU.edu. 2009

12. Cohen J. A population-based approach to cholesterol control. American Journal of Medicine. 1997;102:23-25

13. Kannel WB, McGee DL. Diabetes and cardiovascular risk factors: The framingham study. Circulation. 1979;59:8-13

14. Smoking \& tobacco use. Centers for Disease Control and Prevention. 2008

15. John U, Meyer C, Hanke M, Völzke H, Schumann A. Relation between awareness of circulatory disorders and smoking in a general population halth examination. BMC Public Health. 2006;6

16. Yusuf S, Hawken S, Ôunpuu S, Dans T, Avezum A, Lanas F, McQueen M, Budaj A, Pais P, Varigos J, Lisheng L. Effect of potentially modifiable risk factors associated with myocardial infarction in 52 countries (the interheart study): Case control study. Lancet. 2003;364:937-952

17. Pate RR, Pratt M, Blair SN, Haskell WL, Macera CA, Bouchard C, Buchner D, Ettinger W, Heath GW, King AC, Kriska A, Leon AS, Marcus BH, Morris J, Paffenbarger Jr RS, Patrick K, Pollock ML, Rippe JM, Sallis J, Wilmore JH. Physical activity and public health: A recommendation from the centers for disease control and prevention and the american college of sports medicine. Journal of the American Medical Association. 1995;273:402-407

18. Wei M, Kampert JB, Barlow CE, Nichaman MZ, Gibbons LW, Paffenbarger J, Ralph S, Blair SN. Relationship between low cardiorespiratory fitness and mortality in normal-weight, overweight, and obese men. Journal of the American Medical Association. 1999;282:1547-1553 
19. Wilson PWF, D'Agostino RB, Sullivan L, Parise H, Kannel WB. Overweight and obesity as determinants of cardiovascular risk. Archives of Internal Medicine. 2002;162:1867-1872

20. Flegal KM, Graubard BI, Williamson DF, Gail MH. Cause-specific excess deaths associated with underweight, overweight, and obesity. Journal of the Americn Medical Association. 2007;298:2028-2037

21. Wilson PWF, D’Agostino RB, Levy D, Belanger AM, Silbershatz H, Kannel WB. Prediction of coronary heart disease using risk factor categories. Circulation. $1998 ; 97: 1837-1847$

22. Ridker P BJERNCNR. Development and validation of improved algorithms for the assessment of global cardiovascular risk in women: The reynolds risk score. JAMA. 2007;297:611-619

23. Asahara T, Murohara T, Sullivan A, Silver M, van der Zee R, Li T, Witzenbichler B, Schatteman G, Isner JM. Isolation of putative progenitor endothelial cells for angiogenesis. Science. 1997;275:964-966

24. Asahara T, Masuda H, Takahashi T, Kalka C, Pastore C, Silver M, Kearne M, Magner M, Isner JM. Bone marrow origin of endothelial progenitor cells responsible for postnatal vasculogenesis in physiological and pathological neovascularization. Circulation Research. 1999;85:221-228

25. Jujo K, Ii M, Losordo DW. Endothelial progenitor cells in neovascularization of infarcted myocardium. J Mol Cell Cardiol. 2008;45:530-544

26. Deanfield JE, Halcox JP, Rabelink TJ. Endothelial function and dysfunction. $2007 ; 115: 1285-1295$ 
27. Deanfield J, Donald A, Ferri C, Giannattasio C, Halcox J, Halligan S, Lerman A, Mancia G, Oliver JJ, Pessina AC, Rizzoni D, Rossi GP, Salvetti A, Schiffrin EL, Taddei S, Webb DJ. Endothelial function and dysfunction. Part i: Methodological issues for assessment in the different vascular beds: A statement by the working group on endothelin and endothelial factors of the european society of hypertension. Journal of Hypertension. 2005;23:7-17

28. Brunner H, Cockcroft JR, Deanfield J, Donald A, Ferrannini E, Halcox J, Kiowski W, Lüscher TF, Mancia G, Natali A, Oliver JJ, Pessina AC, Rizzoni D, Rossi GP, Salvetti A, Spieker LE, Taddei S, Webb DJ. Endothelial function and dysfunction. Part ii: Association with cardiovascular risk factors and diseases. A statement by the working group on endothelins and endothelial factors of the european society of hypertension. Journal of Hypertension. 2005;23:233-246

29. Bhatnagar A. Environmental cardiology: Studying mechanistic links between pollution and heart disease. Circulation Research. 2006;99:692-705

30. O'Toole TE, Hellmann J, Wheat L, Haberzettl P, Lee J, Conklin DJ, Bhatnagar A, Pope III CA. Episodic exposure to fine particulate air pollution decreases circulating levels of endothelial progenitor cells. Circulation Research. 2010;107:200-203

31. Brook RD, Franklin B, Cascio W, Hong Y, Howard G, Lipsett M, Luepker R, Mittleman M, Samet J, Smith SC, Tager I. Air pollution and cardiovascular disease: A statement for healthcare professionals from the expert panel on population and prevention science of the american heart association. Circulation. 2004;109:2655-2671 
32. Brook RD, Rajagopalan S, Pope III CA, Brook JR, Bhatnagar A, Diez-Roux AV, Holguin F, Hong Y, Luepker RV, Mittleman MA, Peters A, Siscovick D, Smith Jr SC, Whitsel L, Kaufman JD. Particulate matter air pollution and cardiovascular disease. An update to the scientific statement from the american heart association. Circulation. 2010;121:2331-2378

33. Pope CA, Muhlestein JB, May HT, Renlund DG, Anderson JL, Horne BD. Ischemic heart disease events triggered by short-term exposure to fine particulate air pollution. Circulation. 2006;114:2443-2448

34. Madrigano J, Kloog I, Goldberg R, Coull BA, Mittleman MA, Schwartz J. Longterm exposure to pm2.5 and incidence of acute myocardial infarction. Environ Health Perspect. 2013;121:192-196

35. Peters A, von Klot S, Heier M, Trentinaglia I, Hörmann A, Wichmann HE, Löwel H. Exposure to traffic and the onset of myocardial infarction. New England Journal of Medicine. 2004;351:1721-1730

36. Rosenlund M, Bellander T, Nordquist T, Alfredsson L. Traffic-generated air pollution and myocardial infarction. Epidemiology. 2009;20:265-271

37. Gan WQ, Tamburic L, Davies HW, Demers PA, Koehoorn M, Brauer M. Changes in residential proximity to road traffic and the risk of death from coronary heart disease. Epidemiology. 2010;21:642-649

38. Rosenbloom JI, Wilker EH, Mukamal KJ, Schwartz J, Mittleman MA. Residential proximity to major roadway and 10-year all-cause mortality after myocardial infarction. Circulation. 2012;125:2197-2203 
39. Hoffmann B, Moebus S, Möhlenkamp S, Stang A, Lehmann N, Dragano N, Schmermund A, Memmesheimer M, Mann K, Erbel R, Jöckel K-H, Group ftHNRSI. Residential exposure to traffic is associated with coronary atherosclerosis. Circulation. 2007;116:489-496

40. Brook RD, Rajagopalan S. Particulate matter, air pollution, and blood pressure. Journal of the American Society of Hypertension. 2009;3:332-350

41. Brook RD. Cardiovascular effects of air pollution. Clinical Science. $2008 ; 115: 175-187$

42. Franchini M, Guida A, Tufano A, Coppola A. Air pollution, vascular disease and thrombosis: Linking clinical data and pathogenic mechanisms. Journal of Thrombosis and Haemostasis. 2012;10:2438-2451

43. Toxfaqs for acrolein. Agency for Toxic Substances and Disease Registry. 2010

44. Haberzettl P, Vladykovskaya E, Srivastava S, Bhatnagar A. Role of endoplasmic reticulum stress in acrolein-induced endothelial activation. Toxicology and Applied Pharmacology. 2009;234:14-24

45. Parent RA, Paust DE, Schrimpf MK, Talaat RE, Doane RA, Caravello HE, Lee SJ, Sharp DE. Metabolism and distribution of [2,3-14c]acrolein in spraguedawley rats. Toxicological Sciences. 1998;43:110-120

46. Conklin DJ, Haberzettl P, Lesgards J-F, Prough RA, Srivastava S, Bhatnagar A. Increased sensitivity of glutathione s-transferase p-null mice to cyclophosphamide-induced urinary bladder toxicity. Journal of Pharmacology and Experimental Therapeutics. 2009;331:456-469 
47. Stevens JF, Maier CS. Acrolein: Sources, metabolism, and biomolecular interactions relevant to human health and disease. Molecular Nutrition \& Food Research. 2008;52:7-25

48. Medicine Io. Secondhand smoke exposure and cardiovascular effects: Making sense of the evidence. Washington D.C.: The National Academies Press; 2010.

49. Conklin DJ, Barski OA, Lesgards J-F, Juvan P, Rezen T, Rozman D, Prough RA, Vladykovskaya E, Liu S, Srivastava S, Bhatnagar A. Acrolein consumption induces systemic dyslipidemia and lipoprotein modification. Toxicology and Applied Pharmacology. 2010;243:1-12

50. Conklin DJ, Haberzettl P, Prough RA, Bhatnagar A. Glutathione-s-transferase p protects against endothelial dysfunction induced by exposure to tobacco smoke. American Journal of Physiology and Heart and Circulatory Physiology. 2009;296:H1586-H1597

51. Wheat LA, Haberzettl P, Hellmann J, Baba SP, Bertke M, Lee J, McCracken J, O'Toole TE, Bhatnagar A, Conklin DJ. Acrolein inhalation prevents vascular endothelial growth factor-induced mobilization of flk-1+/sca-1+ cells in mice. Arteriosclerosis, Thrombosis, and Vascular Biology. 2011;31:1598-1606

52. Kondo T, Hayashi M, Takeshita K, Numaguchi Y, Kobayashi K, Iino S, Inden Y, Murohara T. Smoking cessation rapidly increases circulating progenitor cells in peripheral blood in chronic smokers. Vascular Biology. 2004;24:1442-1447

53. Dong J-Z, Moldoveanu SC. Gas chromatography-mass spectrometry of carbonyl compounds in cigarette mainstream smoke after derivatization with 2,4dinitrophenylhydrazine. Journal of Chromatography A. 2004;1027:25-35 
54. Florescu A, Ferrence R, Einarson T, Selby P, Soldin O, Koren G. Methods for quantification of exposure to cigarette smoking and environmental tobacco smoke: Focus on developmental toxicology. Therapeutic Drug Monitoring. 2009;31:14-30

55. Duda DG, Cohen KS, Scadden DT, Jain RK. A protocol for phenotypic detection and enumeration of circulating endothelial cells and circulating progenitor cells in human blood. Nature Protocols. 2007;2:805

56. Man CN, Gam L-H, Ismail S, Lajis R, Awang R. Simple, rapid and sensitive assay method for simultaneous quantification of urinary nicotine and cotinine using gas chromatography-mass spectrometry. Journal of Chromatography B. 2006;844:322-327

57. VITROS. Vitros chemistry products hscrp reagent. 2006;J21261_EN:12

58. Daum P, Estergreen J. Fibrinogen in plasma by rate of clot formation on the stacompact. CDC.gov. 2002

59. Hur J, Yoon C-H, Kim H-S, Choi J-H, Kang H-J, Hwang K-K, Oh B-H, Lee MM, Park Y-B. Characterization of two types of endothelial progenitor cells and their different contributions to neovasculogenesis. Arteriosclerosis, Thrombosis, and Vascular Biology. 2004;24:288-293

60. Takahashi T, Kalka C, Masuda H, Chen D, Silver M, Kearney M, Magner M, Isner JM, Asahara T. Ischemia- and cytokine-induced mobilization of bone marrow-derived endothelial progenitor cells for neovascularization. Nat Med. $1999 ; 5: 434-438$ 
61. Asahara T, Takahashi T, Masuda H, Kalka C, Chen D, Iwaguro H, Inai Y, Silver M, Isner JM. Vegf contributes to postnatal neovascularization by mobilizing bone marrow-derived endothelial progenitor cells. EMBO J. 1999;18:3964-3972

62. Werner N, Nickenig G. Influence of cardiovascular risk factors on endothelial progenitor cells: Limitations for therapy? Arteriosclerosis, Thrombosis, and Vascular Biology. 2006;26:257-266

63. Vasa M, Fichtlscherer S, Aicher A, Adler K, Urbich C, Martin H, Zeiher AM, Dimmeler S. Number and migratory activity of circulating endothelial progenitor cells inversely correlate with risk factors for coronary artery disease. Circulation Research. 2001;89:e1-e7

64. Xiao Q, Kiechl S, Patel S, Oberhollenzer F, Weger S, Mayr A, Metzler B, Reindl M, Hu Y, Willeit J, Xu Q. Endothelial progenitor cells, cardiovascular risk factors, cytokine levels and atherosclerosis - results from a large populationbased study. PLoS One. 2007;2:e975

65. Hill JM, Zalos G, Halcox JP, Schenke WH, Waclawiw MA, Quyyumi A, Finkel T. Circulating endothelial progenitor cells, vascular function, and cardiovascular risk. The New England Journal of Medicine. 2003;348:593-600

66. Kunz GA, Liang G, Cuculoski F, Gregg D, Vata KC, Shaw LK, GoldschmidtClermont PJ, Dong C, Taylor DA, Peterson ED. Circulating endothelial progenitor cells predict coronary artery disease severity. American Heart Journal. 2006;151:190-195

67. Tepper OM, Galiano RD, Capla JM, Kalka C, Gagne PJ, Jacobowitz GR, Levine JP, Gurtner GC. Human endothelial progenitor cells from type ii diabetics exhibit 
impaired proliferation, adhesion, and incorporation into vascular structures. Circulation. 2002;106:2781-2786

68. Chen JZ, Zhang FR, Tao QM, Wang XX, Zhu JH, Zhu JH. Number and activity of endothelial progenitor cells from peripheral blood in patients with hypercholesterolaemia. Clinical Science. 2004;107:273-280

69. Powell TM, Paul JD, Hill JM, Thompson M, Benjamin M, Rodrigo M, McCoy JP, Read EJ, Khuu HM, Leitman SF, Finkel T, Cannon III RO. Granulocyte colony-stimulating factor mobilizes functional endothelial progenitor cells in patients with coronary artery disease. Arteriosclerosis, Thrombosis, Vascular Biology. 2005;25:296-301

70. Pellegatta F, Bragheri M, Grigore L, Raselli S, Maggi FM, Brambilla C, Reduzzi A, Pirillo A, Norata GD, Catapano AL. In vitro isolation of circulating endothelial progenitor cells is related to the high density lipoprotein plasma levels. International Journal of Molecular Medicine. 2006;17:203-208

71. Thum T, Tsikas D, Stein S, Schultheiss M, Eigenthaler M, Anker SD, PooleWilson PA, Ertl G, Bauersachs J. Suppression of endothelial progenitor cells in human coronary artery disease by the endogenous nitric oxide synthase inhibitor asymmetric dimethylarginine. Journal of the American College of Cardiology. 2005;46:1693-1701

72. Güven H, Shepherd RM, Bach RG, Capoccia BJ, Link DC. The number of endothelial progenitor cell colonies in the blood is increased in patients with angiographically significant coronary artery disease. Journal of the American College of Cardiology. 2006;48:1579-1587 
73. Hristov M, Fach C, Becker C, Heussen N, Liehn EA, Blindt R, Hanrath P, Weber C. Reduced numbers of circulating endothelialprogenitorcells in patients with coronary artery disease associated with long-term statin treatment.

Atherosclerosis. 2007;192:413-420

74. Werner N, Kosiol S, Schiegl T, Ahlers P, Walenta K, Link A, Böhm M, Nickenig G. Circulating endothelial progenitor cells and cardiovascular outcomes. The New England Journal of Medicine. 2005;353:999-1007

75. Lyden D, Hattori K, Dias S, Costa C, Blaikie P, Butros L, Chadburn A, Heissig B, Marks W, Witte L, Wu Y, Hicklin D, Zhu Z, Hackett NR, Crystal RG, Moore MAS, Hajjar KA, Manova K, Benezra R, Rafii S. Impaired recruitment of bonemarrow?Derived endothelial and hematopoietic precursor cells blocks tumor angiogenesis and growth. Nature Medicine. 2001;7:1194

76. Mellick AS, Plummer PN, Nolan DJ, Gao D, Bambino K, Hahn M, Catena R, Turner V, McDonnell K, Benezra R, Brink R, Swarbrick A, Mittal V. Using the transcription factor inhibitor of DNA binding 1 to selectively target endothelial progenitor cells offers novel strategies to inhibit tumor angiogenesis and growth. Cancer Research. 2010;70:7273-7282

77. Shaked Y, Ciarrocchi A, Franco M, Lee CR, Man S, Cheung AM, Hicklin DJ, Chaplin D, Foster FS, Benezra R, Kerbel RS. Therapy-induced acute recruitment of circulating endothelial progenitor cells to tumors. Science. 2006;313:17851787

78. Libby P, Ridker PM. Inflammation and atherosclerosis: Role of c-reactive protein in risk assessment. The American Journal of Medicine. 2004;116:9-16 
79. Pearson TA, Mensah GA, Alexander RW, Anderson JL, Cannon RO, Criqui M, Fadl YY, Fortmann SP, Hong Y, Myers GL, Rifai N, Smith SC, Taubert K, Tracy RP, Vinicor F. Markers of inflammation and cardiovascular disease: Application to clinical and public health practice: A statement for healthcare professionals from the centers for disease control and prevention and the american heart association. Circulation. 2003;107:499-511

80. Fadini GP, Losordo D, Dimmeler S. Critical reevaluation of endothelial progenitor cell phenotypes for therapeutic and diagnostic use. Circulation Research. 2012;110:624-637

81. Schmidt-Lucke C, Fichtlscherer S, Aicher A, Tschöpe C, Schultheiss H-P, Zeiher AM, Dimmeler S. Quantification of circulating endothelial progenitor cells using the modified ishage protocol. PLOS ONE. 2010;5:e13790

82. Shintani S, Murohara T, Ikeda H, Ueno T, Honma T, Katoh A, Sasaki K-i, Shimada T, Oike Y, Imaizumi T. Mobilization of endothelial progenitor cells in patients with acute myocardial infarction. Circulation. 2001;103:2776-2779

83. Leone AM, Rutella S, Bonanno G, Abbate A, Rebuzzi AG, Giovannini S, Lombardi M, Galiuto L, Liuzzo G, Andreotti F, Lanza GA, Contemi AM, Leone G, Crea F. Mobilization of bone marrow-derived stem cells after myocardial infarction and left ventricular function. European Heart Journal. 2005;26:11961204

84. Massa M, Rosti V, Ferrario M, Campanelli R, Ramajoli I, Rosso R, De Ferrari GM, Ferlini M, Goffredo L, Bertoletti A, Klersy C, Pecci A, Moratti R, Tavazzi 
L. Increased circulating hematopoietic and endothelial progenitor cells in the early phase of acute myocardial infarction. Blood. 2005;105:199-206

85. Sobrino T, Hurtado O, Moro MÁ, Rodríguez-Yáñez M, Castellanos M, Brea D, Moldes O, Blanco M, Arenillas JF, Leira R, Dávalos A, Lizasoain I, Castillo J. The increase of circulating endothelial progenitor cells after acute ischemic stroke is associated with good outcome. Stroke. 2007;38:2759-2764

86. Yip H-K, Chang L-T, Chang W-N, Lu C-H, Liou C-W, Lan M-Y, Liu JS, Youssef AA, Chang H-W. Level and value of circulating endothelial progenitor cells in patients after acute ischemic stroke. Stroke. 2008;39:69-74

87. Vasa M, Fichtlscherer S, Adler K, Aicher A, Martin H, Zeiher AM, Dimmeler S. Increase in circulating endothelial progenitor cells by statin therapy in patients with stable coronary artery disease. Circulation. 2001;103:2885-2890

88. Dimmeler S, Aicher A, Vasa M, Mildner-Rihm C, Adler K, Tiemann M, xFc, tten H, Fichtlscherer S, Martin H, Zeiher AM. Hmg-coa reductase inhibitors (statins) increase endothelial progenitor cells via the pi 3-kinase/akt pathway. The Journal of Clinical Investigation. 2001;108:391-397

89. Levy BI. Beneficial effects of circulating progenitor endothelial cells activated by angiotensin receptor antagonists. Hypertension. 2005;45:491-492

90. Walter DH, Zeiher AM, Dimmeler S. Effects of statins on endothelium and their contribution to neovascularization by mobilization of endothelial progenitor cells. Coronary Artery Disease. 2004;15:235-242

91. Llevadot J, Murasawa S, Kureishi Y, Uchida S, Masuda H, Kawamoto A, Walsh K, Isner JM, Asahara T. Hmg-coa reductase inhibitor mobilizes bone marrow- 
derived endothelial progenitor cells. The Journal of Clinical Investigation. 2001;108:399-405

92. Smadja DM, Bièche I, Uzan G, Bompais H, Muller L, Boisson-Vidal C, Vidaud M, Aiach M, Gaussem P. Par-1 activation on human late endothelial progenitor cells enhances angiogenesis in vitro with upregulation of the sdf-1/cxcr4 system. Arteriosclerosis, Thrombosis, and Vascular Biology. 2005;25:2321-2327

93. Nuzzolo ER, Iachininoto MG, Teofili L. Endothelial progenitor cells and thrombosis. Thrombosis Research. 2012;129:309-313

94. Modarai B, Burnand KG, Sawyer B, Smith A. Endothelial progenitor cells are recruited into resolving venous thrombi. Circulation. 2005;111:2645-2653

95. Suh W, Kim KL, Choi J-H, Lee Y-S, Lee J-Y, Kim J-M, Jang H-S, Shin I-S, Lee J-S, Byun J, Jeon E-S, Kim D-K. C-reactive protein impairs angiogenic functions and decreases the secretion of arteriogenic chemo-cytokines in human endothelial progenitor cells. Biochemical and Biophysical Research Communications. 2004;321:65-71

96. Verma S, Kuliszewski MA, Li S-H, Szmitko PE, Zucco L, Wang C-H, Badiwala MV, Mickle DAG, Weisel RD, Fedak PWM, Stewart DJ, Kutryk MJB. C-reactive protein attenuates endothelial progenitor cell survival, differentiation, and function: Further evidence of a mechanistic link between c-reactive protein and cardiovascular disease. Circulation. 2004;109:2058-2067

97. Koshikawa M, Izawa A, Tomita T, Kumazaki S, Koyama J, Shimodaira S, Ikeda U. Association between circulating endothelial progenitor cells and hs-crp in 
patients with diabetes. The British Journal of Diabetes \& Vascular Disease. 2010;10:133-138

98. Makino H, Okada S, Nagumo A, Sugisawa T, Miyamoto Y, Kishimoto I, Akie TK, Soma T, Taguchi A, Yoshimasa Y. Pioglitazone treatment stimulates circulating cd34-positive cells in type 2 diabetes patients. Diabetes Research and Clinical Practice. 2008;81:327-330

99. Schmidt-Lucke C, Rössig L, Fichtlscherer S, Vasa M, Britten M, Kämper U, Dimmeler S, Zeiher AM. Reduced number of circulating endothelial progenitor cells predicts future cardiovascular events: Proof of concept for the clinical importance of endogenous vascular repair. Circulation. 2005;111:2981-2987

100. Robb AO, Mills NL, Smith IBJ, Short A, Tura-Ceide O, Barclay GR, Blomberg A, Critchley HOD, Newby DE, Denison FC. Influence of menstrual cycle on circulating endothelial progenitor cells. Human Reproduction. 2009;24:619-625

101. Elsheikh E, Sylvén C, Ericzon B-G, Palmblad J, Mints M. Cyclic variability of stromal cell-derived factor-1 and endothelial progenitor cells during the menstrual cycle. International Journal of Molecular Medicine. 2011;27:221-226

102. Brook RD, Bard RL, Burnett RT, Shin HH, Vette A, Croghan C, Phillips M, Rodes C, Thornburg J, Williams R. Differences in blood pressure and vascular responses associated with ambient fine particulate matter exposures measured at the personal versus community level. Occupational and Environmental Medicine. $2011 ; 68: 224-230$ 
103. Rundell KW, Hoffman JR, Caviston R, Bulbulian R, Hollenbach AM. Inhalation of ultrafine and fine particulate matter disrupts systemic vascular function. Inhalation Toxicology. 2007;19:133-140

104. Dales R, Liu L, Szyszkowicz M, Dalipaj M, Willey J, Kulka R, Ruddy T. Particulate air pollution and vascular reactivity: The bus stop study. Int Arch Occup Environ Health. 2007;81:159-164

105. Carmella SG, Chen M, Zhang Y, Zhang S, Hatsukami DK, Hecht SS. Quantitation of acrolein-derived (3-hydroxypropyl)mercapturic acid in human urine by liquid chromatography-atmospheric pressure chemical ionization tandem mass spectrometry: Effects of cigarette smoking. Chemical Research in Toxicology. 2007;20:986-990

106. Kan H, Heiss G, Rose KM, Whitsel EA, Lurmann F, London SJ. Prospective analysis of traffic exposure as a risk factor for incident coronary heart disease: The atherosclerosis risk in communities (aric) study. Environ Health Perspect. 2008;116:1463-1468

107. Gan WQ, Koehoorn M, Davies HW, Demers PA, Tamburic L, Brauer M. Longterm exposure to traffic-related air pollution and the risk of coronary heart disease hospitalization and mortality. Environ Health Perspect. 2011;119:501-507

108. Tonne C, Melly S, Mittleman M, Coull B, Goldberg R, Schwartz J. A casecontrol analysis of exposure to traffic and acute myocardial infarction. Environ Health Perspect. 2007;115:53-57 
109. Medina-Ramon M, Goldberg R, Melly S, Mittleman MA, Schwartz J. Residential exposure to traffic-related air pollution and survival after heart failure. Environ Health Perspect. 2008;116:481-485

110. Baccarelli A, Martinelli I, Pegoraro V, Melly S, Grillo P, Zanobetti A, Hou L, Bertazzi PA, Mannucci PM, Schwartz J. Living near major traffic roads and risk of deep vein thrombosis. Circulation. 2009;119:3118-3124

111. Maheswaran R, Elliott P. Stroke mortality associated with living near main roads in england and wales: A geographical study. Stroke. 2003;34:2776-2780

112. Rioux CL, Tucker KL, Mwamburi M, Gute DM, Cohen SA, Brugge D. Residential traffic exposure, pulse pressure, and c-reactive protein: Consistency and contrast among exposure characterization methods. Environmental health perspectives. $2010 ; 118: 803-811$

113. Jacobs L, Emmerechts J, Hoylaerts MF, Mathieu C, Hoet PH, Nemery B, Nawrot TS. Traffic air pollution and oxidized ldl. PLOS ONE. 2011;6:e16200

114. Roorda-Knape MC, Janssen NAH, De Hartog JJ, Van Vliet PHN, Harssema H, Brunekreef B. Air pollution from traffic in city districts near major motorways. Atmospheric Environment. 1998;32:1921-1930

115. Zhu Y, Hinds WC, Kim S, Sioutas C. Concentration and size distribution of ultrafine particles near a major highway. Journal of the Air \& Waste Management Association. 2002;52:1032-1042

116. Zhou Y, Levy JI. Factors influencing the spatial extent of mobile source air pollution impacts: A meta-analysis. BMC public health. 2007;7:89 
117. Allen RW, Criqui MH, Diez Roux AV, Allison M, Shea S, Detrano R, Sheppard L, Wong ND, Stukovsky KH, Kaufman JD. Fine particulate matter air pollution, proximity to traffic, and aortic atherosclerosis. Epidemiology (Cambridge, Mass.). $2009 ; 20: 254-264$

118. Langrish JP, Bosson J, Unosson J, Muala A, Newby DE, Mills NL, Blomberg A, Sandström T. Cardiovascular effects of particulate air pollution exposure: Time course and underlying mechanisms. Journal of Internal Medicine. 2012;272:224239

119. Leon Bluhm G, Berglind N, Nordling E, Rosenlund M. Road traffic noise and hypertension. Occupational and Environmental Medicine. 2007;64:122-126

120. Babisch W. Traffic noise and cardiovascular disease: Epidemiological review and synthesis. Noise \& health. 2000;2:9-32

121. Babisch W. Road traffic noise and cardiovascular risk. Noise \& health. $2008 ; 10: 27-33$

122. Banerjee S, Brilakis E, Zhang S, Roesle M, Lindsey J, Philips B, Blewett CG, Terada LS. Endothelial progenitor cell mobilization after percutaneous coronary intervention. Atherosclerosis. 2006;189:70-75

123. Nonaka-Sarukawa M, Yamamoto K, Aoki H, Nishimura Y, Tomizawa H, Ichida M, Eizawa T, Muroi K, Ikeda U, Shimada K. Circulating endothelial progenitor cells in congestive heart failure. International Journal of Cardiology. $2007 ; 119: 344-348$ 
124. Janssen I, Katzmarzyk PT, Ross R. Waist circumference and not body mass index explains obesity-related health risk. The American Journal of Clinical Nutrition. 2004;79:379-384

125. Dalton M, Cameron AJ, Zimmet PZ, Shaw JE, Jolley D, Dunstan DW, Welborn TA, On behalf of the AusDiab steering c. Waist circumference, waist-hip ratio and body mass index and their correlation with cardiovascular disease risk factors in australian adults. Journal of Internal Medicine. 2003;254:555-563

126. Quan SF, Howard BV, Iber C, Kiley JP, Nieto FJ, O'Connor GT, Rapoport DM, Redline S, Robbins J, Samet JM, Wahl PW. The sleep heart health study: Design, rationale, and methods. Sleep. 1997;20:1077-1085

127. D'Agostino SRBGSSLMWPftCHDRPG. Validation of the framingham coronary heart disease prediction scores: Results of a multiple ethnic groups investigation. JAMA. 2001;286:180-187

128. Conroy RM, Pyörälä K, Fitzgerald AP, Sans S, Menotti A, De Backer G, De Bacquer D, Ducimetière P, Jousilahti P, Keil U, Njølstad I, Oganov RG, Thomsen T, Tunstall-Pedoe H, Tverdal A, Wedel H, Whincup P, Wilhelmsen L, Graham IM. Estimation of ten-year risk of fatal cardiovascular disease in europe: The score project. European Heart Journal. 2003;24:987-1003

129. Assmann G, Cullen P, Schulte H. Simple scoring scheme for calculating the risk of acute coronary events based on the 10-year follow-up of the prospective cardiovascular münster (procam) study. Circulation. 2002;105:310-315 
130. Diamond GA, Forrester JS. Analysis of probability as an aid in the clinical diagnosis of coronary-artery disease. New England Journal of Medicine. 1979;300:1350-1358 


\title{
CURRICULUM VITAE
}

\author{
Natasha Krystal DeJarnett \\ 580 South Preston Street \\ Delia Baxter Building, 428a \\ Louisville, KY 40202
}

\section{Education}

Doctorate of Philosophy in Public Health Sciences - Environmental Health, May 2013

University of Louisville

Master of Public Health - Environmental and Occupational Health Sciences, May 2009

University of Louisville

Bachelor of Science - Chemistry, Biology. December 2004

Western Kentucky University

\section{Fellowships}

Ethnic Minority Fellowship

University of Louisville (2011 - 2013)

Environmental and Occupational Health Sciences Department Assistantship

University of Louisville (2009 - 2011)

Graduate Teaching Assistantship

University of Louisville (2007 - 2009)

\section{Professional Experience}

Graduate Fellow, University of Louisville, August 2011 - Present

- Coordinated the biochemical activities and served as a liaison between clinicians and investigators in a multidisciplinary research team for a peer-reviewed study

- Participated in planning the research activities; patient recruitment, consenting, and enrolling; managed sample collection; established and maintained the patient database; and participated in biochemical and statistical analyses

- Organized the written and oral communication of research findings for the research team and for national audiences

Graduate Research Assistant, University of Louisville, August 2009 - July 2011

- Investigated toxicity and viability of human and mouse cells after environmental toxin exposure using enzyme-linked immunosorbent assays (ELISA) and colorimetric enzymatic assays 
- Prepared research activities: cultured cells, generated environmental toxins, treated cells with environmental toxins, and evaluated cell vitality

- Compiled and completed literature reviews of cellular toxicity to common environmental exposures

- Exploring fetal impacts of toxin exposures through administering a modified diet to animals

Public Health Practicum, Lexmark International, Inc., August 2008 - May 2009

- Performed, evaluated, and analyzed product life cycle assessments to present recommendations concerning ozone layer depletion, abiotic depletion, nonrenewable energy depletion, human toxicity, and global warming potential to Lexmark and the University of Louisville School of Public Health

- Observed the International Organization for Standardization (ISO) 14001 audit and indoor air quality sampling

- Participated in the Climate Leaders Conference, Top Management Review, and the Laser Safety Audit

- Job shadowed the Environmental Health and Safety staff

Graduate Teaching Assistant, Debate Coach, University of Louisville, August 2007 May 2009

- Created and administered the Academic Success Plan for debate team members

- Coached team members on winning strategies for debate tournaments at Wake Forest University and the 2008 regional qualifier for the National Debate Tournament

- Taught specific areas of coursework for Communications 319, as defined by the debate team director

Chemical Technician Specialist, Analysts International, February 2005 - July 2007; April - July 2008

- Contracted at Lexmark International, Inc.

- Created database systems to share and summarize research data and provided technical support for engineers and scientists, working in areas of research and manufacturing

- Adapted current PC applications, formed procedures, techniques, tools, materials and/or equipment to meet research and/or development needs

- Applied knowledge of chemical lab safety guidelines, safe handling of chemicals, proper hood use, and interpretations of Material Safety Data Sheets

Resident Assistant, Western Kentucky University, August 2001 - December 2004

- Supervised a floor of 52 men and women

- Maintained a professional setting at the work environment

- Assisted in solving residents' crises and performed conflict mediation

- Performed security and administrative tasks

- Assisted in staff training 
- Designed and implemented creative programs for hall residents, including an awareness program about sexual health

- Received the "Super Resident Assistant" award for November 2001, April 2002, November 2002, and November 2003

\section{Affiliations}

American Heart Association (2012 - Present)

Delta Omega Honorary Society in Public Health (2009 - Present)

American Public Health Association (2009 - Present); Abstract Reviewer (2012); Environment Section Student Involvement Committee Leadership Team (2009 Present); Environmental Justice Forum Roundtable Facilitator and Moderator (2009)

Kentucky Public Health Association, University of Louisville Chapter, Vice President (2008 - 2009); coordinated the inaugural Meet the Dean Night and the SPHIS Etiquette Dinner; assisted in the creation and implementation Career Development Month

National Association of Health Services Executives (2008 - 2009), Case Competition Participant (2008)

Golden Key International Honor Society (2008 - Present)

Delta Sigma Theta Sorority, Incorporated (2004 - Present); coordinated marketing publications for the Delta Ecology Project (2009); Project Science and Everyday Experiences Co-Chair (2006); coordinated a sexual health awareness seminar for regional high school students (2006); Chaplain (2004)

Western Kentucky University Black Student Alliance Co-Founder, President (2004), Vice President (2002 - 2003)

NAACP, Western Kentucky University Chapter, President (2004), Vice President (2003), Historian (2002)

Alpha Epsilon Delta Pre-Professional Honor Society President (2004), Scalpel Reporter (2003)

\section{Honors}

Graduate Dean's Citation, University of Louisville (2013)

Basic Cardiovascular Sciences Council Travel Grant Recipient, American Heart Association (2012)

Winner, Public Health Research and Practice Graduate Student Poster at Research! Louisville, University of Louisville (2012)

Second Place, Public Health Graduate Student Poster at Research! Louisville, University of Louisville (2011) 
Third Place, Public Health Graduate Student Poster at Research! Louisville, University of Louisville (2010)

Environment Section Travel Award Recipient, American Public Health Association Environment Section (2010)

Travel Award Recipient, University of Louisville School of Public Health and Information Sciences (2010)

Dean's Award, University of Louisville School of Public Health and Information Sciences (2009)

Outstanding Student, University of Louisville (2009)

Graduate Dean's Citation, University of Louisville (2009)

Who's Who Among Students at American Colleges and Universities (2005)

Dynamic Leadership Institute (2004)

Academic Award of Distinction Scholarship, Western Kentucky University (2000 2004)

Western Kentucky University Spirit Master, student ambassador and recruiter (2003 2004)

Western's Outstanding Black Leaders (2003)

Honorable Order of Kentucky Colonels Designation (2002)

Kentucky Governor's Scholar (1999); Governor's Scholar Resident Assistant (2002)

YMCA Black Achievers Youth Achiever of the Year (2000)

\section{Publications}

Tumor Necrosis Factor-Alpha Mediates Interactions between Macrophages and Epithelial Cells Underlying Proinflammatory Gene Expression Induced by Particulate Matter. Musah, Sadiatu; DeJarnett, Natasha; Hoyle, Gary. Toxicology. 23 May 2012.

The Sustainable City and Biking: Implications for Health, Environment, and Economy. Gilderbloom, John; O'Neill, Brian; DeJarnett, Natasha; Kenitzer, Zachary. Sustain: A Journal of Environmental and Sustainability Issues. Spring/Summer 2012. 26:23-30.

\section{Presentations}

\section{Oral Presentations}

Traditional Cardiovascular Disease Risk Factors Predict Acrolein Metabolite Level in a Population-Based Study. DeJarnett, Natasha, et al. San Francisco, CA: American Public Health Association, 2012. American Public Health Association 140th Annual Meeting and Exposition. 
Contribution of Tobacco Smoke Constituent Acrolein to Circulating Endothelial Progenitor Cell Levels in Humans. Bhatnagar, Aruni, et al. New Orleans, LA. Southern Society for Clinical Investigation, 2012. Society for Clinical Investigation Southern Regional Meeting.

\section{Poster Presentations}

Decreased Levels of Circulating "Early" Vascular Progenitor Cells are Associated with Cardiovascular Disease Risk. DeJarnett, Natasha, et al. Los Angeles, CA: American Heart Association, 2012. American Heart Association Scientific Meeting 2012.

Novel Insights into the Association between Residential Proximity to Major Roadways and Vascular Progenitor Cell Levels. DeJarnett, Natasha, et al. Louisville, KY: Research! Louisville, 2012.

Contribution of Air Pollutant Combustion Product Acrolein to Circulating Endothelial Progenitor Cell Level and Cardiovascular Disease Risk. DeJarnett, Natasha, et al. Washington DC: American Public Health Association, 2011. American Public Health Association 139th Annual Meeting and Exposition.

Traditional Cardiovascular Disease Risk Factors Predict Acrolein Metabolite Level in a Population-Based Study. DeJarnett, Natasha, et al. Louisville, KY: Research! Louisville, 2011.

Tumor Necrosis Factor-Alpha (tnf) Mediates Proinflammatory Gene Expression Induced by Particulate Matter in Co-Cultures of Macrophage and Lung Epithelial Cell Lines. Musah, Sadiatu; DeJarnett, Natasha; Hoyle, Gary. American Journal of Respiratory and Critical Care Medicine. 2011. 183:A3239 